\title{
STRESS ANALYSIS
}

PWR SEED I, CORE I

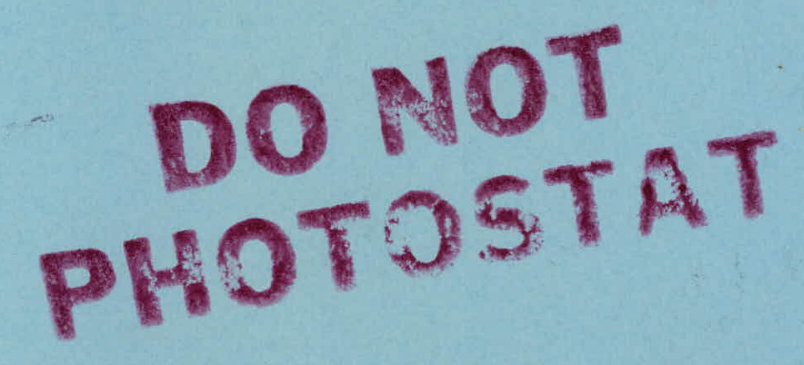

PREPARED FOR

WESTINGHOUSE ELECTRIC COMPANY

ATOMIC POWER DIVISION

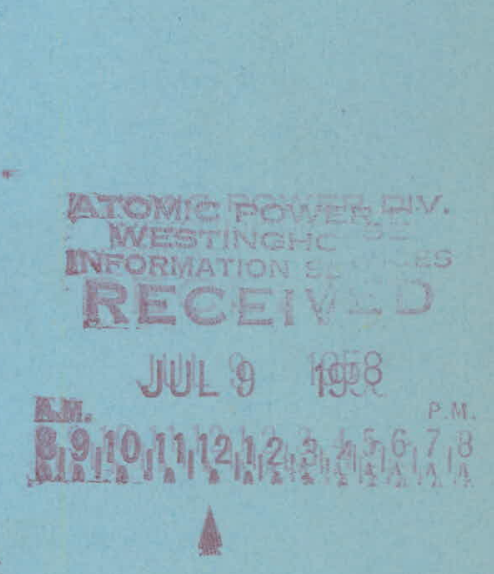

ARDE ASSOCIATES 


\section{DISCLAIMER}

This report was prepared as an account of work sponsored by an agency of the United States Government. Neither the United States Government nor any agency Thereof, nor any of their employees, makes any warranty, express or implied, or assumes any legal liability or responsibility for the accuracy, completeness, or usefulness of any information, apparatus, product, or process disclosed, or represents that its use would not infringe privately owned rights. Reference herein to any specific commercial product, process, or service by trade name, trademark, manufacturer, or otherwise does not necessarily constitute or imply its endorsement, recommendation, or favoring by the United States Government or any agency thereof. The views and opinions of authors expressed herein do not necessarily state or reflect those of the United States Government or any agency thereof. 


\section{DISCLAIMER}

Portions of this document may be illegible in electronic image products. Images are produced from the best available original document. 


\section{ARDE}

DATE October 1957

REPORT NO. $9561-3$

COPY NO:

REVISION NO.

FINAL STRESS ANALYSIS

OF

PKR SEED I

CORE I

Purchase Order No. 73-(14-477)

Prepared for:

WESTINGHOUSE ELECTRIC COMPANY

ATOMIC POWER DIVISION

PITISBURGH, PENNSYLVANIA

PREPARED BY R._Mark

APPROVED BY B. J. Aleck
A R D E
A S S S O C I A T E S
ENGINEERS
DESIGNERS
FABRICATORS 
III. Discussion

III-1 Stress Analysis Results

III.1

III-2 Analysis of Weld Tests

III.2

IIIm3 Conc1usions

III.3

III $\operatorname{Ref}$ erences

III.5

IV. Theoretical Stress Analysis of Seed

IV. 1

V. Report on Static and Fatigue Testing of Zircaloy Fusion Helds

This document is an interim memorandum prepared primarlly for internal reference and does not represent a marlly for internal reference and of Westinghouse. When final expression of the opinion of Westinghouse. Whith this memorandum is distributed externally, it is with the express understanding that Westinghouse makes no representation as to completeness, 


\section{1}

\section{Sumary}

This report describes the structural analysis of the PWR Core I Seed I under prescribed thermal and mechanical loading with the object of predicting the structural rellability of the seed during actual service. Static and fatigue tests performed on fusion welded Zircaloy specimens are described and the results of these tests are incorporated in the rellability study.

The applied stresses in the seed during operation of the reactor are quite low except at the end welds. Here, based upon the test data, a safety factor of about $4 \frac{1}{2}$ appears to exist for 6000 cycles of loading. 


\section{Introduction}

The subject seed is fabricated from Zircaloy plates which are welded together as illustrated in figure (II-1). Fusion welding is -

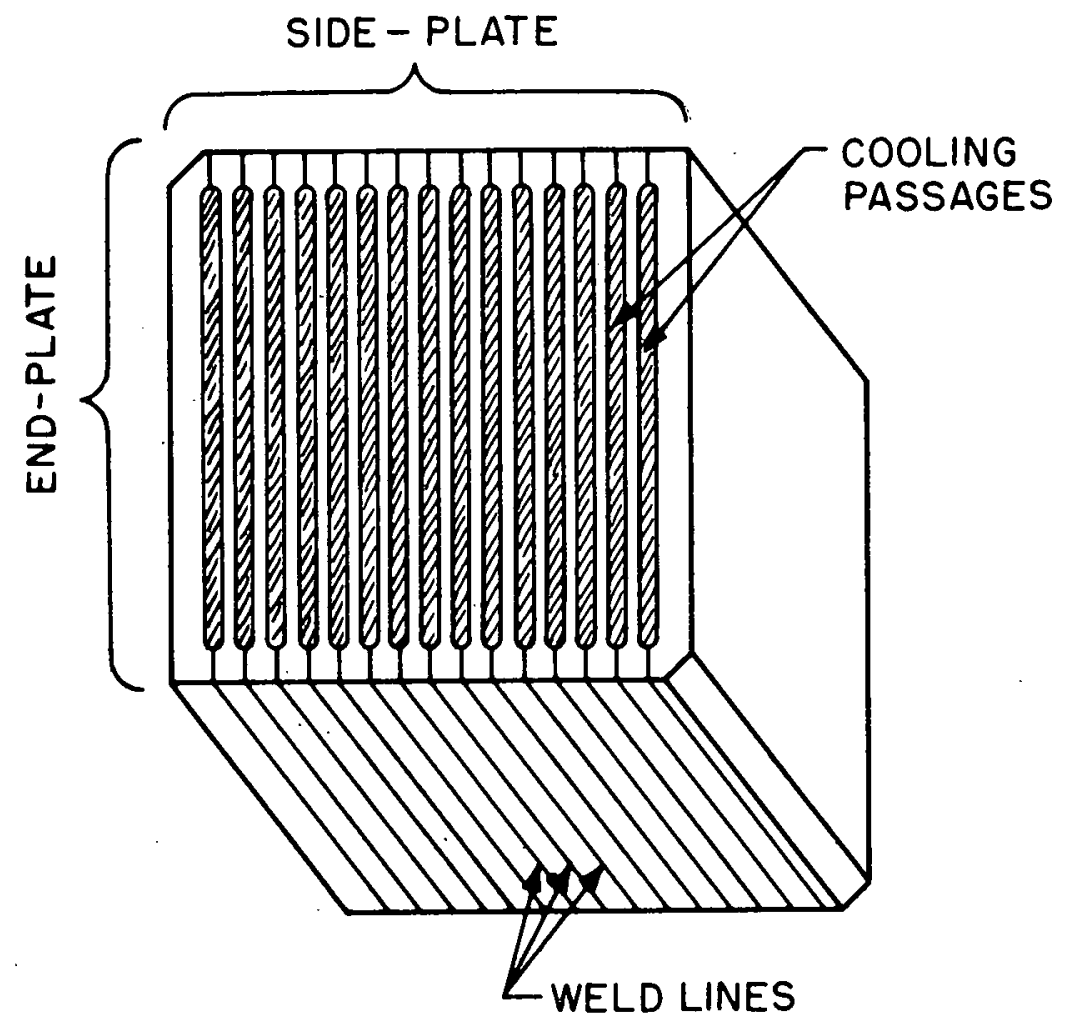

FIG. II-I $\sim$ SEED

employed; there is no deposition of additional veld material. In order to insure effective cooling throughout the passages, fully penetrated welds are not desirable as the ends of the passages may become blocked by the resulting bead. The nature of the stress distribution in the 


\section{2}

"side plate" because of the incomplete weld penetration, remalns somem what of an enigma. Various possible distributions are discussed in Section IV (pages IV.3m5). In order to better ascertain the physical characteristics of the velds, thirty relded specimens were prepareu and tested in tension, tensile fatigue and bending fatigue. A description of these tests and the results comprise Section V. This data and the results of the theoretical stress calculations are analyzed in Section III. 


\section{Discussion}

\section{III-1 Stress Analysis Results}

Stated loadings and resulting stress levels throughout the seed structure are reported on page IV.6. The stresses are 10w everywhere except in the "side-plate" (calculation Hos. 1 and 2). These values are derived from assuming the "side-plate" to act as a homogeneous beem on an elastic foundation and considering the bending moments at the welds to be resisted across cross-sections equal in depth to specified weld penetrations.

Both assumptions may be challenged. Stress concentrations and increased bending deflection are introduced by the notch at the weld. Thus, the reported stresses are nominal and not precise values. A more accurate indication of the "side-plate" strength is in analysis of the impressed deformations. This view is justifled by the knowledge that most of the side-plate strain is the result of unequal thermal expansion throughout the seed structure rather than the application of constant forces.

The deforation of the nominal $1 / 8$ inch thick 2ircaloy plate corresponding to the maximum given moment (iI) in the "side-plate" of $14.0 \mathrm{in}-1 \mathrm{bs} / \mathrm{ln}$. (page IV.18) at $600^{\circ} \mathrm{F}$ (ref. a) is

$$
\frac{d^{2} y}{d x^{2}}=\frac{A}{D}=.0070 \mathrm{in} / \mathrm{in}^{2}
$$

with $D=E(.125)^{3} /\left(1-\nu^{2}\right) 12$ and $E$ and $\nu$, respectively, equal 
to $11.22(10)^{6}$ psi and 0.3 . This value is compared with the bending test results in subsection III-3.

III-2 Analysis of Held Tests

The results of the static tension and tensile fatigue tests are given on Table ( $\mathrm{V}-1$ \& 2). Wide variance in the reported stress levels is probably the result of additional bonding having taken place in the "unwelded" region. (This subject is more fully discussed on page V.11). The small number of specimens used for these tests does not lend itself to statistical evaluation; however, the reported stress levels do indicate that normal notch-stress intensiflcation factors need not be considered for this type of weld. As about $85 \%$ of the reported "side-plate" loading is bending, we are primarily concerned with the results of the bending fatigue tests. These are reported on Table $(\mathrm{V}-3)$. If the lower penetration types are considered as a group, it is seen that there is fairly good agreement anong the reported mominal" stress levels. Scatter In the "apparent weld" stress levels is not considerable.

The higher penetration specimens as a group appear to exhibit no increase in strength over the lower penetration group and the "apparent weld" stress levels are considerably lower. Greater "unwelded" area avallable for additional bonding in the lower penetration types explains some of the apparent discrepancy; however, the 
well known strengthening effect of fatigue understressing (reference 1) probably was the major contribution to the generally high failure stress levels in this lower penetration group.

The bending specimens which exhibited the minimum resistance to imposed deformation vere numbers 7 and 9 (Table V.8). Number 7 appears to have resisted greater moments, however the data sheet indicates that number 9 was subjected to greater strain (the eccentric throw of the machine vas greater). For purposes of comparison, we shall use the lowest reported stress value in order to derive a minimum imposed strain. With $M=t^{2} \sigma / 6$ and $t=$ the nominal thickness of .125 inches and $\sigma=.30,400 \mathrm{psi}$, the deformation given by the formula from subsection III-1 is

$$
\left(\frac{d^{2} y}{d x^{2}}\right)=\frac{t^{2} \sigma}{6 D}=.0310 \mathrm{in} / \mathrm{in}^{2}
$$

with $\mathrm{B}=14.3(10)^{6} \mathrm{psi}$. The specimen failed after 6000 cycles of this deformation.

\section{III-3 Conclusions}

Comparison of the analytically derived maximum impressed veld curvature and the deflection causing failure to the veakest bending fatigue specimen after 6000 cycles reveals an apparent safety factor of (See page III.4) 


$$
S F=\frac{\left(\frac{d^{2} y}{d x^{2}}\right)_{\text {test failure }(\min .)}}{\left.\left(\frac{d^{2} y}{d x^{2}}\right)_{\text {seed weld }(\max }\right)}=\frac{.0310}{.0070}=\frac{4.4}{\text { fycles }} \begin{aligned}
& 6000 \text { transient } \\
& \text { cycles }
\end{aligned}
$$

This value is conservative for the following reasons:

1. The fatigue tests were run at room temperature. At operating temperatures, Young's Modulus decreases which produces a more elastic structure and one that can better withstand cyclic thermal variation.

2. During normal reactor operation, considerable fatigue understressing (reference i) will take place so that the weld fatigue strength will increase in time as is indicated by the results of the lower penetration bending tests.

These factors are somewhat offset because as the seed fusion velds are of great length, variations in the degree and quality of the welds are inevitable. Lower strength regions will be aided by adjoining higher strength regions in resisting direct loadings, hovever, impressed deformations will be common to both so that failure of the seed welds will be more dependent upon minimum rather than average veld resistance to fatigue. 


\section{III-4 References}

(a) F. Seely \&

J. 0. Smith

(b) S. Timoshenko

(c) H. Hetenyi

(d) S. Timoshenko

(e)

(f)

(g)

(h) B. A. Boley

(i) J. B. Kommers
"Resistance of Materials", Fourth Edition, Wiley, (1956).

"Strength of Materials", Vo1. II, Second Editions, McGraw-Hill, (1941).

"Beams on Elastic Foundation", The University of Michigan Press, (1946).

"Theory of Plates and Shells, McGrav-HI11, (1940)

Letter - F. V. Naugle (KAPD-PWR-

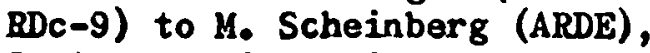
September 20, 1956.

Letter - F. V. Naugle (KAPD-PWR$R D C-12$ ) to $M$. Scheinberg (ARDE), September 27, 1956.

Mechanical Properties Evaluation of Zircaloy-3n, KAPD-143, AEC

Research and Development Report, (March 1956).

The Determination of Temperature, Stresses and Deflections in TwoDimensional Thermoelastic Problems", Journal of the Aeronautical Sciences, (January 1956).

"Overstressing and Understressing in Patigue", ASME Metals Bnginearing Design", McGraw-Hill (1953). 
IV-2 Discussion

A. General

IV.3

B. Results of Stress Analysis

IV.6

C. Table of Symbols

IV.7

IV-3 Analysis and Stress Calculations

IV.9

IV 4 Appendices

A. General Theory of the Beam on an Elastic Foundation IV.21

B. Critical Loading Analysis IV.28 
IV. Theoretical Stress Analysis of Secd

IV.1 Summary

This section presents a theoretical method of stress analysis

of a proposed $P_{0} H_{0} R_{0}$ seed type under steady state thermal and pressure 1oads. Critical loads are considered for the P.W.R॰ Core I, Seed I and the resulting maximum stresses are reported. 


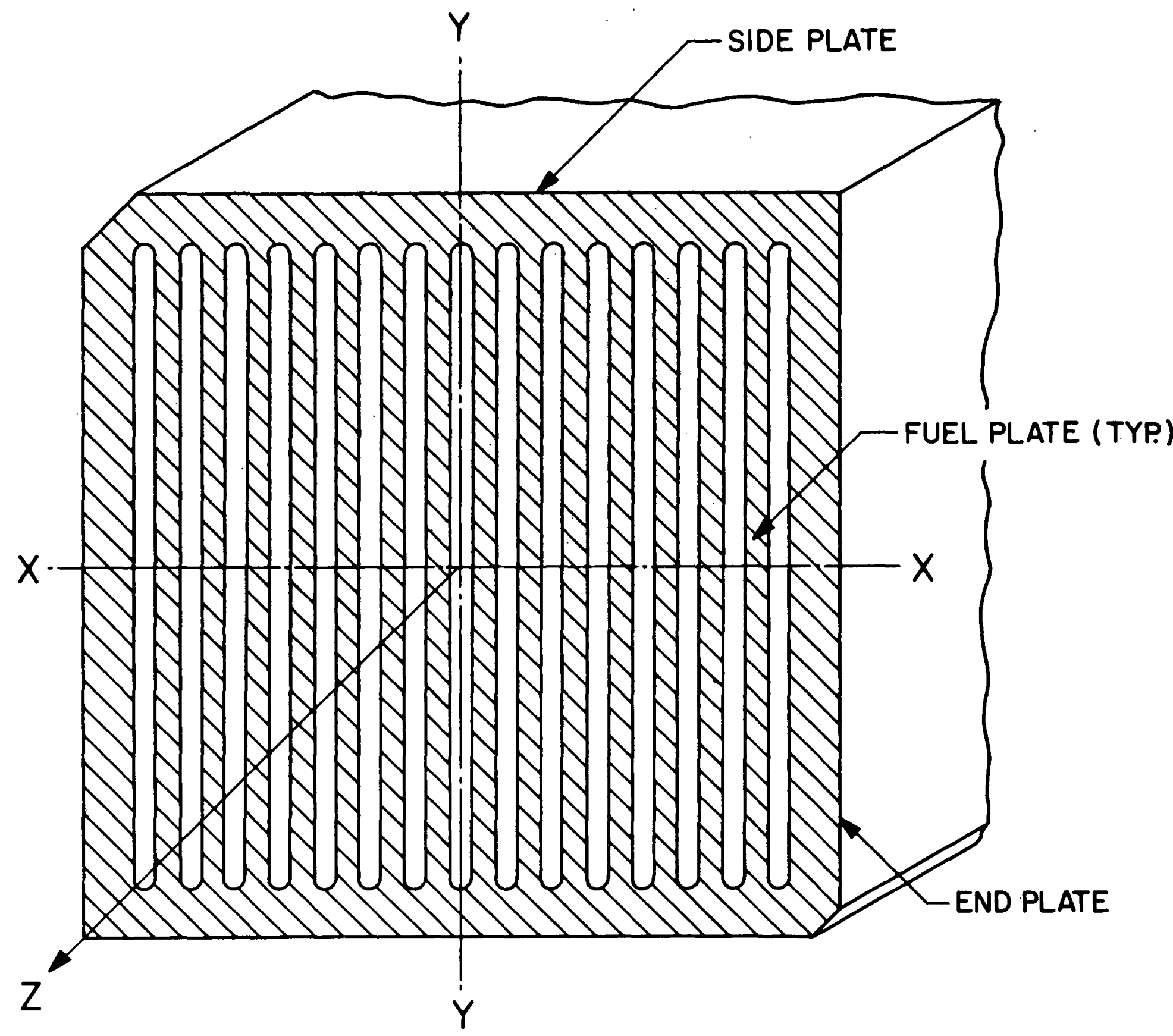

FIG. $\mathbb{\nabla}-1$

TYPICAL SECTION

THROUGH SEED

SCALE: APX. $2 X$ 


\section{IV-2 Discussion}

\section{A. General}

The seed structure is highiy indeterminate. However, several characteristics of its crossmsection (Fig. IV-1) suggest that considerable simplification may be performed:

1. Crossmection symmetry

2. Probable symmetry of loading about the $X-X$ axis

3. Uniformity of the fuel elements.

By witing down equations for forces at all the joints, the technique of treating the side plate-fuel plate system as a beam on an elastic foundation becomes evident (Page IV.10). The general solution of a beam on an elastic foundation accounting for all the interacting forces is derived in Appendix "AM. As might be anticipated, the fuel plate interacting moments and the normal force acting in the side plate effect the side plate-fuel plate systen deflections very 1ittle. The error resulting from neglecting them is given by equation (9), Appenw dix "AF, and will be seen to be negligible for most practical cases.

Purther assumptions must be made regarding the distribution of bending stress in the side plate resulting from in complete weld penetration. Figure (IVm2a) indicates the probable bending stress path with the direction of moment as shown. With a reversal of moment, the path may be similar (IV-2b), or 


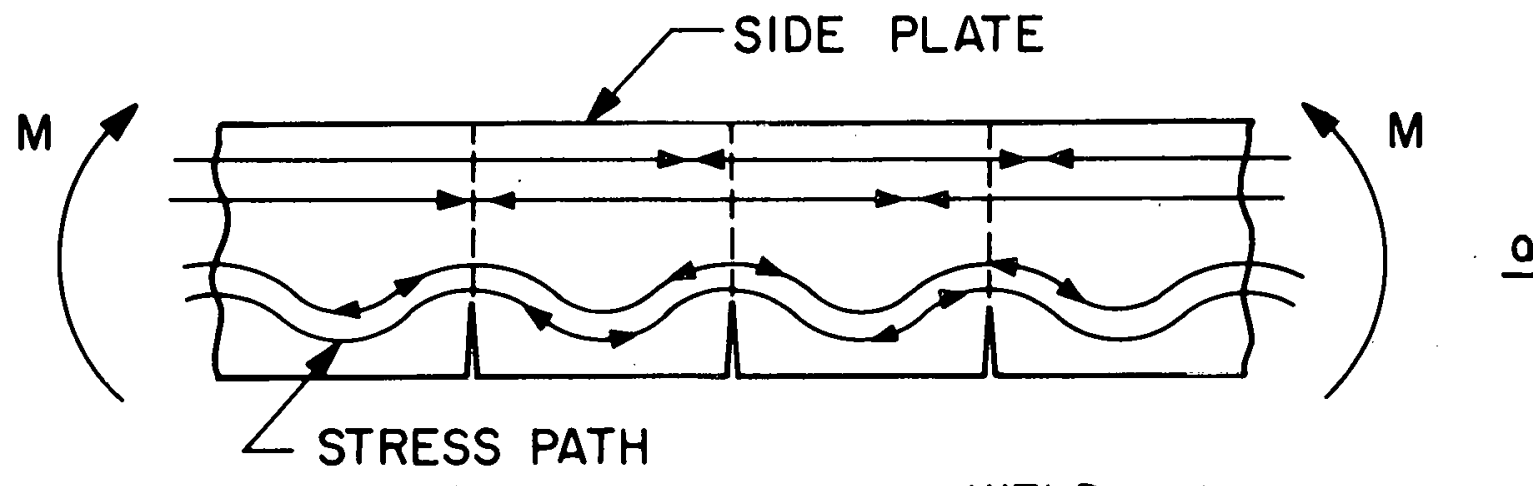

으
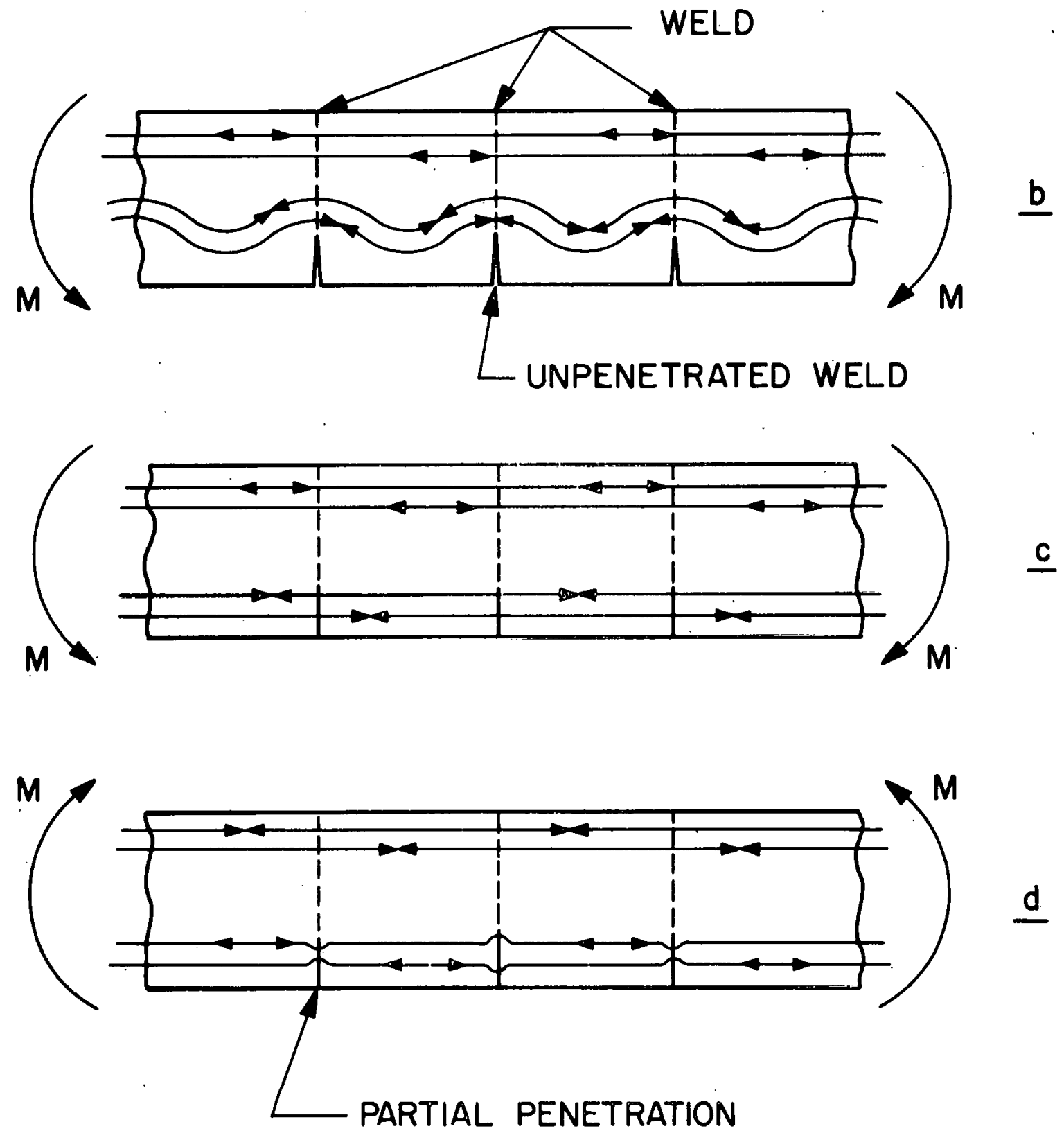

FIG. IV-2

BENDING STRESS DISTRIBUTION

IN WELDED SIDE PLATE 
if the unwelded faces are in contact, the usual homogeneous pattern will be developed $(I V-2 c)$. There is also the possibility that partial fusion will have taken place in the unwelded area and the beam will act substantially homogeneous regardless of the direction of the moment (IVm2d) as long as the stress levels are low enough so that the partial bonds remain unbroken. The choice of an average effective depth for the side plate is, therefore, quite difficult to make. We have considered the side plate to act as in Fig. (IV-2c) or (IV-2d) (depending upon the direction of the applied moment) for one set of force calculations, and to act as in (a) or (b) in another for comparison with the above. The attenuation of local loading effects in a relatively short length is characteristic of beams on an elastic foundation (see page IV-11). The general side plate solution must, therefore, be solved in two parts. The solution for the region of the end plate is more complex, as two additional unknow interacting forces are present. Consequent1y, more emphasis has been placed upon this area. Completely general equations based upon an assumed thermal variation given by Fig. (B) are presented (Pages IV.14 - 16). The curve assumes the possibility of linearizing the actual distribution in this region with only one discontinuity. This should be ample 
for all practical problems since this region is actually quite sma11 and, therefore, the slope of the gradient cannot vary greatly along the short length of side p1ate involved. In Appendix "B", we have investigated several loading patterns in order to determine definite loadings which give rise to critical bending moments. He have considered only "square" patterns for all cases as the only known characteristic of the thermal loading pattern is its maximum value. By assuming this maximum to be constant for the entire length of pattern, the result will be conservative for almost all cases. In the region of the end plate, we have shown (Table I, Appendix "B") that a uniform semi-infinite loading is the most critical. Hence, this case was used for our sample calculation. Moment in the side plate in the region away from the end plate arising from variations in the fuel plate temperature may be easily solved with equations given by reference (c) for various 1oad distributions. In Appendix "B", we have indicated the finite uniform load which causes critical bending moment in the side plate. The calculation for the region away from the end plate is, therefore, based upon a thermal loading having these characteristics.

Stresses arising from non-linear temperature gradients along the length of the seed may be found from applying theory from reference $(h)$. These stresses are approximately propor- 
tional to the second derivative of the axial temperature distribution. The Poisson effect of the result must be added to the stresses found above for their final maximum value.

\section{Bo Results of Stress Analysis}

Critical stresses in the P.W.R. Core I, Seed I arising from the loadings described above are given by the following table:

\begin{tabular}{cccccc} 
Component & $\begin{array}{c}\text { Calc. } \\
\text { No. }\end{array}$ & $\begin{array}{c}\text { Location of } \\
\text { Critical Stress }\end{array}$ & $\begin{array}{c}\text { Critical } \\
\text { Stress }\end{array}$ & $\begin{array}{c}\text { Type of } \\
\text { Stress }\end{array}$ & $\begin{array}{c}\text { Analysis } \\
\text { Page No. }\end{array}$ \\
\cline { 2 - 3 } & 1 & outside corner & 5700 psi & compression & IV.18 \\
2 & 3 & $N$ & 6300 & $n$ & $n$
\end{tabular}

Fuel Plate 1

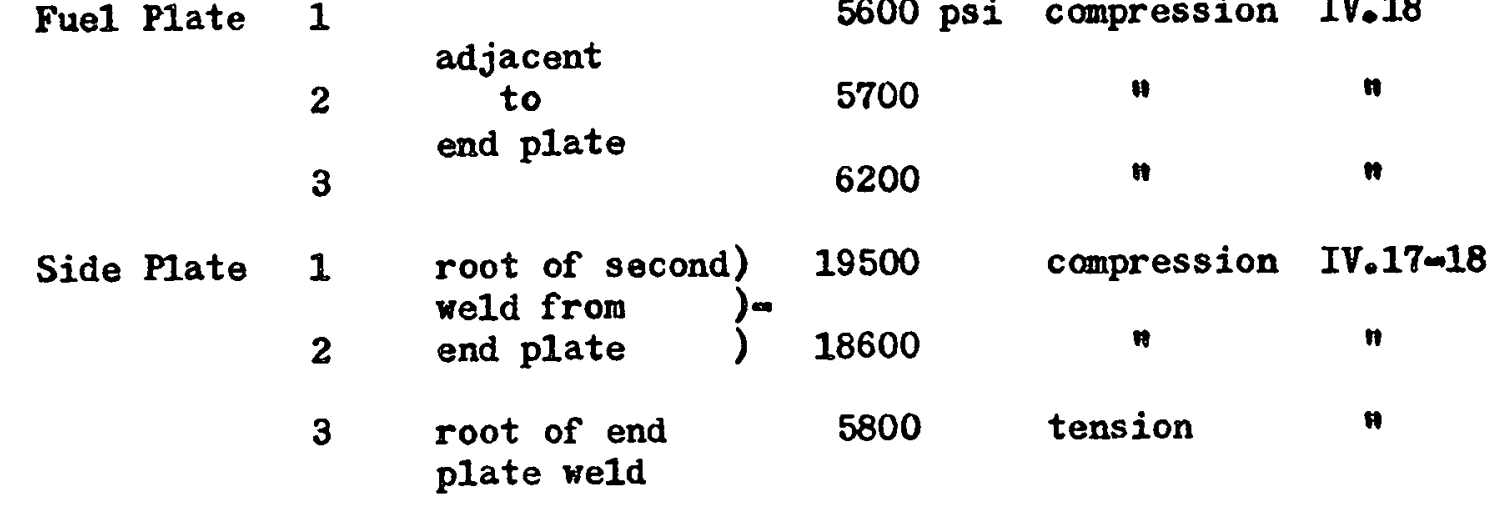

5600 psi compression IV.18

Calculation number $(1)$ is based upon nominal seed dimeno sions and normal operating pressures at the elevation (along the length of the seed) corresponding to the greatest differential temperature between the fuel plates and the end plates. Calcum lation number (2) is similar to the above except that the forcing pressure across the core is specified to be 75 psi. Calculation number (3) is based upon the maximum manufacturing tolerance for the end plate thickness, and the effective depth of the entire 
side-plate equal to the minimum weld penetration at any point. The forcing pressure is also specified to be $75 \mathrm{psi}$ for this calculation. All three calculations are based upon the same maximum differential temperature (above). Discontinuity stress concentrations and axial temperature variations have not been considered. It should be noted that the bending moment in the vicinity of the end plate weld is extremely sensitive relative to the exact location of the weld (see Fig. (F), page IV.17), with a greater distance from the centerline of the end plate giving rise to a more favorable condition. The reported stresses at this weld must therefore be considered to be of nominal magnitudes rather than absolute values.

As the anticipated average fuel plate temperature in the region away from the end plate is substantially constant (as a function of $x$ ), stresses from the "sample" calculation for that region (page 20) do not appear here.

C. Table of Symbols

$\alpha=$ coeffictent of linear expansion

$\beta=(\mathrm{k} / 4 \mathrm{~L})^{\frac{1}{4}}$

$\gamma, \xi=$ constants

$\Delta_{c}=$ change of slope of temperature gradients at (c)

$\zeta, \theta, \phi, \psi=$ influence coefficients

$\eta$ = error value

$\nu=$ Poisson's ratio

$\sigma=$ stress valve 


$$
\begin{aligned}
A, B, C, C_{1}, C_{2}, C_{3}, C_{4}, D_{1}, L, a, b, C_{0}=\text { constants } \\
C=\text { distance, degree of weld penetration } \\
D=B t^{3} / 12\left(1-V^{2}\right) \\
E=\text { Inung's modulus } \\
\text { - (subscript) denotes end plate } \\
f \text { (subscript) denotes fuel plate } \\
I=\text { monent of inertia } \\
K=\text { defiection restraint constant } \\
K=\text { degrep of end fixity }
\end{aligned}
$$

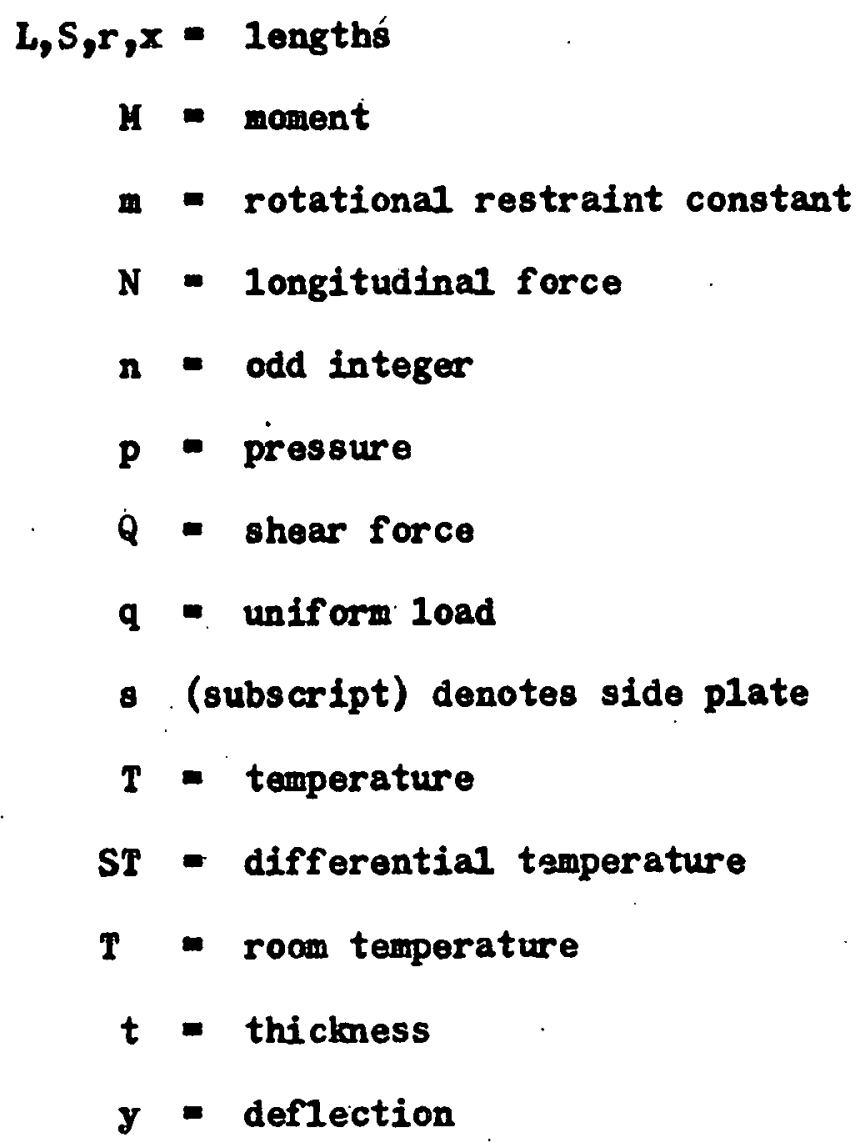




\section{A- GENERAL}

NOVEMBER 5 '56 R. MARK

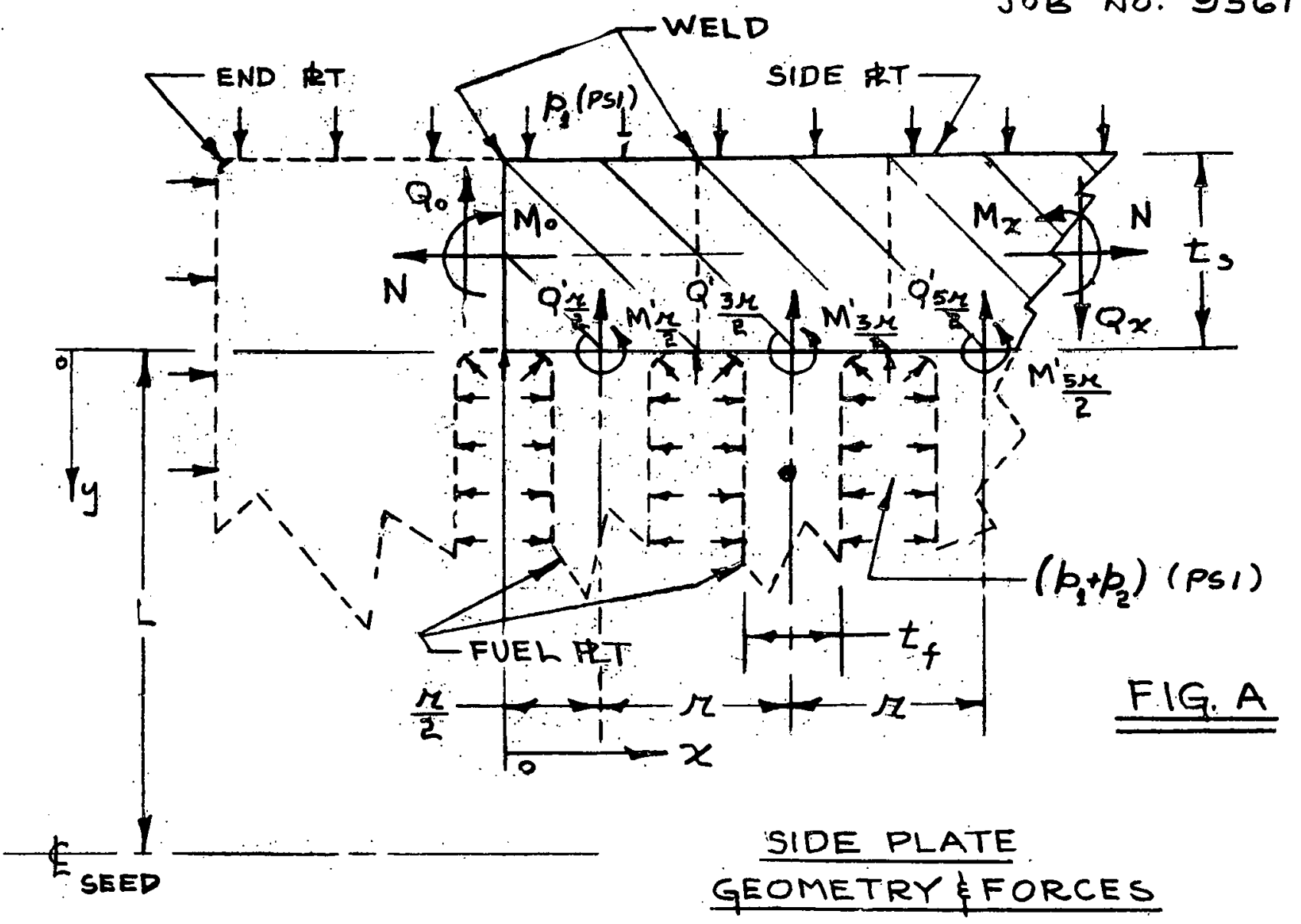

LET $r=$ TYPICAL FUEL ELEMENT SPACING. FOR A ONE INCH WIDE STRIP(INTO THE PAPER), $\left(b_{1}\right)=$ EX.TERNAL HYDROSTATIC FORCE $\left(\angle B / I N^{2}\right)$ AND $\left(p_{1}+p_{2}\right)=$ INTERNAL HYDROSTATIC FORCE $\left(\angle B / \mathbb{N}^{2}\right)$. AT $x=r / 2 ; 1 T$ MAY bE OBgERVED THAT NO SHEAR EXISTS IN THE FUEL PLATE AS THE LATERAL FORCES ARE BALANCED. HENCE

$$
\begin{aligned}
M_{\frac{r}{2}}^{\prime}=\frac{D_{f}}{L}\left(\frac{d y}{d x}\right)_{x=}(I N-L B / 2 & \\
\text { WITH: } D_{f}= & {\left[E t^{3} / 12\left(1-V^{2}\right)\right]_{f} } \\
& \text { (SUBSCRIPT }(f) \text { DENOTES FUEL HT) } \\
& \text { PROPERTIES) } \\
E & =\text { YOUNG'S MODULUS } \\
V & =\text { POISSON'S RATIO }
\end{aligned}
$$

THE COMPRESSIVE FORCE IN THE FUEL RT IS

$$
Q_{\frac{\alpha}{2}}^{\prime}=(E \alpha t)_{f}\left(T-T_{\beta}\right)_{x=\frac{\mu}{2}}+\frac{(E t)_{f}}{L} y_{x=\frac{\mu}{2}} \quad \text { (LB/IN) }
$$


IV $\cdot 10$

WITH: $d$ = AVERAGE COEFFICIENT OF THERMAL EXPANSION $T$ = AVERAGE TEMPERATURE OF FUEL RT T $T_{\phi}=$ ROOM: TEMPERATURE

SIMILARLY; AT $X=\frac{3}{2} r$, WE HAVE

$$
\begin{aligned}
M_{\frac{3 \mu}{2}}^{\prime} & =\frac{D_{f}}{L}\left(\frac{d y}{d x}\right)_{x=\frac{3 \mu}{2}}(I N-L B / I N .) \\
\xi Q_{\frac{3 \mu}{2}}^{\prime} & =(E d t)_{f}\left(T-T_{\phi}\right)_{x=\frac{3 \mu}{2}}+\frac{(E L)_{f}}{L} y_{x=\frac{3 \mu}{2}} \cdot\left(L_{B} / I_{N}\right)
\end{aligned}
$$

THUS FOR ANY FUEL ELEMENT AT $x=\frac{n \Omega}{2}$ (WITH $n=1,3,5, E T C$ ), WE MAY WRITE:

$$
\begin{aligned}
M_{\frac{n \pi}{2}}^{\prime} & =\frac{D_{f}}{L}\left(\frac{d y}{d x}\right)_{x=\frac{n \pi}{2}} \quad(I N-L B / I N .) \\
\xi Q_{\frac{n \pi}{2}}^{\prime} & =(E d t)_{f}\left(T-T_{\phi}\right)_{x=\frac{n \pi}{2}}+\frac{(E t)_{f}}{L} y_{x=\frac{n \pi}{2}} \quad(L B / I N .)
\end{aligned}
$$

WITH $\frac{(E t)_{f}}{L}=K_{f} ; \frac{D_{f}}{L}=m_{f}$, THE ABOVE MAY BE REWRITTEN AS

$$
\begin{aligned}
& M_{\frac{n r}{2}}^{\prime}=m_{f}\left(\frac{d y}{d x}\right)_{x}=\frac{n \pi}{2} . \quad(I N-L B / I N) \\
& Q_{\frac{n \mu}{2}}^{\prime}=K_{f}\left[L d_{f}\left(T-T_{\phi}\right)+y\right]_{x=\frac{n r}{2}} \quad(L B / I N .)
\end{aligned}
$$

THESE EQUATIONS SUGGEST A SOLUTION IN THE FORM OF AN ELASTIC FOUNDATION PROBLEM. HETENYI (REF. C) STATES THAT WHEN

$$
\sqrt[4]{\frac{64 r^{3} k}{D_{S}}}<\pi
$$

(SUBSCRIPT (S) DENOTES SIDE RT PROPERTIES) IS FULFILLED, THE METHOD OUTLINED IN APPENDIX (A) IS APPLICABLE.

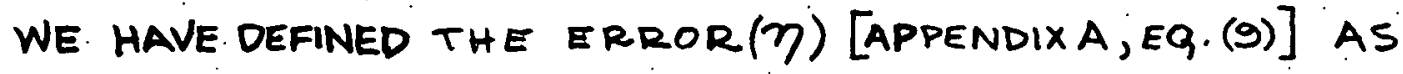

$$
\begin{aligned}
& \eta=0.25(m+N)\left(K D_{s}\right)^{-0.5} \\
& \text { WITH: } m=m_{f} r^{-1}=D_{f} / r L \quad\left(I N-L B / N^{2}\right) \\
& N=p_{2} L-p_{1} t_{s} \quad \text { (LB/IN) } \\
& K=k_{f} r^{-1}=(E t)_{f} / r L \quad\left(L B / I N N^{3}\right)
\end{aligned}
$$

(6)

IF EqUATION (3) IS SATISFIED, AND IF THE VALVE OF EQUATION (4) IS DEEMED SUFFICIENTLY SMALL, WE MAY APPLY THE ORDINARY ELASTIC FOUNDATION THEORY AS OUTLINED BY TIMOSHENKO (REF B).

$468 \quad .22$ 
THE. CHARACTERISTIC DEFLECTION CONSTANT $(\beta)$ IS DEFINED IN APPENDIX (A) AS

(8)

$$
\beta=\sqrt[4]{\frac{K}{4 D_{s}}}
$$

THE INFLUENCE COEFFICIENTS OF CONCENTRATED MOMENTS AND SHEARS ARE PLOTTED AS A FUNCTION OF $(\beta x)$ ON PAGE FOUR (OP. CIT.). IT IS OBSERVED THAT AT $\beta X=\pi$; THE COEFFICIENTS ARE VERY SMALL, AND THAT AT $\beta X=5$, THEY APPROACH ZERO. WE MAY CONCLUDE FROM THE ABOVE THAT A SOLUTION FOR. SIDE RT INTERNALFORCES IN THE REGION OF THE END RT NEED ONLY BE BASED UPON THE ACTION OF FORCES IN THAT REGION $(x=0$ TO $x=\pi / \beta)$. LIKEWISE, AWAY. FROM THE END RT $(x>\pi / \beta)$, THE INTERACTINGEND HT FORCES NEED NOT BE CONSIDERED.

B-IN THE END RT REGION, WE MAY ASSUME THE AVERAGE TEMPERATURE LEVEL WITHIN THE END AT \& FUEL ELEMENTS TC BE GIVEN BY THE FOLLOWING GENERAL DIAGRAM:

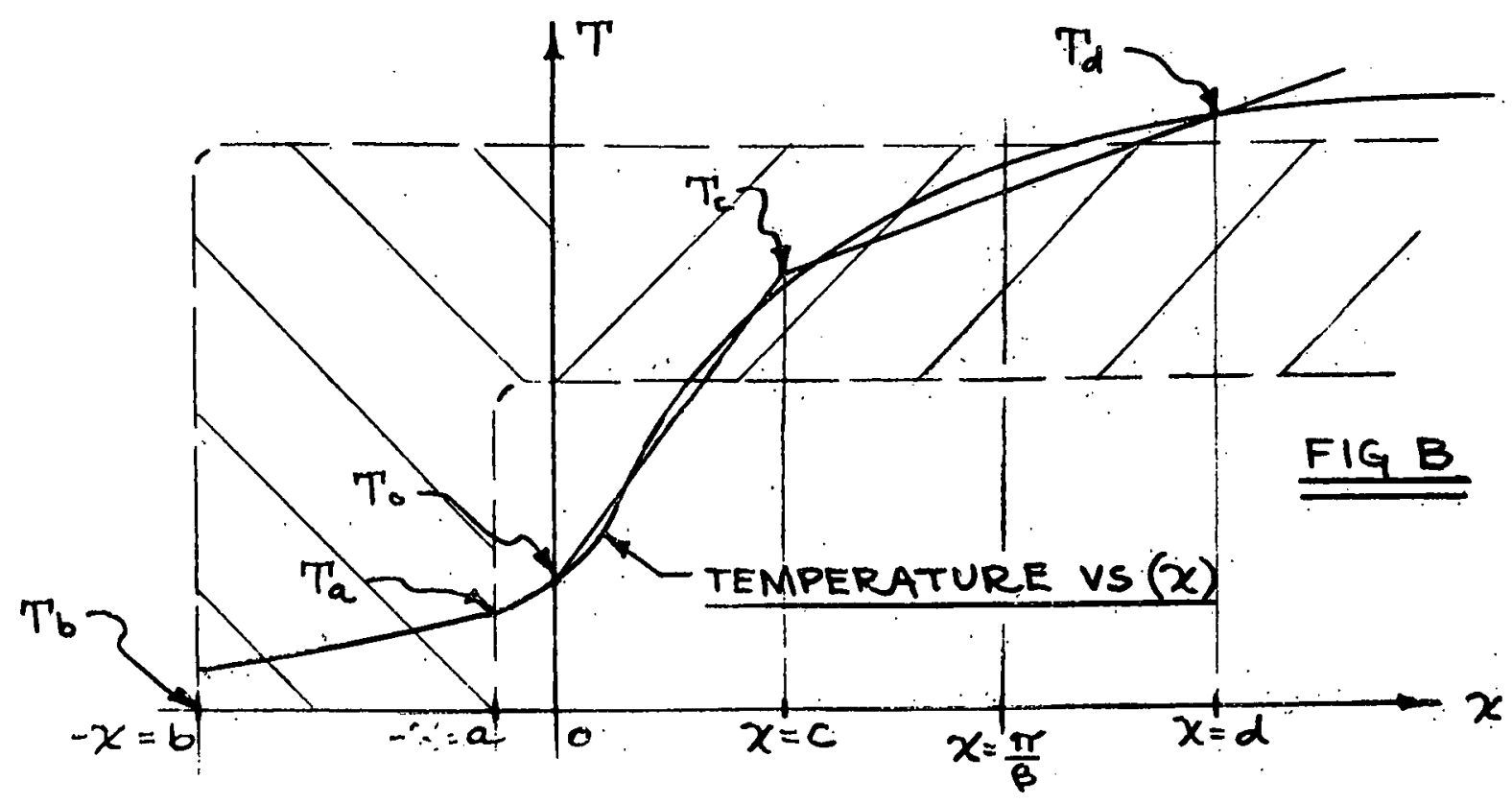

AS EXPLAINED ABOVE, WE ARE CONCERNED ONLY WITH THAT PORTION OF THE CURVE BETWEEN $x=0$ AND $x=\pi / \beta$. THE CURVE MAY BE APPROXIMATED BY THE STRAIGHT LINE CONSTRUCTIONS AS SHOWN.THE AVERAGE FUEL RTT TEMPERATURE IS THEN GIVEN AS
(9a)
$T=T_{0}+\left(\frac{T_{c}-T_{0}}{C}\right) x$
$0 \leqq x \leqq c$
E0:
23 
II $\cdot 12$

AND

(ob) $T-T_{c}+\left(\frac{T \alpha-T_{c}}{d-c}\right)(x-c) \quad c \leqslant x \leqslant \alpha$

THE CHANGE OF SLOPE OF THE TEMPERATURE GRADIENTS AT (C) IS

(10) $\left.\Delta_{c}=\frac{T_{c}-T_{0}}{C}-\frac{T d-T_{c}}{d-C}\right)$

CONSIDER NOW AN INFINITE SIDE RT WITH A TEMPERATURE DISCONTIMITY AT ANY POINT (C) THE SLOPES OP THE GRADIENTS TO THE RIGHT \&LEFT OF (C) ARE- $\phi_{R} \xi-\phi_{L}$

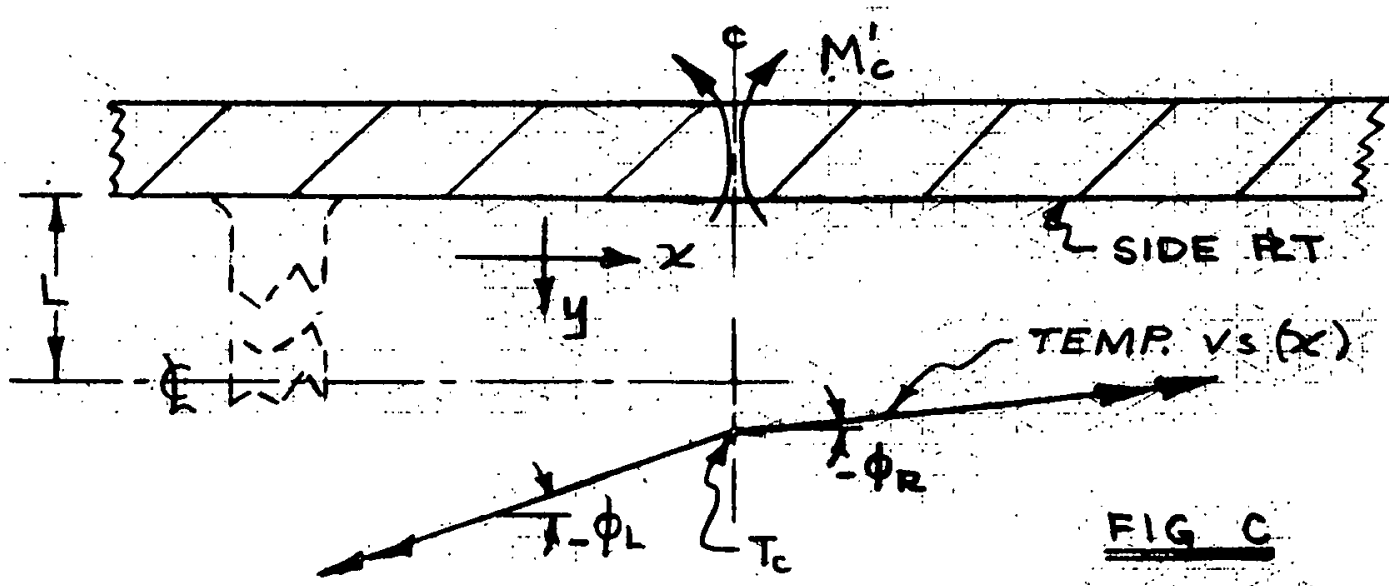

If THE BEAM IS BROKEN AT (C), THE SLOPE OP THE RIGHT SEGMENT WOULD BE

$-\left(\phi_{R} \alpha L\right)$

AND OF. THE LEFT SEGMENT WOULD BE

$$
-\left(\phi_{L} \alpha \cdot L\right)
$$

FOR CONTINUITY AT (C) HOWEVER

$$
\left(\frac{d y}{d x}\right)_{R}=\left(\frac{d y}{d x}\right)_{L}
$$

FROM SYMETRY CONSIDERATIONS, IT IS EVIDENT THAT NO SHEAR MAY EXIST AT (C); THEREFORE MIC IS THE ONLY INTERNAL FORCE TO BE CONSIDERED AT THAT POINT. THE ROTATION OF THE END OF EITHER SEGMENT DUE TO MOMENT IS

$$
\left|M_{c}^{\prime} / E D_{s}\right|
$$

THEREFORE

(II) $\left(\frac{d y}{d x}\right)_{R}=-\phi_{R} \alpha L-\frac{M_{c}^{\prime}}{\beta D_{S}}=\left(\frac{d y}{d x}\right)_{L}=-\phi_{L} \alpha L+\frac{M_{c}^{\prime}}{\beta D_{s}}$

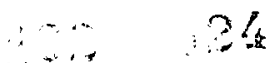


II $\cdot 13$

FROM WHICH

(12)

$$
M_{c}^{\prime}=-\frac{\alpha L \beta D_{3}}{2}\left(\phi_{R}-\phi_{L}\right)
$$

SINCE $\Delta_{C}=-\phi_{L}+\phi_{R}$

(12a) $\quad M_{c}^{\prime}=-\frac{\alpha L \beta D_{s} \Delta_{c}}{2}$

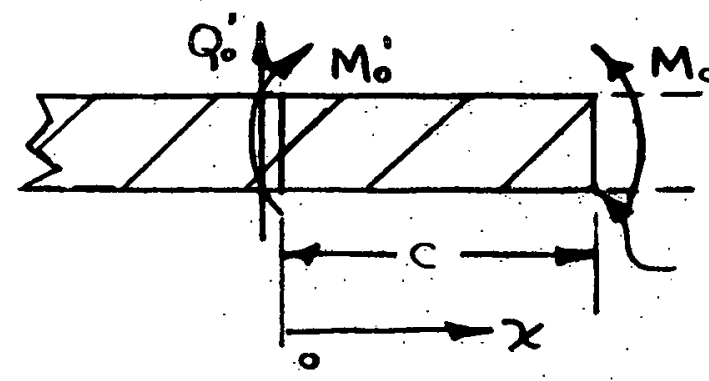

SEMI-INFINITE SEgMENT. OF SIDE PLATE TO LEFT OF POINT (C)

WITHIN THE INFINITE RT, AT $(x=0)$,THE MOMENT AND SHEAR RESULTING FROM THE DISCONTINUITY AT (C) ARE

(14)

$$
\begin{aligned}
M_{0}^{\prime}=M_{c}^{\prime} \varphi(\beta x)_{x=c} \\
Q_{0}^{\prime}=2 M_{c}^{\prime} \beta \zeta(\beta x)_{x}=c \\
\text { WITH } \phi(\beta x)=e^{-\beta x}(\cos \beta x+\sin \beta x) \\
\xi \cdot S(\beta x)=e^{-\beta x} \sin \beta x
\end{aligned}
$$

THE CHANGE OF DEFLECTION OF THE INFINITE RT ( ACCOMPANYING THE DISCONTINUITY) AT $(X=0)$ IS

(15)

$$
\begin{aligned}
y_{0}^{\prime}=-\frac{M_{c}^{\prime}}{2 \beta^{2} D_{S}} \psi(\beta x)_{x}=c \\
\text { WITH } \psi(\beta x)=e^{-\beta x}(\cos \beta x-\sin \beta x)
\end{aligned}
$$

AND THE CHANGE OF SLOPE AT $(x=0)$ is

$(16)$

$$
\begin{aligned}
\left(\frac{d y}{d x}\right)_{0}^{\prime}=-\frac{M_{c}^{\prime}}{\beta D_{s}} \theta(\beta x)_{x} & =c \\
\text { WITH } \theta(\beta x) & =e^{-\beta x} \cos \beta x
\end{aligned}
$$

BY MAINTAINING $\left(M^{\prime}\right) \xi\left(Q_{0}^{\prime}\right)$, THE SIDE RT TO THE LEFT OF $(x=0)$ MAY BE SEVERED WITHOUT AFFECTING THE STRUCTURE TO THE RIGHT. WE MAY NOW IMPOSE INTERACTION BOUNDARY CONDITIONS FOR THE SOLUTION OF THE SIDE RT - FUEL \&T SYSTEM IN THE REGION OF THE END RT 
II $\cdot 14$

IT IS EXTREMELY UNLIKELY THAT THE FORCES AT THE END OP. THE SIDE FLT. (MO QQ - SEE FIG. A) REQUIRED TO MAINTAIN CONTINUITY IN THE SEED are Equal to (Mo') $\left(Q_{0}^{\circ}\right)$. THE TOTAL DEFLECTION (AND ROTATION) OF THE END OF THE SIDE RT. IS THEREFORE EQUAL TO THE SUM OF DEFLECTIONS RESULTING FROM THE DIFFERENCE BETWEEN $\left(M_{0}\right) \&\left(M_{0}^{\prime}\right)$, AND $\left(Q_{0}\right) \&\left(Q_{0}^{\prime}\right)$, AS WE IL AS THE IMPRESSED (INFINITE BEAM) DEFLECTION CHANGE ARISING FROM THE THERMAL DISCONTINUITY, THE TEMPERATURE AND SLOPE OF THE THERMAL GRADIENT AT THE END, AND THE UNBALANCED HYDROSTATIC FORCE ACTING ON THE SIDERT. IN EQUATION FORM:

(Ii) $\quad y_{03}=\left[\left(M_{0}-M_{0}^{\prime}\right) \beta+\left(Q_{0}-Q_{0}^{\circ}\right)\right] \frac{-1}{2 \beta^{3} D_{s}}+y_{0}^{\prime}-q_{f}\left(T_{0}-T_{f}\right) L+\left[p_{1} \frac{t_{f}}{r}-p_{2}\left(1-\frac{t_{f}}{r}\right)\right] \frac{1}{k}$ (18) $\left(\frac{d y}{d x}\right)_{0 s}=\left[\left(M_{0}-M_{0}^{\prime}\right) 2 \beta+\left(Q_{0}-Q_{0}^{\prime}\right)\right] \frac{-1}{2 \beta^{2} D_{s}}+\left(\frac{d y}{d x}\right)_{0}^{\prime}-\left[\frac{T_{c}-T_{0}}{c}\right] d_{f} L$

THE CORRESPONDING EDGE DEFLECTION OF. THE END RT. IS

(19) $\quad y_{e}=\left[Q_{0}+p_{1} t_{e}-p_{2}\left(\frac{r_{-}-t_{f}}{2}\right)\right] \frac{L}{(t E)_{e}}-\left[\left(\frac{\left(T_{a}+T_{b}\right)}{2}\right)-T_{\phi}\right] d_{f} L+S\left(\frac{d y}{d x}\right)_{0 . s}$ AND THE EDGE ROTATION IS

(SUBSCRIPT (e) DENOTES END RT)

(20) $\left(\frac{d y}{d x}\right)_{0 e}=\left[Q_{0} s-M_{0}-p_{2}\left(\frac{t_{e}}{2}+\frac{r-t_{f}}{4}\right)\left(\frac{r-t_{f}}{2}\right)\right] \frac{L}{D_{e}}+\frac{p_{e} L^{3}}{3 D_{e}}-\left(\frac{d}{t}\right)_{e} L\left(T_{a}-T_{b}\right)$

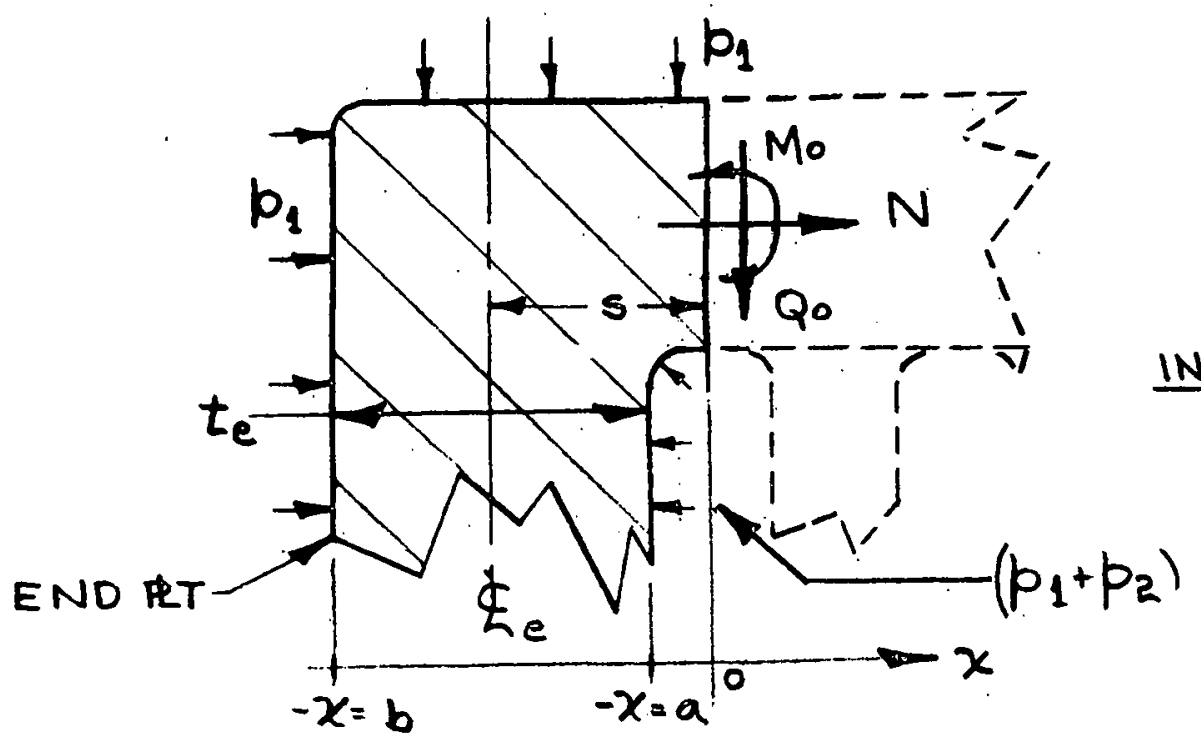

END RT INTERACTING EHYDROSTATK FORCES, \& GEOMETRY

CONTINUITY REQUIRES THAT;

(ii) $y_{0 s}=y_{\infty}$

FIG .E

(Ri) $\left(\frac{d y}{d x}\right)_{0}=\left(\frac{d y}{d x}\right)_{0 e}$

$25: \quad 26$ 
II $\cdot 15$

THE SOLUTION OF THIS SIMULTANEOUS SYSTEM (E gS. 2\$22), YIELDS Mo AND QO. THE MOMENT IN THE SIDE PLATE (MA). FOR ANY. POINT $(x)$ IN THE VICINITY OF THE END PLATE $(x \leq \pi / \beta)$ is THEN GIVEN BY:

(23) $M_{x}=\left(M_{0}-M_{0}^{\prime}\right) \varphi(\beta x)+\frac{1}{\beta}\left(Q_{0}-Q_{0}^{\prime}\right) \zeta(\beta V)+M_{c}^{\prime} \varphi(\beta|x-c|)$ $\left(Q_{x}\right),\left(y_{x}\right) \xi\left(\frac{d y}{d x}\right)_{x}$ MAY ALSO BE FOUND (SEE REFERENCE $b$ ) AND THUS SOLUTIONS FOR $\left(Q_{n / 2}^{\prime}\right)$ \& $\left(M_{n \pi / 2}^{\prime}\right)$ ARE OBTAINED FROM: EQUATIONS (1) $\xi$ (2); HOWEVER. AN ADEQUATE ANALYSIS OF THE FUEL ELEMENTS NEED ONLY CONSIST OF CHECKING THE FIRST ELEMENT $(x=n / 2)$ AT THE END PLATE, AND ANOTHER AWAY FROM THE VICINITY OF THE END PLATE $(x \geq \pi / \beta)$. AS THE FIRST ELEMENT IS SO NEAR THE ORIGIN OF THE SIDE PLATE; WE MAY WRITE;

$$
\begin{aligned}
& y_{\frac{n}{2}}=y_{0}+\frac{\pi}{2}\left(\frac{d y}{d x}\right)_{0} \\
& \&\left(\frac{d y}{d x}\right)_{\frac{1}{2}}=\left(\frac{d y}{d x}\right)_{0} .
\end{aligned}
$$

SUBSTITUTING THE ABOVE INTO EQUATIONS (1) \& (2) YIELDS

$$
\begin{aligned}
& M_{\frac{n}{2}}^{\prime}=\frac{D_{f}}{L}\left(\frac{d y}{d x}\right)_{0} \\
& Q_{\frac{n}{2}}^{\prime}=\frac{(E t)_{f}}{L}\left[L \alpha_{f}\left(T-T_{\varphi}\right)_{\frac{\Omega}{2}}+y_{0}+\frac{\Omega}{2}\left(\frac{d y}{d x}\right)_{0}\right]
\end{aligned}
$$

THE BENDING STRESS (THROUGH WELD SECTIONS) IN THE SIDE PLATE IS

$$
\begin{array}{ll}
\sigma_{b}=6 M_{x} /\left(c t_{s}\right)^{2} & M_{x} \text { is GIVEN BY Eq. (23) } \\
& c=\text { DEGREE OF WELD PENETRATION }
\end{array}
$$

THE MAXIMUM STRESS IN THE SIDE PLATE IS THEREFORE

(26) $\quad \sigma_{S \text { MAX }}=\left|\frac{6 M_{x \text { MAX }}}{\left(C \cdot t_{S}\right)^{2}}\right|+\left|\frac{N}{C t_{S}}\right|\left(\right.$ LBS/ IN $\left.{ }^{2}\right)$

$N$ IS GIVEN BY EQ .(6)

THE TOTAL STRESS IN THE END FUEL ELEMENT IS

(27) $\quad \sigma_{f}=\left|\frac{6 M_{n / 2}^{\prime}}{t_{f}^{2}}\right|+\left|\frac{Q_{i / 2}^{\prime}}{t_{f}}\right| \quad\left(L B S / 1 N^{2}\right)$ 
II $\cdot 16$

THE BENDING STRESS IN THE OUTSIDE CORNER OF THE END RT 15

$$
\text { (28) } \sigma_{b c e}=\frac{6}{t_{e}^{2}}\left[Q_{0} S-M_{0}-p_{2}\left(\frac{t_{e}}{2}+\frac{r-t_{f}}{4}\right)\left(\frac{r-t_{f}}{2}\right)\right]
$$

THE TOTAL STRESS AT THIS POINT IS

$$
\text { (29) } \quad \sigma_{c e}=\left|\sigma_{b c e}\right|+\left|\frac{q_{0}+p_{1} t_{e}-p_{2}\left(\frac{r-t_{t}}{2}\right)}{t_{e}}\right|
$$

THE TOTAL STRESS IN THE MIDDLE OF THE END RT IS

$$
\text { (30) } \sigma_{m e}=\left|\sigma_{b_{c e}}+\frac{6 p_{2} L}{t_{e}^{2}}\left(\frac{L+t_{s}}{2}\right)\right|+\left|\frac{q_{0}+p_{1} t_{e}-p_{2}\left(\frac{\mu-t_{f}}{2}\right)}{t_{e}}\right|
$$

CALCULATION FOR MAXIMUM STRESS IN THE END RT REGION in APPENDIX (B), WE HAVE INDICATED THAT THE CRITICAL LOADING PATTERN FOR THIS REGION (GIVING RISE TO MAXIMUM BENDING MOMENT IN THE SIDE RT) IS A SEMIINFINITE UNIFORM LOADING. WE SHALL THEREFORE CONSIDER AN ANALYSIS WITH $\left(T-T_{\varphi}\right)=T_{K}$ (A CONSTANT). THREE SEPERATE CALCULATIONS ARE OFFERED;EACA IS BASED UPON SOMEWHAT DIFFERENT VALUES OF INTERNAL PRESSURE AND (OR) COMPONENT THKKNESSES, HOWEVER THE FOLLOWING VALUES ARE COMMON TO ALL:

$$
\begin{aligned}
& E=11.2(10)^{6} \text { PSI (REF. } f \text { ) } \\
& v=0.3 \\
& \alpha=3.6(10)^{-6} \text { PER OF (REEf) } \\
& L=1.125 \mathrm{iN} . \\
& \nearrow=0.138 \mathrm{iN} .
\end{aligned}
$$

$$
\begin{aligned}
& \text { DISTANCE ABOVE BASE OF CORE TO MAX ST= } 67 \mathrm{~cm} \text {. (REF } \text { ) } \\
& T_{0}=T_{c}=T_{d}=\left(T_{Q}+T_{k}\right) \\
& T_{a}=T_{b}=\left(T_{\phi}+T_{k}-\delta T\right)
\end{aligned}
$$

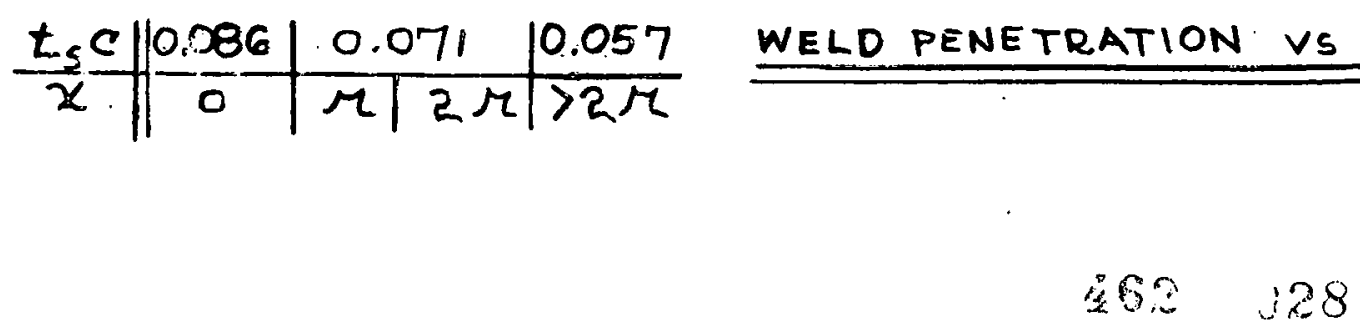




\section{TV. 17}






\begin{tabular}{|c|c|c|c|c|c|c|}
\hline ITEM ND. & ITEM & UNITS & CALC.NO1 & CALC. NOZ & CALC. NO.3 & NOTES \\
\hline 1 & $t_{e}$ & INCHES & 0.181 & 0.181 & 0.206 & SEE FIGURES (A) $\xi(E)$ \\
\hline 2 & $t_{f}$ & 1 & 0.069 & 0.069 & 0.069 & \\
\hline 3 & $t_{s}$ & & 0.125 & 0.125 & 0.057 & \\
\hline 4 & $s$ & $\downarrow$ & 0.125 & 0.125 & 0.138 & $\varphi$ \\
\hline 5 & $\begin{array}{l}\text { FORCING } \\
\text { PRESSURS }\end{array}$ & PSI. & 60 & 75 & 75 & (ACROSS CDRE) \\
\hline 6 & $P_{2}$ & $\mid$ & 37.7 & 47. & 47.1 & AT POINT OF MAXIMUM ST (REF $E$ ) \\
\hline 7 & P. & t & 2000 & 2000 & 2000 & (SYSTEM PRESSURE) \\
\hline 8 & $\delta T$ & ${ }^{\circ} \mathrm{F}$ & 208 & 208 & 208 & (REFERENCE e) \\
\hline 9 & $D_{F}$ & $\angle B-I N^{7} / I N$ & 336 & 336 & 336 & FPOM PAGE (II.9) \\
\hline 10 & $D_{s}$ & & 2000 & 2000 & 190 & \\
\hline 11 & De & $\downarrow$ & 6080 & 6080 & 8970 & \\
\hline 12 & $m$ & $1 N-28 / 1 N^{3}$ & 2170 & 2170 & 2170 & FROM EQUATION (5) \\
\hline 13 & $N$ & $\angle B / I N$ & -208 & -197 & -61.0 & FROM EQUATION (6) \\
\hline 14 & $K$ & $\angle B / 1 N^{3}\left(10^{6}\right)$ & 4.98 & 4.98 & 4.98 & FPOM EQUATION (T) \\
\hline 15 & $\eta$ & - & 0.005 & 0.005 & 0.017 & FROM EQUATION (4) \\
\hline 16 & $\beta$ & $1 N^{-1}$ & 4.99 & 4.99 & 8. 99 & FROM EQUATION (8) \\
\hline 17 & $\Delta^{\prime} c$ & F/IN/IN & 0 & 0 & 0 & FROM EQUATION (10) \\
\hline 18 & $M^{\prime} c$ & IN- $-\angle B / / N$ & 0 & 0 & 0 & FAOM EQUATION (IZa) \\
\hline 19 & M'o & 1 & 0 & 0 & 0 & FROM EQUATION (13) \\
\hline 20 & $Q^{\prime} \circ$ & $\angle B / I N$ & 0 & 0 & 0 & FPOM EQUATION (14) \\
\hline 21 & $y^{\prime} 0$ & $\mathbb{I N}$ & 0 & 0 & 0 & FAOM EQUATION $(15)$ \\
\hline 22 & $(d y / d x)_{0}^{1}$ & IN/IN & 0 & 0 & 0 & FROM EQUATION (16) \\
\hline \multirow{2}{*}{23} & \multirow{2}{*}{ Mo } & \multirow{2}{*}{ WN-LE/IN } & \multicolumn{2}{|c|}{$0.212 P_{2}-0.0393 \delta T$} & $\begin{array}{l}0.018 P_{2} \\
+0.0141\end{array}$ & \multirow{2}{*}{$\begin{array}{l}\text { FROM SOLUTION OF } \\
\text { EQUATIONS (17-22) }\end{array}$} \\
\hline & & & -0.018 & 1.81 & 8.06 & \\
\hline \multirow{2}{*}{24} & \multirow{2}{*}{ Qo } & \multirow{2}{*}{$L B / I N$} & \multicolumn{2}{|c|}{$-1.29 P_{2}-0.802 \delta T$} & $\begin{array}{l}-1.54 P_{2} \\
-0.6568 T\end{array}$ & \multirow{2}{*}{$\begin{array}{l}\text { FROM SOLUTION OF } \\
\text { EQUATIONS (17-22) }\end{array}$} \\
\hline & & & -215 & -228 & -209 & \\
\hline 25 & $y_{0}$ & IN. $\left(10^{-5}\right)$ & $63.3-0.4057 \pi$ & $63.5-0.405 T_{\kappa}$ & $69.0-0.405 T_{k}$ & FPOM EQUATION (IT) \\
\hline 26 & $(d y / d x)_{0}$ & $\ln / \ln \left(10^{-5}\right)$ & -217 & -209 & -209 & FROM EQUATION (18) \\
\hline 27 & $M^{\prime} \mu / 2$ & IN-LB/IN & -0.650 & -0.625 & -0.625 & FPOM EQUATION (24) \\
\hline 28 & $Q^{\prime} \mu / 2$ & LB/IN & 331 & 337 & 375 & FPOM EQUATION (25) \\
\hline 29 & $\sigma_{f}$ & PSI. & 5630 & 5680 & 6220 & FROM EQUATION (2T) \\
\hline 30 & Foce & 1 & -4920 & -5570 & -5240 & FROM EQUATION (28) \\
\hline 31 & $\sigma_{c e}$ & & 5730 & 6310 & 6220 & FROM EQUATION (29) \\
\hline 32 & $\sigma_{m c}$ & t & $8 / 3$ & 721 & 1790 & FROM EQUATION (30) \\
\hline 33 & Marit & IN-LB/IN & 13.9 & 13.3 & 8.06 & FROM FIG. F, DERIVED FROM EQ. (23) \\
\hline 34 & $\left(t_{s} c\right)_{c r i t}$ & IN & 0.071 & 0.071 & 0.086 & FROM FIG F \& PAGE $(I I \cdot 16)$ \\
\hline 35 & $\sigma_{s}$ max. & PSI. & 19,500 & 18,600 & $\begin{array}{l}7240 \text { comp. } \\
5820 \text { tens. }\end{array}$ & FROM EQUATION (26) \\
\hline
\end{tabular}


C- CALCULATION FOR MAXIMUM STRESS IN THE REGION AWAY FROM THE END RT $(x>\pi / \beta)$

Ne haVE ASCERTAINED (APPENDIX B) THAT. THE CRITICAL LOADING IN THE SIDE $R$ T IS GIVEN BY CASE 1 (TABLE I, APPENDIX B). THIS FORM OF THERMAL LOADING LACKS PHYSICAL SIgNIFICANCE, HOWEVER, IT IS INCLUDED TO PRESENT THE METHOD OF ANALYSIS IN THIS AREA. FROM ABOVE,

(3i)

$$
M_{\text {max }}=0.161 q / \beta^{2}
$$

WITH THE RT LOADED AS IN FIG. (G).

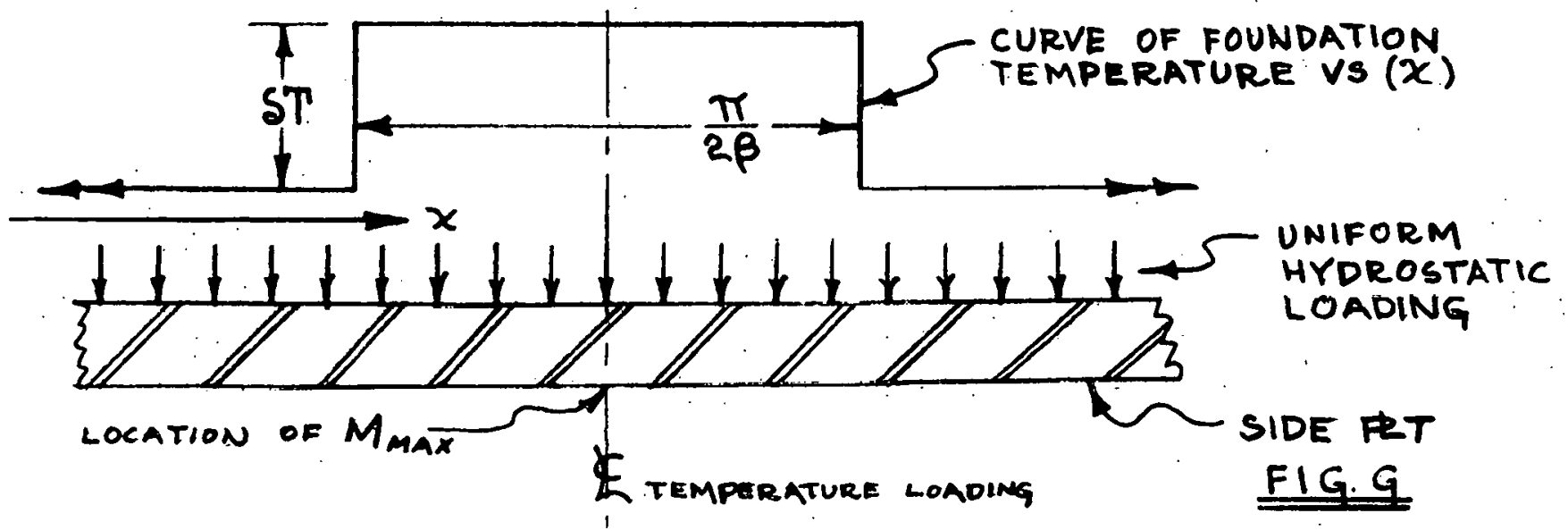

AS THE HYDROSTATIC LOADING DOES NOT CONTRIBUTE TO BENDING, IT NEED NOT BE CONSIDERED IN THE CALCULATION For ( $M_{\text {max }}$ ). THE EgUIVALENT THERMAL LOADING TO bE SUBSTITUTED FOR (q) IN EQ (31) IS.

$$
\text { (32) } \quad q_{T}=(\alpha E t)_{f} S T r^{-1}
$$

THE MAXIMUM TOTAL STRESS IN THE SIDE RT IS GIVEN BY EQ (26).

THE CRITICAL FUEL RT IS TO BE FOUND JUST TO THE INSIDE OF THE POINT OF THERMAL DISCONTINUITY. THE DEFLECTION AT THIS POINT IS GIVEN BY REF. (C) FIG. (A) TO BE

$$
\begin{array}{rl}
y=\frac{-q_{T}}{2 K} & {[2-\theta(\beta x)-\theta(\beta \cdot[L-x])]-\alpha_{f} L\left(T_{K}-\delta T\right)} \\
+ & \frac{1}{K}\left[p_{1} \frac{t_{f}}{r}-p_{2}\left(1-\frac{t_{f}}{r}\right)\right] \\
\text { WITH }(\beta x)=\pi / 2 & \\
\xi \beta(L-x)=0 & 311
\end{array}
$$


II $\cdot 20$

THE ROTATION OF THE END OF THE FUEL RT - AT THIS POINT IS GIVEN BY REF (C) TO

(34)

$$
\frac{d y}{d x}= \pm \frac{q+\beta}{2 k}[\varphi(\beta x)-\varphi[\beta(L-x)]]
$$

THE TOTAL STRESS IN THE FUEL RT IS GIVEN BY EQUATIONS (1), (2), \& (27) TO BE

(35) $\quad \sigma_{f}=\left|\frac{6 m_{f}}{t_{f}^{2}} \frac{d y}{d x}\right|+\left|\frac{E_{f} y}{L}+(E \alpha)_{f} T_{k}\right|$

WITH $\varphi(\beta x)=0.209$

$$
\begin{aligned}
& \varphi[\beta(L-x)]=1.0 \\
& \theta(\beta x)=1: 0
\end{aligned}
$$

$\theta[\beta(L-x)]=1.0$, AND FROM EQUATION (7) \& ABOVE

(33a) $y=\frac{1}{k}\left[p_{1} \frac{t}{r} f-p_{2}\left(1-\frac{t_{f}}{r}\right)\right]-\alpha_{f} L\left[T_{k}-\frac{S T}{2}\right]$

(34a) $\frac{d y}{d x}= \pm 0.396 \mathrm{~L} \alpha_{f}$ ST $\beta$

(35a) $\quad \underline{\sigma_{f}}=\left|\frac{2.38 L \alpha_{f} m_{f} \beta S T}{t_{f}^{2}}\right|+\left|\frac{E_{f}}{L K}\left[p_{1} \frac{t_{f}}{r}-p_{2}\left(1-\frac{t_{f}}{\pi}\right)\right]+(E d)_{f} \frac{S T}{2}\right|$

THE TOTAL STRESS IN THE SIDE FT IS GIVEN BY EqUATIONS (26), (31), F(32) TO BE

$$
\underline{\sigma_{s}}=\left|\frac{0.9 \nabla(\alpha E t)_{f} S T}{\left(c t_{s} \beta\right)^{2} \mu}\right|+\left|\frac{N}{c t_{s}}\right|
$$

STRESSES MAY NOW BE COMPUTED FOR THESE COMPTONENTS BASEP UPON THE CONSTANT VALUES (FOR cASES 1,2, \$3) GIVEN ON PAGES $(I I \cdot 16) \xi(I F \cdot 18)$. THE RESULTS ARE:

\begin{tabular}{c|c|c} 
CASE [FROM DG $(15)]$ & $\sigma_{f}$ & $\sigma_{S}$ \\
\hline 1 & $10,700 \mathrm{psi}$ & $53900 \mathrm{psi}$ \\
\hline 2 & $10,700 \mathrm{psi}$ & $53100 \mathrm{psi}$ \\
\hline 3 & $14,300 \mathrm{psi}$ & $16000 \mathrm{psi}$
\end{tabular}

$\$ 60 \quad 132$ 
ARDE ASSOCIATES

IV. 21

A P P E $\underline{\text { N } ~} \mathbb{I} \underline{\mathbf{X}} \quad \underline{A}$

GENERAL THEORY OF THE BEAM

ON AN ELASTIC FOUNDATION 
II $\cdot 22$

GENERAL SOLUTION FOR BEAM ON

ELASTIC. FOUNDATION

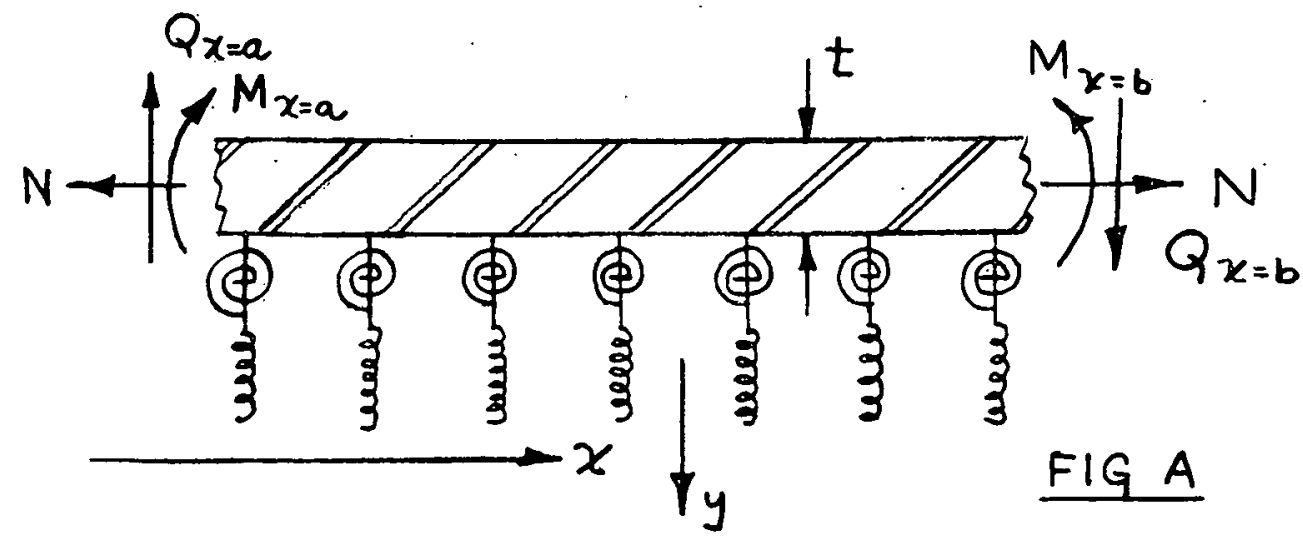

OCTOBER 24 '56.

R. MARK

JOB NO.. 9561

- GEOMETRY AND INTERNAL \& SPRING FORCES

CONSIDER the beam to be LOADED IN THE Y-DIRECTION, AND BY A PAIR OF EQUILIBRATING AXIAL TENSILE FORCES (N). WE MAY CONSIDER AN ELEMENTAL LENGTH OF BEAM WITH THE ROTATIONAL RESTRAINT EQUAL TO

$$
m \frac{d y}{d x} \text { IN.-LBS/IN. }
$$

AND THE TOTAL ( $y$-DIRECTION )LOAD AT ANY POINT $(x)$ EQUAL TO

(Ia)

$$
q(x, y)=q_{1}(x)-k y \quad L B S / I N .
$$

$$
\begin{aligned}
\text { WITH } q_{1}(x) & =\text { EXTERNAL LOADING (AS A FUNCTION OF } x \text { ) } \\
\xi & k y=\text { DEFLECTION RESTRAINT }
\end{aligned}
$$

UNDEFLECTED $\notin$

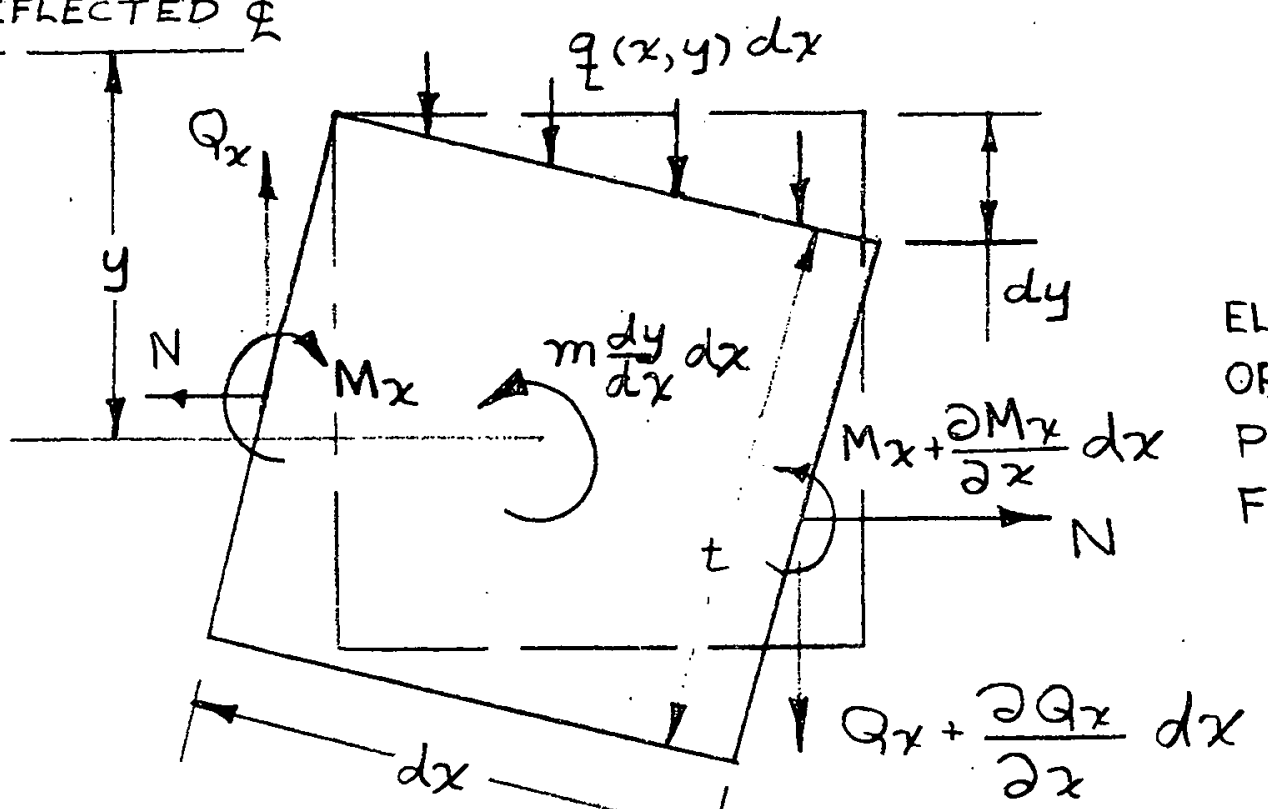

FIG B

ELEMENTAL LENGTH OF BEAM AT ANY POINT $(x)$, FORCES GEOMETRY $260 \quad 134$ 
IV $\cdot 23$

THE SUMMATION OF MOMENTS ABOUT THE CENTER OF THE ELEMENT (FIG 2); NEGLECTING $\left(\frac{\partial Q_{x}}{\partial x} d x\right)$ AS BEING SMALL COMPARED WITH $\left(Q_{x}\right)$, YIELDS

(2) $\frac{\partial M_{x}}{\partial x} d x+N d y+m \frac{d y}{d x} d x-Q_{x} d x=0$

$$
=\frac{\partial M x}{\partial x}+(N+m) \frac{d y}{d x}-Q x
$$

THE EQUILIBRIUM OF FORCES IN THE $Y$-DIRECTION YIELDS

(3) $\frac{\partial Q_{x}}{\partial x} d x+q(x, y) d x=0=\frac{\partial Q_{x}}{\partial x}+q(x, y)$

DIFFERENTIATING (2) \& SUBSTITUTING $\left(\frac{\partial Q x}{\partial x}\right)$ FROM (3) GIVES

(4) $\frac{\partial^{2} M x}{\partial x^{2}}+(m+N) \frac{d^{2} y}{d x^{2}}+q(x, y)=0$

from elementry theory (ref), we have

$$
M_{X}=-E I \frac{d^{2} y}{d x^{2}}
$$

As We are interested IN a beaM WHICH is actually a one UNIT WIDE STRIP FROM A PLATE, WE SHALL SUBSTITUTE THE PLATE FLEXURAL RIGIDITY CONSTANT (D) FOR (ET). THUS

(5)

$$
\begin{aligned}
& M_{x}=-D \frac{d^{2} y}{d x^{2}} \\
& \text { WITH D }=\frac{E t^{3}}{12\left(1-v^{2}\right)} \text { WHERE } E=\text { YOUNG'S MODULUS } \\
& t=\text { RT THICKNESS } \\
& \gamma=\text { POISSON'S RATIO }
\end{aligned}
$$

SUBSTITUTING (5) \& (Ia) INTO (4) YIELOS THE FINAL DIFFERENTIAL EQUATION OF THE UNIT STRIP:

(6) $D \frac{d^{4} y}{d x^{4}}-(m+N) \frac{d^{2} y}{d x^{2}}+k y=q_{1}(x)$

CONSIDERING AN UNLOADED SPAN LENGTH, WE HAVE

(ba) $D \frac{d^{4} y}{d x^{4}}-(m+N) \frac{d^{2} y}{d x^{2}}+K y=0$

IF WE ASSUME A SOLUTION OF THE FORM:

$$
y=e^{L x}
$$

$26 \quad 135$ 
II $\cdot 24$

THE EquATION FON L MAY BE WRITTEN AS

$$
\begin{aligned}
& L^{4}-\frac{(m+N)}{D} L^{2}+\frac{k}{D}=0 \\
& L^{2}=\frac{m+N}{2 D} \pm\left[\left(\frac{m+N}{2 D}\right)^{2}-\frac{k}{D}\right]^{1 / 2}
\end{aligned}
$$

WITH $\left(\frac{m+N}{2 D}\right)^{2}$ LESS THAN $\left(\frac{K}{D}\right)$, THE EQUATION FOR L BECOMES

$$
\begin{aligned}
& L_{1,2,3,4}= \pm \sqrt{\frac{m+N}{2 D} \pm i\left[\frac{K}{D}-\left(\frac{m+N}{2 D}\right)^{2}\right]^{1 / 2}}=\xi+i \gamma \\
& W I T H \xi=\left[\beta^{2}+\frac{(m+N)}{4 D}\right]^{1 / 2} \\
& \gamma=\left[\beta^{2}-\frac{(m+N)}{4 D}\right]^{1 / 2} \quad \text { WHERE. } \beta=\left[\frac{K}{4 D}\right]^{1 / 4}
\end{aligned}
$$

THE GENERAL SOLUTION TO EQUATION (Ga) IS

$$
y=C_{1} e^{L_{1} x}+C_{2} e^{L_{2} x}+C_{3} e^{L_{3} x}+C_{4} e^{L_{4} x}
$$

WITH SUBSTITUTION OF THE ABOVE NOTATION, THE EQUATION TAKES THE FORM (Gb) $y=e^{5 x}(A \cos \gamma x+B \sin \gamma x)+e^{-\zeta x}\left(C \cos \gamma x+D_{1} \sin \gamma x\right)$

AT AT INFINITE DISTANCE AWAY FROM THE FINITE LOADED PORTION OF THE STRIP, IT IS APPARENT THAT THE MOMENT $\left(M_{x}=\infty\right)$ AND THE DEFLECTION $\left(y_{x=\infty}\right)$ ARE EqUAL TO ZERO. THEREFORE

$$
A=B=0
$$

THUS $y=e^{-\xi x}\left(C \cos \gamma x+D_{1} \sin \gamma x\right)$

IF WE CONSIDER AN INFINITE BEAM WITH A CONCENTRATED LOAD (P) AT $(x=0)$, THE DEFLECTION CURVE MUST BE SYMMETRICAL ABOUT THE ORIGIN. THEREFORE, THE ADDITIONAL BOUNDARY CONDITIONS ARE

$$
\left\{\begin{array}{l}
Q_{x=0}=P / 2 \\
\frac{d y}{d x}=0
\end{array}\right.
$$

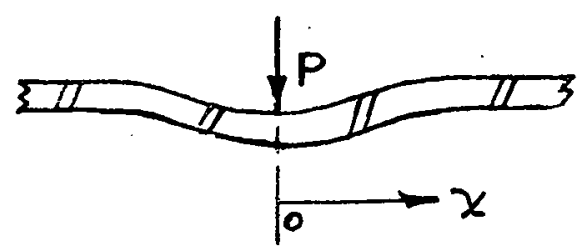
FIG. $C^{\circ}$

SUBSTITUTION OF THE ABOUE. INTO (2) YIELDS

$$
\frac{d M_{x}}{d x} \underset{(x=0)}{=} \frac{P}{2}
$$

$402 \quad 36$ 
II $\cdot 25$

THE SOLUTION TO (CC) FOR THIS LOADING (Fl SC) IS.

(Gd) $y=\frac{P}{2 k} \frac{\beta^{2}}{\beta \gamma} e^{-\xi x}(\gamma \cos \gamma x+\xi \sin \gamma x)$

SINCE $\frac{K}{4 D}=\beta^{4}$

EqUATION (Gd) MAY BE WRITTEN AS

$$
y=\frac{P}{8 D} \frac{1}{\beta^{2} \xi \gamma} e^{-\xi x}(\gamma \cos \gamma x+\xi \sin \gamma x)
$$

DIFFERENTIATING (Gd) AND SUBSTITUTING THE IDENTITY:

$$
\beta^{2}+\gamma^{2}=2 \beta^{2}
$$

WE HAVE

$$
\text { (ce) } \begin{aligned}
& \frac{d y}{d x}=-\frac{P}{4 D} \frac{1}{\xi \gamma} e^{-\xi x} \sin \gamma x \\
& \text { (cf) } M_{x}=D \frac{d^{2} y}{d x^{2}}=\frac{P}{4} \frac{1}{\xi \gamma} e^{-\xi x}(\gamma \cos \gamma x-\sin \gamma x)
\end{aligned}
$$

SUBSTITUTING the above into Equation (a) AND using the IDENTITY $\xi^{2}-r^{2}=(m+N) / 2 D$

WE HAVE
(cg) $Q_{x}=-\frac{p}{4} \frac{1}{\xi \gamma} e^{-\xi x}\left(2 \xi \gamma \cos \gamma x+\left[\xi^{2}-\gamma^{2}\right] \sin \gamma x\right)$

IF WE CONSIDER A SEMI-INFINITE BEAM WITH A CONCENTRATED SHEAR MOMENT AT THE. ORIGIN, THE ADDITIONAL BOUNDARY CONDITIONS (EQ.6C) BECOME.

$$
\begin{gathered}
\left.D \frac{d^{2} y}{d x^{2}}=-M_{0}=0\right) \\
\xi\left[D \frac{d^{3} y}{d x^{3}}+(m+N) \frac{d y}{d x}\right]_{(x=0)}=-P
\end{gathered}
$$

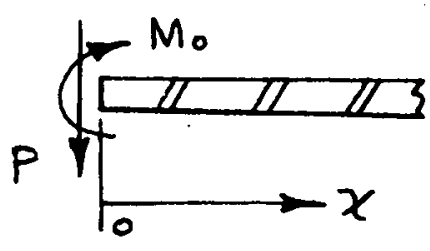

THE SOLUTION OF EQUATION (CC) FOR THIS CASE

FIG. D IN THE SAME MANNER AS ABOVE YIELDS

$$
\text { (Eh) } \begin{aligned}
y= & \frac{P}{D} \frac{1}{3 \xi^{2}-\gamma^{2}} \frac{e^{-\xi x}}{2 \beta^{2} \gamma}\left[2 \xi \gamma \cos \gamma x+\left(\xi^{2}-\gamma^{2}\right) \sin \gamma x\right] \\
& -\frac{M_{0}}{D} \frac{1}{3 \xi^{2}-\gamma^{2}} \frac{e^{-\xi x}}{\gamma}(\gamma \cos \gamma x-\xi \sin \gamma x)
\end{aligned}
$$


(Gi.) $\frac{d y}{d x}=-\frac{P}{D} \frac{1}{3 \xi^{2}-\gamma^{2}} \frac{e^{-\xi x}}{\gamma}(\gamma \cos \gamma x+26 \sin \gamma x)$

$$
+\frac{M_{0}}{D} \frac{1}{3 \xi^{2}-\gamma^{2}} \frac{e^{-\xi x}}{\gamma}\left[2 \xi \gamma \cos \gamma x-\left(\xi^{2}-\gamma^{2}\right) \sin \gamma x\right]
$$

(sj) $M_{x}=-\frac{P}{\gamma} \frac{2 \beta^{2}}{3 \xi^{2}-\gamma^{2}} e^{-\xi x} \sin \gamma x$

$$
+\frac{M_{0}}{\gamma} \frac{1}{3 \xi^{2}-\gamma^{2}} \cdot e^{-\xi x}\left[\left(3 \xi^{2}-\gamma^{2}\right) \gamma \cos \gamma x-\left(\xi^{2}-3 \gamma^{2}\right) \xi \sin \gamma x\right]
$$

(Gk) $Q_{x}=-\frac{P}{\gamma} \frac{e^{-\xi x}}{3 \xi^{2}-\gamma^{2}}\left[\left(3 \xi^{2}-\gamma^{2}\right) \gamma \cos \gamma x-\left(3 \gamma^{2}-\xi^{2}\right) \xi \sin \gamma x\right]$

$$
-\frac{M_{0}}{\gamma} \frac{2 \beta^{2}}{3 \xi^{2}-\gamma^{2}} e^{-\xi x} \sin \gamma x
$$

THE DEFLECTION AND ROTATION AT THE ORIGIN ARE FOUND FROM EQUATIONS (6h\&i.) TO BE

(7) $\quad y_{0}=\frac{P}{D} \frac{\xi}{\left(3 \xi^{2}-\gamma^{2}\right) \beta^{2}}-\frac{M_{0}}{D} \frac{1}{3 \xi^{2}-\gamma^{2}}$

$$
=\frac{1}{3 \xi^{2}-\gamma^{2}}\left[\frac{\xi}{\beta^{2}} \frac{P}{D}-\frac{M_{0}}{D}\right]
$$

(8)

$$
\begin{aligned}
\frac{d y}{d x_{(x}} & =-\frac{P}{D} \frac{1}{3 \xi^{2} \cdot \gamma^{2}}+\frac{M_{0}}{D} \frac{2 \xi}{3 \xi^{2}-\gamma^{2}} \\
& =\frac{1}{3 \xi^{2}-\gamma^{2}}\left[-\frac{P}{D}+2 \xi \frac{M_{0}}{D}\right]
\end{aligned}
$$

HAVING DEVELOPED THE ABOVE EqUATIONS FOR SEVERAL FOUNDATION RESTRAINTS, IT IS WELL TO EXAMINE THE RELATIVE IMPORTANCE, TO THE accuracy of THE SOLUTION, OF EACH RESTRAINT. THE DEFINITION OF (乡) IS

$$
\xi=\left(\beta^{2}+\frac{m+N}{4 D}\right)^{1 / 2}
$$

AND OF $(\gamma)$ IS

$$
\gamma=\left(\beta^{2}-\frac{m+N}{4 D}\right)^{1 / 2}
$$

$462: 38$ 
IV $\cdot 27$

WE MAY WRITE

$$
\begin{aligned}
\frac{\xi}{\beta} & =\left(1+\eta_{\xi}\right) \\
\xi \quad \frac{\gamma}{\beta} & =\left(1-\eta_{\gamma}\right)
\end{aligned}
$$

WITH $\eta$ = THE ERROR WHICH WE MAY PERMIT TO ENTER INTO OUR CALCULATION FOR $(\xi) \notin(\gamma)$

SUBSTITUTING $\beta=(K / 4 D)^{1 / 4}$ INTO THE ABOVE \$ SQUARING BOTH SIDES YIELDS

$$
\begin{aligned}
1+\frac{m+N}{2(K D)^{1 / 2}} & =\left(1+\eta_{\xi}\right)^{2}=1+2 \eta_{\xi}+\eta_{\xi}^{2} \\
\xi & 1-\frac{m+N}{2(K D)^{1 / 2}}=\left(1-\eta_{\gamma}\right)^{2}=1-2 \eta_{\gamma}+\eta_{\gamma}^{2}
\end{aligned}
$$

NEGLECTING SECOND-ORDER TERMS,

(9)

$$
\eta_{r}=\eta_{\xi}=0.25(m+N)(K D)^{-0.5}
$$

IF SUBSTITUTION OF THE APPROPRIATE NUMERICAL CONSTANTS INTO EqUATION ( 9 ) REVEALS THAT $(\eta)$ IS SMALL, $(\beta)$ MAY BE SUBSTITUTED FOR $(\xi) \xi(\gamma)$. THUS, EQUATIONS $(7) \&(8)$ BECOME

$$
\begin{aligned}
& \text { (ia) } y_{0}=\frac{1}{2 \beta^{2} D}\left[\frac{P}{\beta}-M_{0}\right] \\
& \text { (Ba) } \frac{d y}{d x_{(x=0)}}=\frac{1}{2 \beta^{2} D}\left[2 M_{0} \beta-P\right]
\end{aligned}
$$

THESE EqUATIONS CORRESPOND TO THE SEMI-INFINITE BEAM SOLUTION GIVEN ON PAGE IR OF REFERENCE (b). THUS IT IS APPARENT THAT WHEN ( $\eta$ ) IS SUFFICIENTLY SMALL, THE ORDINARY THEORY, FOR BEAMS ON AN ELASTIC FOUNDATION OF A SINGLE RESTRAINT, IS AMPLE FOR SOLUTIONS OF PROBLEMS WITH THREE RESTRAINTS,

$300 \quad 30$ 
A $\underline{P} \underline{P} \underline{E} \underline{N} \underline{D} \underline{I} \underline{\mathbf{B}}$

CRT'TICAL LOADING ANALYSIS

$382: 40$ 
IV $: 29$

Investigation of Finite and Infinite Uniform

Load Conditions which give rise to Critical

Bending Moments in a Beam on an

Elastic Foundation.

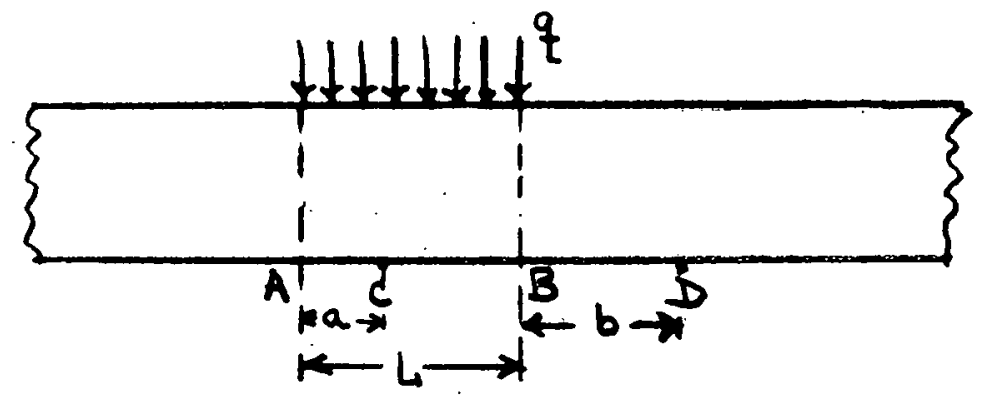

Fig. A

CASE I

Consider an Thfinite beam on an elastic foundation loaded in the y direction over a portion $A B$ of its length, by a uniform load.

- $q_{\# / / N}$. Let the length of $A B$ be $L$.

For points $C$ under the load, let (a) be the distance from $A$ to $C_{j}$ then the distance from $C$ to $B$ is $(i-a)$.

Hetény', Reference (c) gives the moment $\left(M_{c}\right)$ for any point $c$ under the load, as:

$$
\text { (1) } \begin{aligned}
M_{C}= & \frac{q}{4 \beta^{2}}\left[\zeta_{\beta a}+\zeta_{\beta(L-a)}\right] \\
& \text { where } \zeta_{\beta x}=e^{-\beta x} \sin \beta x \\
& \text { and } \beta=\sqrt[4]{\frac{k}{4 D}} \text { as defined in Appendix } A .
\end{aligned}
$$

The bending moment $\left(M_{C}\right)$ will attain a maximum value when

$$
\frac{\partial M_{c}}{\partial a}=\frac{\partial M_{c}}{\partial L}=0
$$

Thus to determine the critical length. $L$, producing a maximum moment at a distance (a) from $A$, we must satisfy the simultaneous equations:

(2a) $\quad \frac{\partial M_{c}}{\partial a}=\frac{q}{4 \beta}\left[\psi_{\beta a}-\psi_{\beta(L-a)}\right]=0$

(ab) $\frac{\partial M_{c}}{\partial L}=\frac{q}{4 \beta}\left[\psi_{\beta(L-a)}\right]=0$ where $\psi_{\beta x}=e^{-\beta x}(\cos \beta x-\sin \beta x)$

$360 \quad: 81$ 
II $\cdot 30$

Direct substitution shows that system (2) is satisfied. when $B a=\pi / 4$ and $\beta L=\pi / 2$.

Thus $M_{c \text { max }}=\frac{q}{4 \beta^{2}}\left[\zeta_{\pi / 4}+\zeta_{\pi / 2}-\pi / 4\right]=\frac{q}{2 \beta^{2}} \zeta_{\pi / 4}$

Finally using the fact that $\xi_{\pi / 4}=.3224$ from Heteny! (OP Cit.), Table $I$, we obtain

(ac) $M_{c_{\text {max. }}}=.1612 \mathrm{q} / \mathrm{\beta}^{2}$

Hence for an infinite beam uniformly loaded over a portion $A B$ of its length, the maximum bending moment under the load occurs at the center of the loaded portion, when The length $A B$ is $\pi / 2 \beta$, and is of magnitude $.1612 \frac{q}{\beta^{2}}$.

For points $D$ to the right of the bad, let $(b)$ be the distance from $B$ to $D_{j}$ then the distance from $A t_{0} D$ is $(L+b)$. Hetényi lop cit) gives the bending moment $M_{D}$ for any -point $D$ to the right of the load, as;

$$
\text { (3) } M_{D}=\frac{q}{4 \beta^{2}}\left[\zeta_{\beta(L+b)}-\xi_{\beta b}\right]
$$

The bending moment $M_{D}$ will be a maximum when $\frac{\partial M_{D}}{\partial b}=\frac{\partial M_{D}}{\partial L}=0$ :

Thus the desired critical values $(L)$ and $(b)$ are the solutions of the simultaneous system of equations:

(Aa). $\frac{\partial M_{p}}{\partial b}=\frac{q}{4 \beta}\left[\psi_{\beta(L+b)}-\psi_{\beta b}\right]=0$

(Ab) $\quad \frac{\partial M_{D}}{\partial L}=\frac{q}{4 \beta} \psi_{\beta(L+b)}=0$

Direct substitution shows that system (4) is satisfied when $\beta b=\pi / 4$ and $\beta L=\pi$.

$$
\therefore M_{D_{\text {MAX }} .}=\frac{q}{4 \beta^{2}}\left[\zeta_{\pi / 4+\pi}-\xi_{\pi / 4}\right]=\frac{q}{4 \beta^{2}}\left[\xi_{5 \pi / 4}-\xi_{\frac{\pi}{4}}\right]=\frac{q}{4 \beta^{2}}[-.0140-.3224]=-.0841 \frac{q}{\beta^{2}}
$$

where $\xi_{5 \pi / 4}$ and $\zeta_{\pi / 4}$ were obtained from Table (op cit).

We can therefore conclude that a uniformly loaded portion of length $\pi / \beta$ on an infinite beam produces maximum i bending moments of magnitude $\left(-.0841 \mathrm{q} / \mathrm{\beta}^{2}\right)$ at distances $\pi / 4 \beta$ from the ends of the loaded portion, but that a uniformly loaded portion of length $\pi / 2 \beta$, which produces the maximum bending moment of magnitude $\left(.1612 q / \beta^{2}\right)$ at the center of the loaded portion, is the more critical load condition.

a 
II ·31

Fig. B

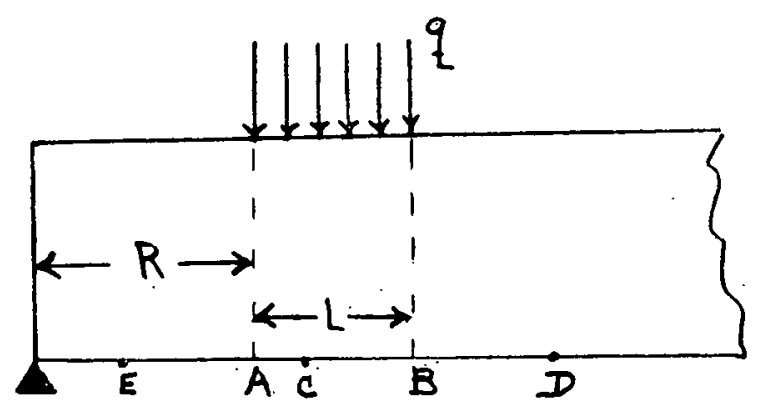

Case II

The next problem to be considered is that of a semi-infinite beam $c n$ an elastic foundation hinged at one end, and loaded in the $y$ direction over a portion $A B$ of its length by a uniform load $q * / i n$, at a distance $R$ from the hinged end. Let the length of $A B$ be $L$.

For points $C$ under the load, let the distance from the hinged end to $C$ be $x$, then the distance from $A$ to $C$ is. $(x-R)$ and that from $B$ to $C$ is $(R+L-x)$. From reference $(C)$ we find that for any point $C$ under the load, the bending moment $\left(M_{C}\right)$ at $C$ may be written as j

(5)

$$
\begin{gathered}
M_{C}=\frac{q}{4 \beta^{2}}\left(\xi_{\beta(x-R)}+\xi_{\beta(R+L-X)}\right)-\frac{q}{4 \beta^{2}}\left(\theta_{\beta R}-\theta_{\beta(R+L)}\right) \psi_{\beta x} \\
\quad+\frac{q}{4 \beta^{2}}\left(\theta_{\beta R}-\theta_{\beta(R+L)}+\zeta_{\beta R}-\xi_{\beta(R+L)}\right) \theta_{\beta X} \\
\theta_{\beta x}=e^{-\beta x} \cos \beta x
\end{gathered}
$$

We note that $\theta_{\beta x}+S_{\beta x}=e^{-\beta x} \cos \beta x+e^{-\beta x} \sin \beta x=e^{-\beta x}(\cos \beta x+\sin \beta x)$. we define $e^{-\beta x}(\cos \beta x+\sin \beta x)$ as $\varphi_{\beta x}$.

Thus equation (5) can be simplified to read;

$$
\text { (sa) } \begin{aligned}
M_{C}=\frac{q}{4 \beta^{2}}\left\{\left(\zeta_{\beta(x-R)}\right.\right. & \left.+\zeta_{\beta(R+L-x)}\right)-\left(\theta_{\beta R}-\theta_{\beta(R+L)}\right) \psi_{\beta x} \\
& \left.+\left(\varphi_{\beta R}-\varphi_{\beta(R+L)}\right) \theta_{\beta x}\right\}
\end{aligned}
$$

The bending moment $\left(M_{c}\right)$ will reach a maximum when $\frac{\partial M_{c}}{\partial x}=\frac{\partial M_{c}}{\partial R}=\frac{\partial M_{c}}{\partial L}=0$. Hence the maximum bending moment under the load occurs for $R, x$; and $L$ as defined by the following system of equations:

$\therefore 8: 43$ 
II $\cdot 32$

(ba) $0=\frac{\partial M_{C}}{\partial x}=\frac{q}{4 \beta}\left\{\left(\psi_{B(x-R)}-\psi_{\beta(R+L-x)}\right)+2\left(\theta_{\beta R}-\theta_{\beta(R+L)}\right) \theta_{\beta X}-\left(\varphi_{\beta R}-\varphi_{\beta(R+L)}\right) \varphi_{B X}\right\}$.

(bb) $0=\frac{\partial M_{C}}{\partial R}=\frac{q}{4 \beta}\left\{-\left(\psi_{\beta(x-R)}-\psi_{B(R+L-x)}\right)+\left(\varphi_{B R}-\varphi_{B(R+L)}\right) \psi_{\beta X}-2\left(\zeta_{\beta R}-\zeta_{\beta(R+L)}\right) \theta_{\beta X}\right\}$

(bc) $0=\frac{\partial M_{c}}{\partial L}=\frac{q}{4 \beta}\left\{\psi_{\beta(R+L-x)}-\varphi_{\beta(R+L)} \psi_{\beta x}+2 \xi_{\beta(R+L)} \theta_{\beta x}\right\}$

Direct substitution shows that system (6) is satisfied for

$$
\beta R=0 ; \beta \dot{x}=\frac{\pi}{4} ; \beta L=\infty
$$

The values of $\psi, \theta, \varphi$, and $\xi$ required in the substitution can be obtained from Table (op .cit.).

$$
\begin{gathered}
\therefore M_{c \text { max }}=\frac{q}{4 \beta^{2}}\left\{\left(\xi_{\pi / 4}+\zeta_{\infty}\right)-\left(\theta_{0}-\theta_{\infty}\right) \psi_{\pi / 4}+\left(\varphi_{0}-\varphi_{\infty}\right) \theta_{\pi / 4}\right\} \\
\sum_{\infty}=\theta_{\infty}=\varphi_{\infty}=0 ; \theta_{0}=\varphi_{0}=1
\end{gathered}
$$

Substituting values from table I (op cit)

$$
M_{C M A X}=\frac{q}{4 \beta^{2}}\left\{\zeta_{\pi / 4}-\psi_{\pi / 4}+\theta_{\pi / 4}\right\}=\frac{q}{4 \beta^{2}}\{.3224-0+.3224\}=.1612 \frac{q}{\beta^{2}}
$$

Hence for a semi-infinite beam hiriged at one end and uniformly loaded over a portion $A B$ of its length at a distance $R$ from the hinged end, the maximum bending moment under the load occurs at a distance $\pi / 4 \beta$ from the hinged end, when. the beam is loaded over its entire length, and is of magnitude $\left(.1612 \mathrm{~g} / \mathrm{\beta}^{2}\right)$.

For points $D$ to the right of a finite load of length $L$ (see Fig. B), let $x$ be the distance from the hinged end to $D$, then the distance from $B$ to $D$ is $(x-R-L)$ and that from $A$ to $D$ is $(x-R)$. From Hetenyi (Ref.C) we find that the bending moment ( $M_{D}$ ) for any. point $D$ to the right of the load, may be written as:

$$
\begin{aligned}
M_{D}=\frac{q}{4 \beta^{2}}\left(\zeta_{\beta(x-R)}\right. & \left.\zeta_{\beta(x-R-L)}\right)-\frac{q}{4 \beta^{2}}\left(\theta_{\beta R}-\theta_{\beta(R+L)}\right) \psi_{\beta x} \\
& +\frac{q}{4 \beta^{2}}\left(\theta_{\beta R}-\theta_{\beta(R+L)}+\zeta_{\beta R}-\zeta_{\beta(R+L)}\right) \theta_{\beta x}
\end{aligned}
$$


II $\cdot 33$

Utilizing the fact that $\left(\theta_{\beta x}+\Gamma_{\beta x}=\varphi_{\beta x}\right)$, equation (7) may be simplified to;

$$
\text { (Ta) } M_{D}=\frac{q}{4 \beta^{2}}\left\{\left(\zeta_{\beta(x-R)}-\zeta_{\beta(x-R-L)}\right)-\left(\theta_{\beta R}-\theta_{\beta(R+L)}\right) \psi_{\beta x}+\left(\varphi_{\beta R}-\varphi_{\beta(R+L)}\right) \theta_{\beta x}\right\}
$$

(MD) will attain a maximum when $\frac{\partial M_{D}}{\partial x}=\frac{\partial M_{D}}{\partial R}=\frac{\partial M_{D}}{\partial L}=0$ : Hence the values of $x, R$, and $L$ which satisfy the following system of equations, produces a maximum bending moment to the right of the load.

(sa) $0=\frac{\partial M}{\partial x} D=\frac{q}{4 \beta}\left\{\left(\psi_{\beta(x-R)}-\psi_{\beta(x-R-L)}\right)+2\left(\theta_{\beta R}-\theta_{\beta(R+L)}\right) \theta_{\beta x}-\left(\varphi_{\beta R}-\varphi_{\beta(R+L)}\right) \varphi_{\beta x}\right\}$

(sb) $\quad 0=\frac{\partial M_{0}}{\partial R}=\frac{q}{4 \beta}\left\{-\left(\psi_{\beta(x-R)}-\psi_{\beta(x-R-L)}\right)+\left(\varphi_{\beta R}-\varphi_{\beta(R+L)}\right) \psi_{\beta X}-2\left(\xi_{\beta R}-\xi_{\beta(R+L)}\right) \theta_{\beta x}\right\}$

(BC) $\quad 0=\frac{\partial M_{D}}{\partial L}=\frac{q}{4 \beta}\left\{\psi_{\beta(x-R-L)}-\varphi_{\beta(R+L)} \psi_{\beta x}+2 \sum_{\beta(R+L)} \theta_{\beta x}\right\}$

Direct substitution show's that system ( 8$)$ is satisfied if $\beta x=7 \pi / 4, \beta R=\pi / 2$, and $\beta L=\pi$

$$
\begin{aligned}
& \text { Then } M_{D \text { max }}=\frac{q}{4 \beta^{2}}\left\{\left(\zeta_{5 \pi / 4}-\zeta_{\pi / 4}\right)-\left(\theta_{\pi / 2}-\theta_{3 \pi / 2}\right) \psi_{7 \pi / 4}+\left(\varphi_{\pi / 2}-\varphi_{3 \pi / 2}\right) \theta_{7 \pi / 4}\right\} \\
& \theta_{\pi / 2}=\theta_{3 \pi / 2}=0 \\
& \therefore M_{D \text { MAX }}=\frac{q}{4 \beta^{2}}\{-.0140-.3224+(.2079+.0090)(.0029)\}=-.0839 \frac{q}{\beta^{2}}
\end{aligned}
$$

Thus a uniform load, placed over a portion of the semi-infinite beam of length $\pi / \beta$, at a distance $\pi / 2 \beta$ from the hinged end, produces a maximum moment at a point $D$ to the right of the load (Fig B.). Point $D$ is at a distance $7 \pi / 4 \beta$ from the hinged end $(\pi / 4 \beta$ to the right of the end of the loaded portion) and the magnitude of the maximum moment is $\left(-.0839 q / \beta^{2}\right)$.

Finally for points $E$ to the left of such a finite load of length $L(F, g . B)$, let the distance from the hinged end to $E$ be $(x)$, then the distance from $A$ to $E$ is $(R-x)$, and that from $B$ to $E$ is $(R+L-x)$. From reference (C) we find that the bending moment ( $M_{E}$ ), for any point $E$ to the left of the load, may be writ en as j

(9)

$$
\begin{aligned}
M_{E}=-\frac{q}{4 \beta^{2}}\left(\zeta_{\beta(R-x)}-\zeta_{\beta(R+L-x)}\right)-\frac{q}{4 \beta^{2}}\left(\theta_{\beta R}-\theta_{\beta(R+L)}\right) \psi_{\beta X} \\
+\frac{q}{4 B^{2}}\left(\theta_{\beta R}-\theta_{\beta(R+L)}+\zeta_{\beta R}-\sum_{\beta(R+L)}\right) \partial_{\beta x} \\
\vdots \cdots
\end{aligned}
$$


TI. 34

and using the pact that $\left(\theta_{B x}+S_{B x}=\varphi_{B x}\right)$, Equation (9) is simplified to;

(qa) $M_{E}=\frac{-q}{4 \beta^{2}}\left\{\left(\varphi_{\beta(R-x)}-\rho_{\beta(R+L-x)}\right)+\left(\theta_{\beta R}-\theta_{\beta(R+L)}\right) \psi_{\beta x}-\left(\varphi_{\beta R}-\varphi_{\beta(R+L)}\right) \theta_{\beta x}\right\}$

$\left(M_{E}\right)$ will be maximum for the values of $x, L$, and $R$ satisfying;

$$
\frac{\partial M_{E}}{\partial x}=\frac{\partial M_{E}}{\partial R}=\frac{\partial M_{E}}{\partial L}=0
$$

Hence we are interested in the values of $x, R_{j}$ and $L$ satisfying the following system of simultaneous equations:

(10a) $\quad 0=\frac{\partial M E}{\partial x}=\frac{q}{4 \beta}\left\{\left(\psi_{\beta(R-L)}-\psi_{\beta(R+L-x)}\right)+2\left(\theta_{B R}-\theta_{\beta(R+L)}\right) \theta_{\beta X}-\left(\varphi_{\beta R}-\varphi_{\beta(R+L)}\right) \varphi_{\beta x}\right\}$

(10 b) $0=\frac{\partial M E}{\partial R}=\frac{q}{4 \beta}\left\{-\left(\psi_{\beta(R-x)}-\psi_{\beta(R+L-x)}\right)+\left(\varphi_{\beta R}-\varphi_{\beta(R+L)}\right) \psi_{\beta x}-2\left(\zeta_{\beta R}-\xi_{\beta(R+L)}\right) \theta_{\beta x}\right\}$

(10C) $0=\frac{\partial M_{F}}{\partial L}=\frac{q}{4 \beta}\left\{\psi_{\beta(R+L-x)}-\varphi_{\beta(R+L)} \psi_{\beta x}+Z \xi_{\beta(R+L)} \theta_{\beta x}\right\}$

Direct substitution shows that system (10) is satisfied for $\beta x=\pi / 2, \beta R=3 \pi / 4, \beta L=\pi$.

$$
\begin{aligned}
& \therefore M_{E \text { MAX }}=\frac{-q}{4 \beta^{2}}\left\{\left(\zeta_{\pi / 4}-\zeta_{5 \pi / 4}\right)+\left(\theta_{3 \pi / 4}-\theta_{7 \pi / 4}\right) \psi_{\pi / 2}-\left(\varphi_{3 \pi / 4}-\varphi_{7 \pi / 4}\right) \theta_{\pi / 2}\right\} \\
& \varphi_{3 \pi / 4}=\varphi_{7 \pi / 4}=0 \\
& M_{E \text { MAX }}=-\frac{q}{4 \beta^{2}}\{.3224+.0140+(-.2079)(-.0671-.0029)\}=-.0877 \frac{q}{\beta^{2}}
\end{aligned}
$$

Hence, if the unifornily loaded portion (Fig. B) is of length $\pi / \beta$ and if it is placed at a distance $3 \pi / 4 \beta$ from the hinged end, then the maximin bending moment at a point to the left of the load is attained at a distance $\pi / 2 \beta$. from the hinged end and is of magnitude $\left(-.0877 q / \beta^{2}\right)$

Summarizing the foregoing results for the case of a semiinfinite beam hinged at one end, we can say that the maximum i bending moment will occur when the beam is uniformly loaded over its entire length. The maximum bending moment is then of magnitude $\left(.16 / 29 / 3^{2}\right)$ and occurs at a distance $\pi / 4 \beta$ from the hinged end.

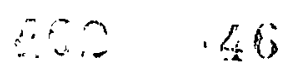


II $\cdot 35$

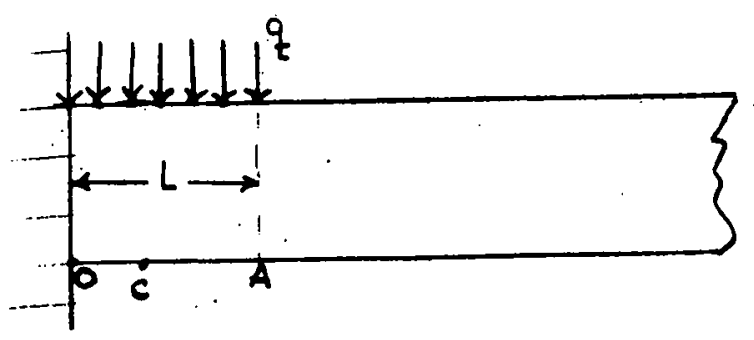

Case II Ia

Fig. C

Consider a semi-infinite beam on an elastic foundation, fully fixed at one end, and loaded by a uniform load $q u / 1 n$. over a finite portion of its length beginning at the wall. Let the distance on be $L$.

For points $C$ under the load, let the distance from the wall to $c$ be $x$, then the distance from $C$ to $A$ is $(L-x)$. from Hetényi (Ref. $C$ ), we find that the bending moment $\left(M_{C}\right)$, for any -point $C$ under the load, is:

(11) $M_{c}=\frac{q}{d \beta^{2}}\left\{\left(\zeta_{\beta K}+\zeta_{\beta(L-x)}\right)-\left(1-\theta_{\beta L}\right) \psi_{\beta x}-\left(1-\varphi_{\beta L}\right) \theta_{\beta x}\right\}$

Note that $\left(\zeta_{\beta x}-\psi_{\beta x}-\theta_{\beta x}\right)=e^{-\beta x}(\sin \beta x-\cos \beta x+\sin \beta x-\cos \beta x)$

$$
=-2 e^{-\beta x}(\cos \beta x-\sin \beta x)=-2 \psi_{\beta x}
$$

Therefore;

$$
\text { (IlIa) } M_{c}=\frac{q}{4 \beta^{2}}\left(\zeta_{\beta(L \cdot x)}-2 \psi_{\beta x}+\theta_{\beta L} \psi_{\beta x}+\varphi_{\beta i} \theta_{\beta x}\right)
$$

$\left(M_{C}\right)$ will be maximum for the values of $x$ and $L$ which make. $\frac{\partial M_{c}}{\partial x}=\frac{\partial M_{c}}{\partial L}=0$. Thus the critical values of $x$ and $L$ satisfy the following system of simultaneous equations:

(12a) $0=\frac{\partial M_{c}}{\partial x}=\frac{q}{4 \beta}\left(-\psi_{\beta(L-x)}+4 \theta_{\beta x}-2 \theta_{\beta L} \theta_{\beta x}-\varphi_{\beta L} \varphi_{\beta x}\right)$

(12b) $\quad 0=\frac{\partial M_{c}}{\partial L}=\frac{q}{4 \beta}\left(\psi_{\beta(L-x)}-\varphi_{\beta L} \psi_{\beta x}-2 \zeta_{\beta L} \theta_{\beta x}\right)$

Direct substitution shows that system (12). is satisfied for $\beta L=\infty$ and $\beta x=\pi / 2$

Therefore:

$$
\begin{aligned}
\text { (II) } M_{C \text { MAX }}=\frac{q}{4 \beta^{2}}\left(\zeta_{\infty}-2 \psi_{\pi / 2}+\theta_{\infty} \psi_{\pi / 2}+\varphi_{\infty} \theta_{\pi / 2}\right) \\
\rho_{\infty}=\theta_{\infty}=\varphi_{\infty}=0 \\
\therefore M_{C} \text { MAX }=-\frac{q}{2 \beta^{2}} \psi_{\pi / 2}=.1040 \frac{q}{\beta^{2}}
\end{aligned}
$$


II $\cdot 36$

When $L=\infty$; the expression for $\left(M_{c}\right)$ becomes

$$
\text { (II) } M_{c}=\frac{q}{4 \beta^{2}}\left(\zeta_{\infty}-2 \psi_{\beta x}+\theta_{\infty} \psi_{\beta x}+\varphi_{\infty} \theta \pi / 2\right)=\frac{-q}{2 \beta^{2}} \psi_{\beta x}
$$

Reference (B), Figure 2 , shows that $\psi_{\beta x}=1$ for $\beta x=0$, and that it decreases until $\beta x=\pi / 2$ when it begins increasing again. Thus while $(M c)$ attains a local mathematical maximum at $B x=\pi / 2$, it has its greatest value at $\beta x=0$. The expression for $\left(M_{C}\right), E_{g}$ (II), is only defined for $x \geq 0$, (ie. $\frac{\partial M_{c}}{\partial \mathcal{X}}$ has no meaning for $x=0$ and system (12) is only meaningful for $x>0$ ).

Thus for a semi-infinite beam on an elastic foundation; fully fixed at one end, the critical bending moment occurs at the wall when the beam is loaded over. its entire length; and is of magnitude $\left(-.5 q / \beta^{2}\right)$. A lesser local maximum of magnitude $\left(.1040 q / \beta^{2}\right)$ is attained for $B x=\pi / 2$.

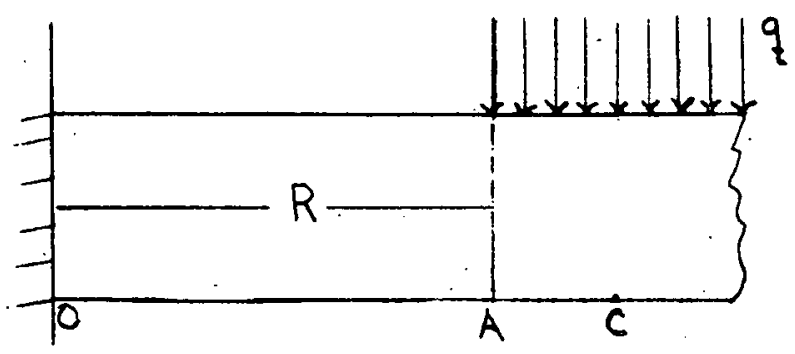

Fig. D

Case III b

closely related to case $\mathbb{I I}_{a}$ is the case of a semi-infinite beam on an elastic foundation, fully fixed at one end and loaded in the $\dot{y}$ direction by a uniform load $q$ /in. from some point $A$ outward. Let the distance from the fixed end to $A$ be $R$ :

If the distance from the fixed end to any point $C$ under the la ad is $x$, their the distance from $A t_{0} C$ is $(x-R)$. From (Ref.C) we find that the bending moment $\left(M_{C}\right)$ at $C$ is;

(13). $\quad M_{C}=\frac{q}{4 \beta^{2}}\left(\zeta_{\beta(x-R)}-\theta_{\beta R} \psi_{\beta x}-\varphi_{\beta R} \theta_{\beta x}\right)$

$\left(M_{c}\right)$ will have its maximum value when $\frac{\partial M_{c}}{\partial x}=\frac{\partial M_{c}}{\partial R}=0$

Thus we must indue the following system of simultaneous equations:

$$
\text { 85, } 48
$$


II $\cdot 37$

(14a) $\quad 0=\frac{\partial M_{c}}{\partial x}=\frac{q}{4 \beta}\left(\psi_{\beta(x-R)}+2 \theta_{\beta R} \theta_{\beta x}+\varphi_{\beta R} \varphi_{\beta x}\right)$

(14b) $\quad 0=\frac{\partial M_{C}}{\partial R}=\frac{q}{4 \beta}\left(-\psi_{\beta(x-R)}+\varphi_{\beta R} \psi_{\beta x}+2 \zeta_{\beta R} \theta_{\beta x}\right)$

Direct substitution shows that the above system is satisfied for $\beta x=\pi / 2$ and $\beta R=0$. Thus, this solution is identical with case III a previously solved.

Take I below summarizes the foregoing results for cases $I, \mathbb{I}$, and $\mathbb{I I}$.

Table I.

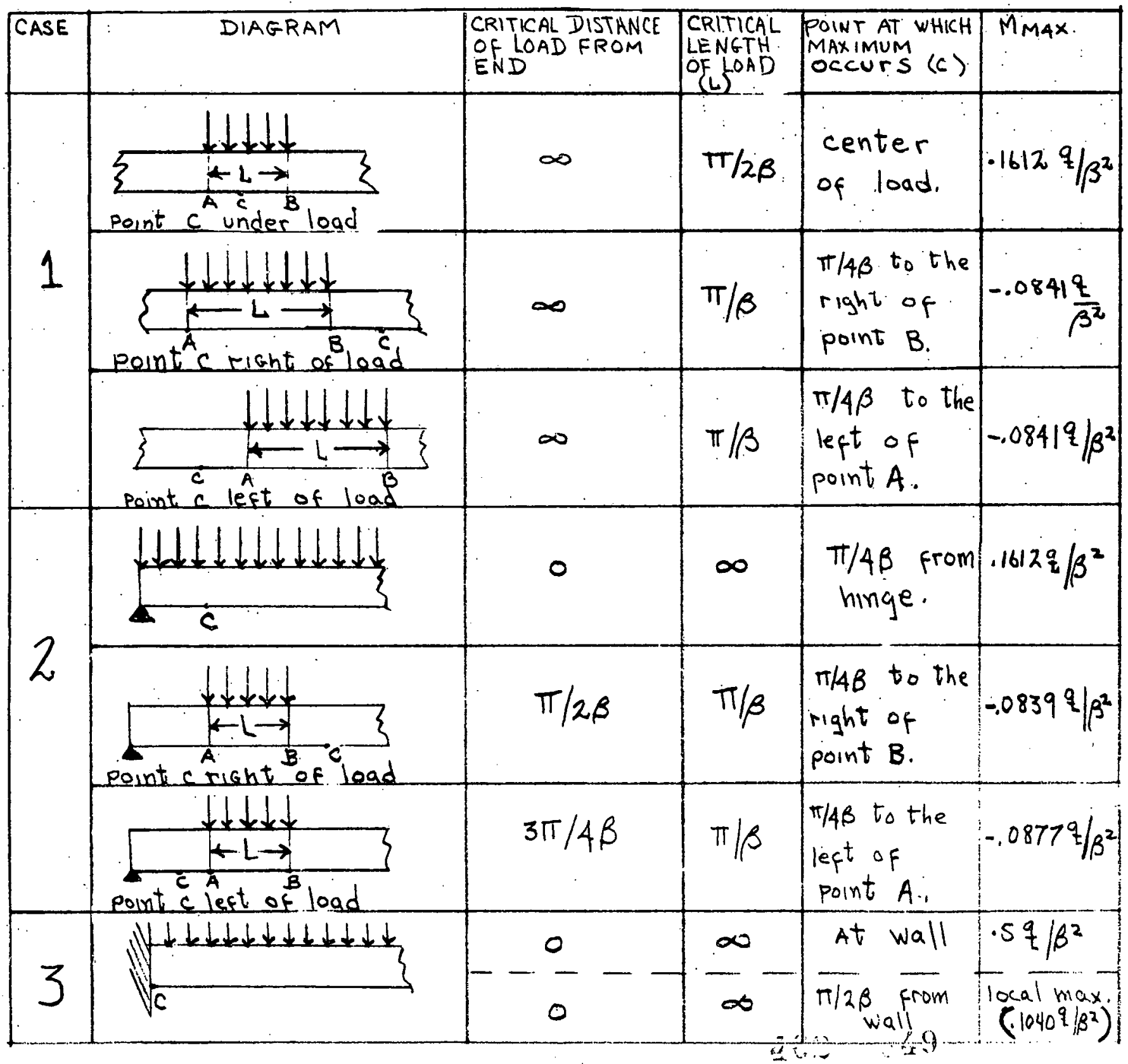


II $\cdot 38$

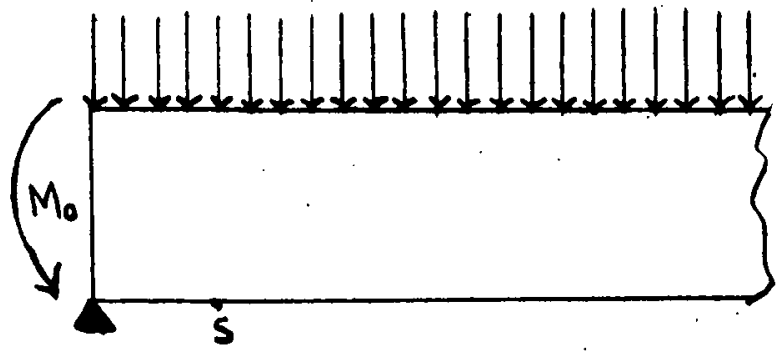

Fig. $E$

A final problem to be considered is that of a semi-infinite beam on an elastic foundation, hinged at one end and subject to a constant end moment (Mo) at that end. We will consider the case where;

$$
\begin{aligned}
& M_{0}=k(F E M) \quad 0 \leq k \leq 1 \\
& F E M=\operatorname{maximum} \text { fixed end moment (case 3, Table I) } \\
& F E M=.5 q / \beta^{2}
\end{aligned}
$$

Therefore $M_{0}=k\left(.5 q / \beta^{2}\right)$

Let $s$ be any point on the beam and let the distance from the hinged end to $S$ be $\psi$, From (reference $C$ ), the bending moment (Ms) at any point $S$ is;

(16) $M_{s}=\frac{q}{4 \beta^{2}}\left(\xi_{\beta x}-\psi_{\beta x}+\theta_{\beta x}-2 k \varphi_{\beta x}\right)$.

Note that $\xi_{\beta x}+\theta_{\beta x}-\psi_{\beta x}=e^{-\beta x}(\sin \beta x+\cos \beta x-\cos \beta x+\sin \beta x)$

$$
=2 e^{-\beta x} \cdot \operatorname{an} \beta x=2 S_{\beta x}
$$

Therefore $\left(M_{s}\right)$ can be simplified to;

$$
\text { (16a) } M_{s}=\frac{q}{2 \beta^{2}}\left(\zeta_{\beta z}-k \theta_{, \beta x}\right)
$$

The maximum bending moment may exist at the fixed end as in case III, or at the shortest distance ( $x$ ) from the hinged end satisfying $\frac{\partial M_{s}}{\partial x}=0$.

(17) $\frac{\partial M_{S}}{\partial x}=\frac{q}{\partial \beta}\left(\psi_{\beta x}+k \varphi_{\beta x}\right)=0$

$$
\begin{aligned}
\therefore(17 a) e^{-\beta x}\{\cos \beta x-\sin \beta x+k(\cos \beta x+\sin 3 x)\}=0 \\
(17 a) \text { in plies }(1+k) \cos \beta x=(1-k) \text { en i } \beta x \\
\text { or } \tan \beta x=\frac{1+k}{1-k}
\end{aligned}
$$

$200 \quad 50$ 


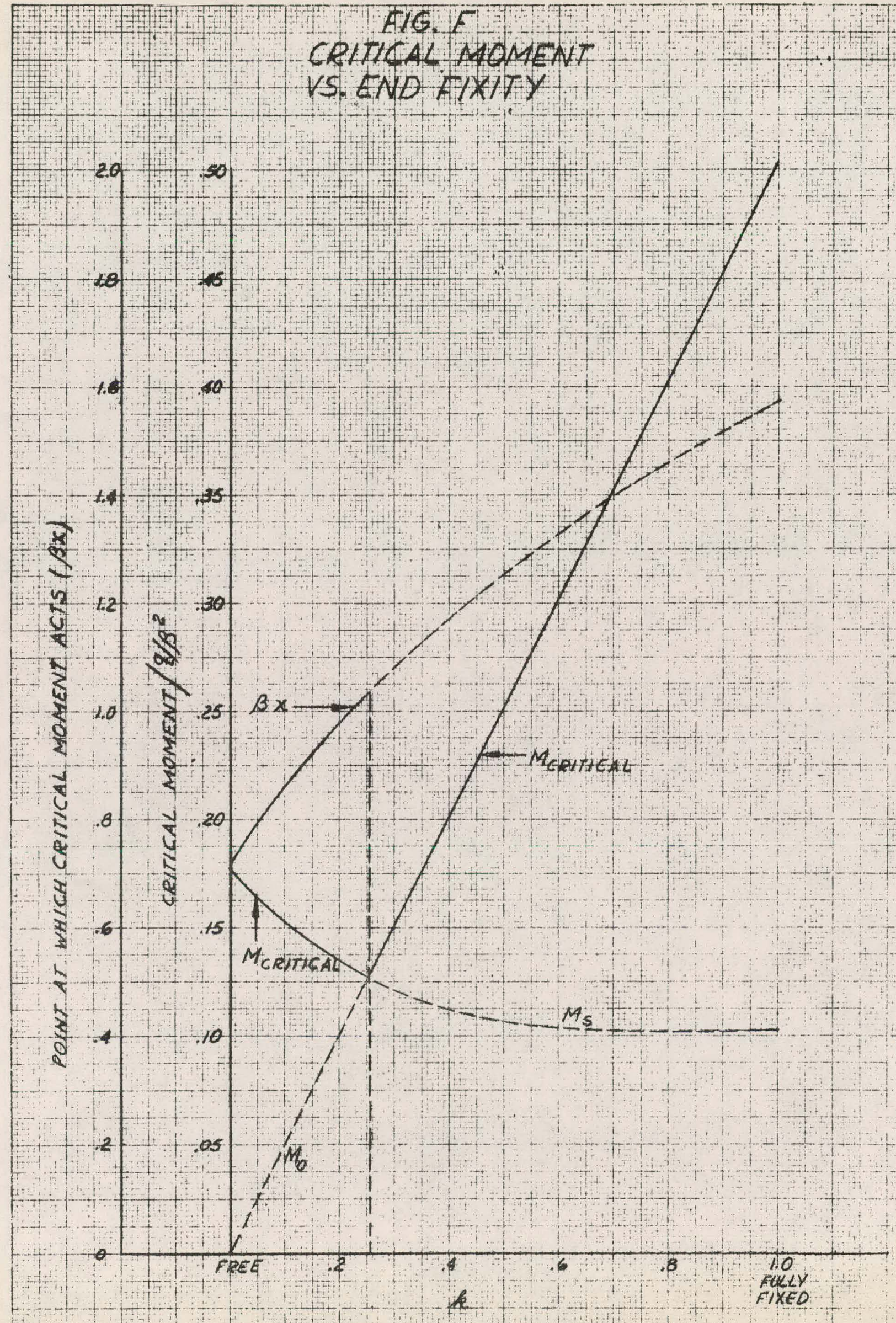

\section{CRITICAL MOMENT VS. END FIXITY}


IV $\cdot 40$

Table II Shows the bending moment (Ms) corresponding to the values of $\beta x$ which are the solutions of Equation (7), and the corresponding end moment Mo.

Table II

\begin{tabular}{|c|c|c|c|c|}
\hline$k$ & $\tan \beta z$ & $\beta x$ & $i 1_{s}$ & $M_{0}$ \\
\hline 0 & $i$ & $\pi / 4$ & $q / 2 \beta^{2}\left(\xi_{\pi / 4}\right)=.16 / 2 . q / \beta^{2}$ & $0\left(.5 q / \beta^{2}\right)=0$ \\
\hline .25 & 1.6667 & 1.03 & $q / 2 \beta^{2}\left(\zeta_{1.03}-1 / 4 \theta_{1.03}\right)=.1301 q / \beta^{2}$ & $.25\left(.5 q / \beta^{2}\right)=.125 q / \beta^{2}$ \\
\hline .50 & 3 & 1.25 & $q / 2 \beta^{2}\left(\zeta_{1.25}-1 / 2 \theta_{1.25}\right)=.1133^{q} / \beta^{2}$ & $.5\left(.5 q / \beta^{2}\right)=.25 q / \beta^{2}$ \\
\hline .75 & 7 & $1.43^{\circ}$ & $q / 2 \beta^{2}\left(\zeta_{1.43}-3 / 4 \theta_{1.43}\right)=.1059 q / \beta^{2}$ & $.75\left(.5 q / \beta^{2}\right)=.375 q / \beta^{2}$ \\
\hline 1.0 & $\infty$ & $\pi / 2$ & $q / 2 \beta^{2}\left(\zeta_{\pi / 2}-\theta_{\pi / 2}\right)=.1040^{q} / \beta^{2}$ & $1\left(.5 q / \beta^{2}\right)=.5 q / \beta^{2}$ \\
\hline
\end{tabular}

Values from Table II are plotted as a function of (k) in Figure $(F)$. The variation of the value and location of the maximum bending moment (M Max) are indicated by solid lines.

$\therefore 0 \quad 52$ 


\section{V.1}

\section{SECTION $\mathbf{V}$}

\section{REPORT ON STATIC AND FATIGUE TESTING}

OF

ZIRCALOY FUSION WELDS

TABLE OF CONTENTS

Page

V*2

V-1 Summary

V.2

A. General

V.4

B. Plan of Testing

V.5

C. Description of Specimens

V.6

a. Static Tension

V. 7

b. Tensile Fatigue

V. 8

c. Bending Fatigue

V-3 Appendices

A. Description of Testing Machines, Test Procedures, and Data Sheets

V. 9

B. Weld Area Cross Section Evaluations

V. 10 


\section{V.2}

V. Report on Static and Fatigue Testing of Zircaloy Fusion Helds

V-1 Summary

This section presents a description of a series of destructive

static and fatigue tests ${ }^{1}$ which were performed on partially penetrated fusion welded 2 ircaloy specimens in order to determine the strength of this type of weld.

Because of the relatively small number of specimens employed, no statistically definite safe stress values can be obtained. The general pattern of failure, however, would seem to indicate that for well joined specimens with penetrations greater than about $50 \%$, the welds are somewhat stronger than the annealed base metal and that the effect of root stress concentrations are negligible.

\section{V-2 Discussion}

\section{A. General}

This program was undertaken in order to determine the reliability of the seed welds when subjected to forces predicted in Section IV. The main determination to be made was

1 The design of the fixtures and the testing was performed by Professor J. 0. Jeffrey at Cornell University and the Morse Chain Company, Ithaca, New York, under ARDE subcontract number P0-1-472. Preliminary and final measurements of weld areas were made by Kr. F. V. Naugle of Westinghouse B.A.P.D. 


\section{3}

the action of the partially penetrated fusion veld under bending moments as this is the major type of loading experienced by the seed during operation of the reactor.

To make a complete study of the veld strength would require hundreds of specimens of varying penetration, however it was decided that thirty specimens, half of which to be of $75 \%$ penetration and the other half of $50 \%$; would be a sufficient number to determine the reliability of the subject seed. In order to learn as much as possible from the bending fatigue tests, the static tension and tensile fatigue tests were run first so as to determine the load limits for the more imm portant bending series. Difficulty was encountered in setting the loads for the fatigue tests because an accurate degree of weld penetration cannot be determined until failure has occurred at the veld. Several specimens were "1ost" (the occurrance of a failure before a meaningful number of cycles have passed) during the tensile fatigue tests. However, this was necessary in order to collect data needed to keep the bending test stress levels 10w enough to prevent similar failures, but sufficiently high so that a considerable amount of fatigue understressing (reference i) would not occur. 


\section{B. Test Procedure}

The original specification for the testing program is given below. Some departures were made from this schedule and they are noted in Appendix (A).

a. Three specimens of each penetration type (50 and 75\% weld penetration) are to be statically tested to tensile rupture in the $20,0001 \mathrm{~b}$. O1sen Universal Testing machine. The cross-section areas of the welds are to be determined and ultimate stress levels are to be obtained.

b. Six specimens of each penetration type are to be tested in tensile fatigue on the Sonntag machine to failure or for a minimum of 10,000 cycles. The alternating load levels shall be determined by the results of the static rupture tests. 75 to $90 \%$ of the ultimate $10 a d$ shall be used as a maximum value for the first specimen of each penetration type. The 10ad may be varied for subsequent tests depending upon the occurrance and nature of failures or nonfailures in preceding tests. The object of this series is to determine a level of stress that is likely to cause failure after about 10,000 cycles of application. c. Six specimens of each penetration type are to be tested in repeated bending on the Upton-Lewis machine. The forced deflection and consequent moment applied to the specimen shall be determined from an analysis of the results of the tensile fatigue tests. The object of this series is to attempt 
to define a maximum "safe". Loading which does not cause any of the specimens to fail before 10,000 cycles. A fairly constant nominal bending stress level based upon the standard flexure formula and using the full specimen cross section shall be maintained for each penetration type. The designated stress level may be varied only in the event that failure has occurred before 10,000 cycles.

The machine shall be calibrated with the use of two unwelded Zircaloy bending specimens with strain gages attached to opposite sides at the normal region of the welds. Young's Modulus at room tenperature shall also be determined from these specimens in the 01sen machine:

\section{Description of Specimens}

The specimens were fabricated from long sheets of Zircaloy-2. The welds were made according to the veld specification for the actual seed. The specimens were then cut out of the long relded plates and machined and ground so that the weld test sections were one inch wide and of the same nominal thickness as the seed. Figure $(\mathrm{V}-2)$ shows the modification of the original tensile specimen (Fig. $V-1$ ) that was made after several of them failed outside of the test section. 


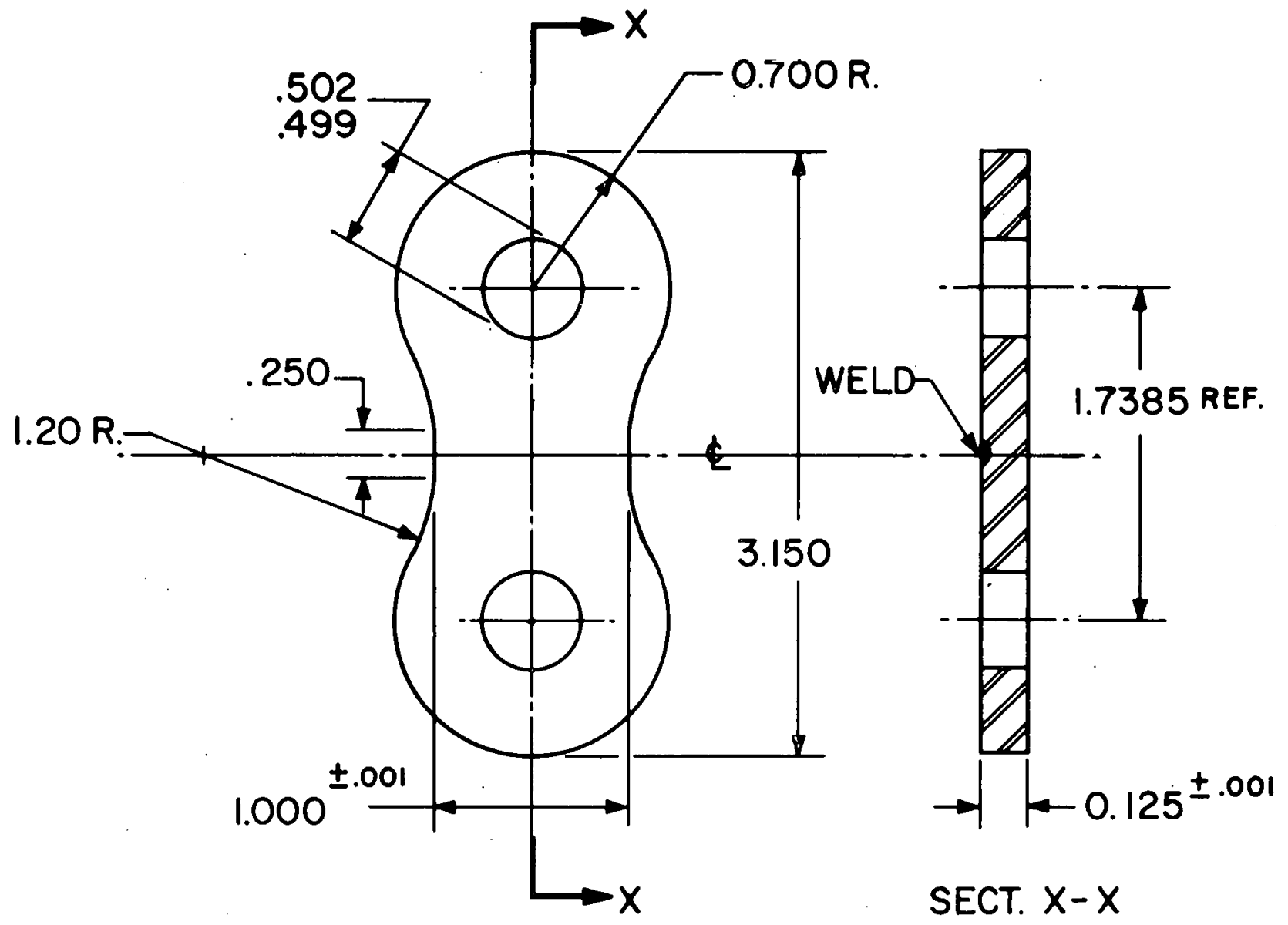

FIG. $\nabla-I$

TENSILE SPECIMEN 


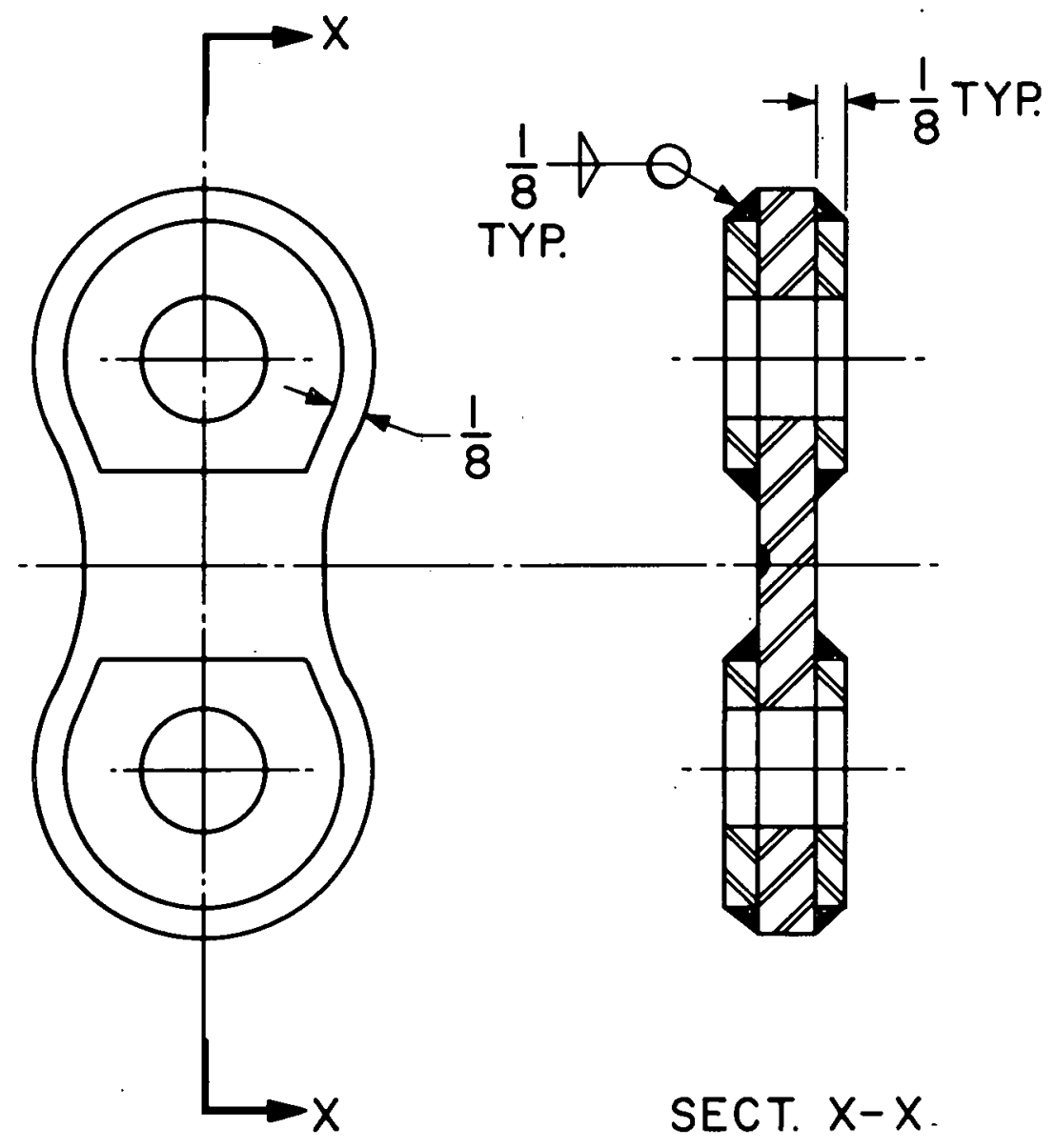

FIG. $\nabla-2$

MODIFIED SPECIMEN 


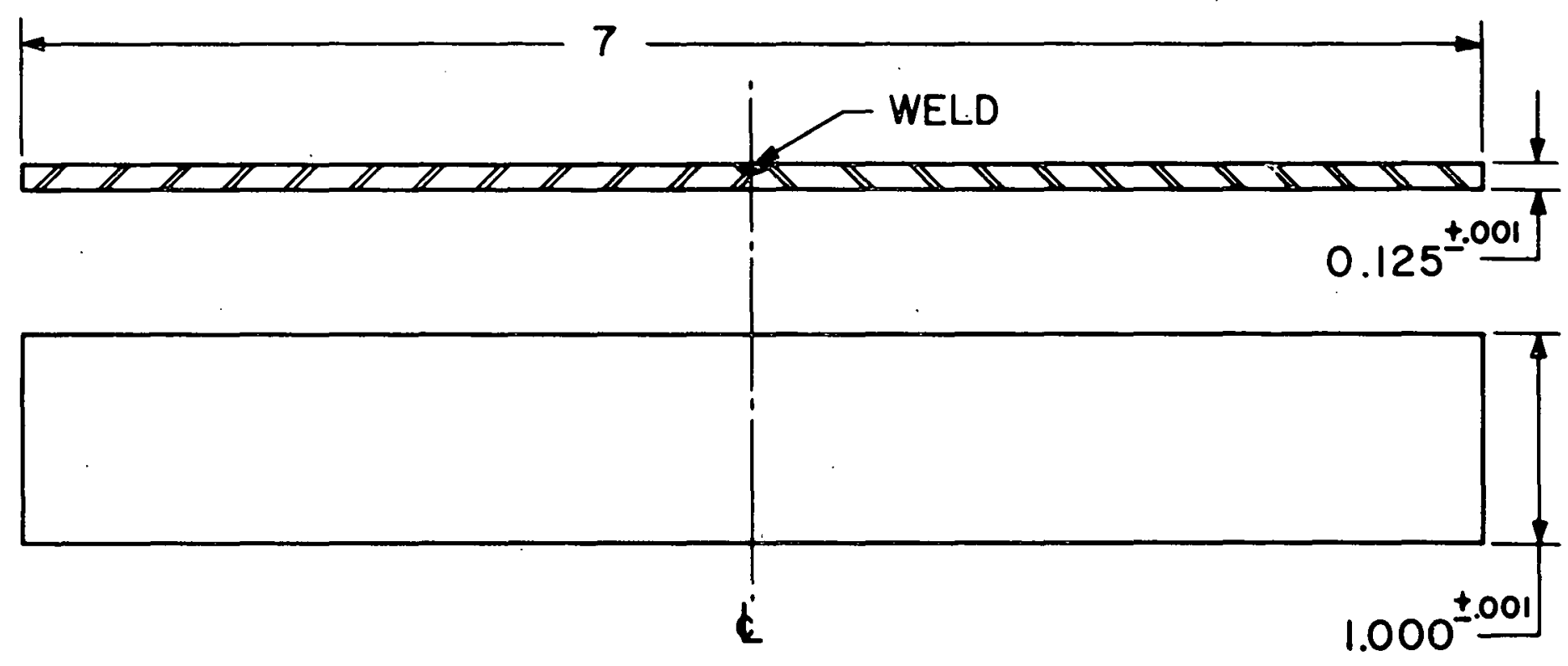

8

FIG. $\nabla-3$

BENDING SPECIMEN 


\section{V.6}

D. Results of Tests

The data sheets, descriptions of the testing machines,

fuil test descriptions and methods of calculation are given in Appendix A.

\section{a. Static Tension}

The tensile specimens as originally designed (Fig. V-1) were found to be inadequate for the tests. The welds exhibited much more strength in tension than had been anticipated and many of the specimens including all the higher penetration types failed away from the weld. The test results are given in Table $(\mathrm{V}-1)$ below:

TABLE $\nabla-1$

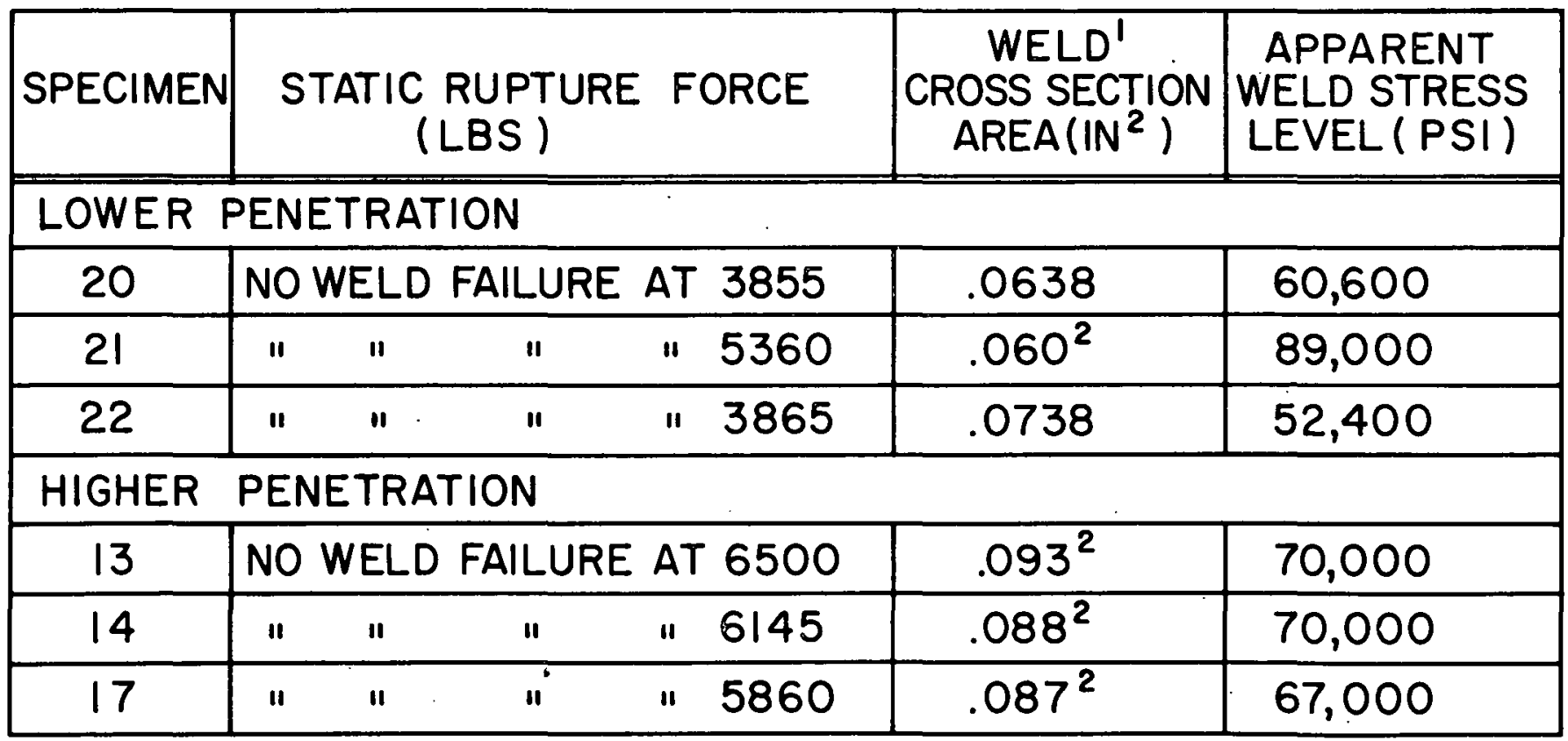




\section{V.7}

Bxcept for specimen Nos. 20 and 22, these tests proved to be inconclusive except that they do indicate that the reld strength of the unbroken specimens is quite high.

b. Tensile Patigue

As the specimens were held in the fixtures by pins, it was desirable not to permit the machine to try to exert a compressive force on the specimens. Hence, the lower load was arbitrarily chosen as 100 pounds in all cases where the upper 10ad was less than 2000 pounds. For upper 10ads of 2000 pounds or more, a lower load limit of 200 pounds was generally used.

Three of the unmodified low penetration specimens were tested in fatigue. The results are given in Table (V-2). An upper $10 a d$ of about $20 \%$ of the apparent static rupture strength was applied to specimen number 24. The eye of the specimen failed after 9000 cycles. A lower load was therefore app1ied to specimen No, 23. It failed through the veld at 10,000 cycles. Specimen 19 was subjected to the same loading for 74,000 cycles when its eye pulled out. Further testing was suspended while the specimens were being modified by welding additional material to the eyes as shown in Figure V-2.

Results from testing the modified specimens are presented in table $(V-2)$. 
TABLE $\nabla-2$

TENSILE FATIGUE TEST RESULTS

\begin{tabular}{|c|c|c|c|c|c|}
\hline SPECIMEN & $\begin{array}{l}\text { LOAD LIMITS } \\
\text { ( LBS) }\end{array}$ & CYCLES & $\begin{array}{l}\text { LOCATION OF } \\
\text { FAILURE }\end{array}$ & $\begin{array}{c}\text { WELD' CROSS } \\
\text { SECTION AREA } \\
\left(\text { IN }^{2}\right)\end{array}$ & $\begin{array}{l}\text { APPARENT WELD } \\
\text { STRESS LEVEL } \\
\text { (PSI) }\end{array}$ \\
\hline \multicolumn{6}{|c|}{ LOWER PENETRATION ( UNMODIFIED) } \\
\hline 19 & $100-2100$ & 74000 & EYE & $.056^{2}$ & 38,000 \\
\hline 23 & $100-2100$ & 10000 & WELD & $.055^{2}$ & 38,000 \\
\hline 24 & $100-3500$ & 9000 & EYE & $.062^{2}$ & 57,000 \\
\hline \multicolumn{6}{|c|}{ LOWER PENETRATION (MODIFIED) } \\
\hline 7 & $200-2000$ & 1 & WELD & .0467 & $0-53,500^{3}$ \\
\hline 8 & $200-2500$ & 1 & WELD & .0495 & $0-40,400^{3}$ \\
\hline \multirow{8}{*}{9} & $100-1500$ & 10000 & & .0505 & 29,700 \\
\hline & $100-1700$ & " & & & 33,700 \\
\hline & $100-1900$ & $"$ & & & 37,600 \\
\hline & $200-2100$ & $"$ & & & 41,600 \\
\hline & $200-2500$ & $"$ & & & 49,500 \\
\hline & $200-2800$ & $"$ & & & 55,400 \\
\hline & $200-3100$ & $"$ & & & 61,400 \\
\hline & $200-3400$ & 1 & WELD & & $61,400-67,000^{3}$ \\
\hline \multirow{9}{*}{16} & $200-2500$ & 20000 & & $.065^{2}$ & 39,000 \\
\hline & $200-2800$ & 10000 & & & 43,000 \\
\hline & $200-3100$ & $"$ & & & 48,000 \\
\hline & $200-3400$ & $"$ & & & 52,000 \\
\hline & $200-3700$ & $\pi$ & & & 57,000 \\
\hline & $200-4000$ & $"$ & & & 62,000 \\
\hline & $200-4300$ & $"$ & & & 66,000 \\
\hline & $200-4600$ & " & & & 71,000 \\
\hline & $200-5000$ & 8000 & EYE & & 77,000 \\
\hline 25 & $200-2500$ & $200 \sim 300$ & WELD & .0612 & 40,900 \\
\hline \multicolumn{6}{|c|}{ HIGHER PENETRATION (MODIFIED) } \\
\hline \multirow{2}{*}{5} & $200-4000$ & 10000 & & .0904 & 44,200 \\
\hline & $200-4500$ & 1 & WELD & & $44,200-49,800^{3}$ \\
\hline 10 & $200-4000$ & 4000 & WELD & .0818 & 48,900 \\
\hline 11 & $200-4000$ & 64000 & $\begin{array}{l}\text { TESTSECTION } \\
\text { OUTSIDE OF WELD } \\
\end{array}$ & $.085^{2}$ & 47,000 \\
\hline \multirow{3}{*}{18} & $200-4000$ & 15000 & & $.090^{2}$ & 44,000 \\
\hline & $200-4500$ & 20000 & & & 50,000 \\
\hline & $200-5000$ & 4000 & $\begin{array}{l}\text { TEST SECTION } \\
\text { OUTSIDE OF WELD } \\
\end{array}$ & & 56,000 \\
\hline
\end{tabular}

I AREAS ARE OBTAINED FROM APPENDIX B

2 AREA IS BASED UPON PRELIMINARY MEASUREMENTS AND IS NOT ACCURATE

3 WHEN SPECIMEN BREAKS UNDER ONE CYCLE OF LOADING, THE LOAD CAUSING FAILURE IS INDETERMINATE 


\section{V.8}

It was observed that most of the specimens are slightly bent, probably as a result of welding the additional material to the ends. The holes for the pins were not parallel, and it was necessary to use loosemfitting pins in order to fit them into the fixtures which are perfectly aligned. This may cause a non-uniform distribution of load on the ends of the pieces, and may contribute to eccentricity of $10 \mathrm{ad}$ in the test area. Specimen No. 11 was particularly bad in this respect.

The variance in results is quite wide primarily because the soundness of the welds can not be satisfactory checked by nonodestructive methods. The results were nevertheless deemed sufficient to set the load limits for the bending fatigue test series.

c. Bending Fatigue

The calibration of the machine is described in Appendix A along with a full description of the machine itself and the test procedure. The results of these tests are given in Table V-3. 


\section{TABLE $\nabla-3$}

\section{BENDING FATIGUE TEST RESULTS}

\begin{tabular}{|c|c|c|c|c|c|}
\hline SPECIMEN & $\begin{array}{l}\text { NOMINAL } \\
\text { STRESS LEVEL } \\
\text { (PSI)! }\end{array}$ & CYCLES & $\begin{array}{l}\text { LOCATION OF } \\
\text { FAILURE }\end{array}$ & $\begin{array}{l}\text { WELD }{ }^{2} \text { CROSS } \\
\text { SECTION AREA } \\
\left(\text { IN }^{2}\right)\end{array}$ & $\begin{array}{l}\text { APPARENT } \\
\text { WELD STRESS } \\
\text { (PSI) }\end{array}$ \\
\hline \multirow{2}{*}{1} & 28100 & 10,020 & & .0850 & 40,500 \\
\hline & 40100 & 1,080 & WELD & & 57,800 \\
\hline \multirow{2}{*}{2} & 23800 & 10,730 & & $.054^{4}$ & 85,000 \\
\hline & 36800 & 10,130 & NO FAILURE & & 131,000 \\
\hline \multirow{2}{*}{3} & 26300 & 10,320 & & .0585 & 80,000 \\
\hline & 38300 & 1,440 & WELD & & 116,600 \\
\hline \multirow{2}{*}{4} & 26100 & 10,020 & & .0662 & 62,000 \\
\hline & 33600 & 10,010 & NO FAILURE & & 79,900 \\
\hline \multirow{2}{*}{5} & 25300 & 10,020 & & .0608 & 71,300 \\
\hline & 35100 & 9,740 & WELD & & 98,906 \\
\hline \multirow{3}{*}{6} & 27600 & 10,090 & & .0595 & 81,200 \\
\hline & 29700 & 10,050 & & & 87,400 \\
\hline & 37800 & 890 & UPPER GRIP & & 111,200 \\
\hline 7 & 32800 & 7,580 & WELD ${ }^{5}$ & .0955 & 37,500 \\
\hline 8 & 32900 & 8,990 & WELD & .0984 & 35,400 \\
\hline 9 & 30400 & 6,000 & WELD 5 & .0935 & 36,200 \\
\hline 10 & 31800 & 10,010 & NO FAILURE & .0946 & 37,000 \\
\hline 11 & 30100 & 10,010 & NO FAILURE & .0912 & 37,700 \\
\hline 12 & 32000 & 10,000 & NO FAILURE $^{5}$ & $.087^{4}$ & 44,000 \\
\hline
\end{tabular}

I STRESS LEVEL IS BASED UPON THE NOMINAL SPECIMEN THICKNESS OF 0.125 INCHES AND WIDTH OF 1.000 IN.

2 AREAS ARE OBTAINED FROM APPENDIX B

3 THE STRESSES GIVEN ARE BASED UPON THE ASSUMPTION OF THE EXISTENCE OF FULLY PLASTIC BENDING MOMENT IN THE WELD (REF. a)

4 AREA IS BASED UPON PRELIMINARY MEASUREMENTS AND IS NOT ACCURATE

5 A CRACK, ABOUT I/32 IN. DEEP SHOWED ON EXPOSED FRONT SIDE OF SPECIMEN DURING INITIAL MANUAL OPERATION OF THE MACHINE 
DESCRIPTION OF TESTING MACHINES,

TEST PROCEDURES, AND DATA SHEETS

(Abstracted from letters from Professor J. O. Jeffrey to R. Mark) 
Report on Prelininary Static Tensile and Tension

Fatigue Tests

This report sumarizes the results of several static tensile tests and tension fatigue tests made at the request of Mr. Robert Mark on specimens submitied by Mrr. Frank V. Naugle of the Westinghouse. Electric Corporation. Most of these tests were performed in the presence of the two men named above, and the details of the results were given to them winile they were here in Ithaca. Some results were also reported by personal correspondence with Mr. Mark.

Dimensions and weld penetration measurements have been furnished by Mr. Naugle and are not repeated. Descriptions of the test equipment and procedures is given in reports on Tensile Fatigue Tests and Bending Fatigue Tests and is therefore omitted from this summary.

The following is quoted from my letter of December 12, 1956 concerning the testing done on December $\%$

$\begin{array}{cl}\text { "Specimen No. 1, Fracture force } & 3,900 \mathrm{lbs} \text {. (broke in weld) } \\ 2 & 5,190 \mathrm{lbs} \text {. (broke in weld) } \\ 3 & 5,330 \mathrm{lbs} \text { (broke in weld) } \\ 4 & 5,825 \mathrm{lbs} \text {. (broke in end radius). }\end{array}$

By holding specimen No. 4 in the redge grips of the testing machine the force was increased to $\zeta, 925$ pounds before it again fractured in the Brip.

Specimen Nlo. 5 was not tested as it was presumed this would also result in a Iracture outside of the weld.

Apparently the welding operation increased the strength of the metal in the waist of the specimen at the expense of ductility in this region. During your previous visit to the laboratory it was agreed that this shape of test specimen and method of loading would be satisfactory assuming, of course, that the entire piece had substantially the same physical properties, and that the weld would not penetrate across the full thickness thereby rorcing stresses to be sufficiently high to induce fracture in the weld.

The tests were performed on a 20,000 Olsen Universal Testing machine. The load was applied mechanically through screws, and weighed through a lever system by manually balancing the beam with its rider. The rate of head movement waș 0.050 inches per ininute maintained by a constant speed motor. A recent calibration of this machine indicated that it was accurate to \pm 10 pounds in this load range. "

The' second series of static tensile tests produced the following results:

Specimen No. 21, ivaximum load 5300 pounds

iracture force 5120 pounds (broke outside of weld)

Specimen No. 22, Fracture force 3805 pounds (broke in weld)

Specimen No. 13, At load of 6,500 pounds the material in the end radius flowed from the grips and the test had to be stopped. 
Specimen No. 14, Behaved similar to No. 13, flow occurring at 0145 pounds load.

Specimen No. 17, Behavior similar to above requiring removal from grips at 5860 pounds force without fracture.

Specimen No. 20,Fracture force 3855 pounds (broke in weld)

Specinen No. 15, This was provided with reinforced ends for gripping. It fractured at 9275 pounds load.

On the tensile fatigue tests made on the Sonntag SF-I-U Fatigue Machine in the Research and Development Laboratories of Morse Chain Co., the following results were obtained:

Specimen No. 23, Survived 10,000 cycles at an upper load of 2100 pounds, lower load 100 pounds.

Specimen No. 24, This was subjected to an upper load of 3500 pounds, lower load of 200 pounds. This falled in the gripped end radius at 9000 cycles.

Specimen No. 19, With an upper load of 2100 pounds and lower load of 100 pounds, this failed in the gripped end radius after 74,000 cycles.

This testing indicated clearly that the ends of the specimens required relnforcement if the pieces were to fracture in the desired test area, and it also gave an indication of the probable minimum strengths of the parts: information which was vital to properly conducting the subsequent fatigue tests.

Respectfully submitted,

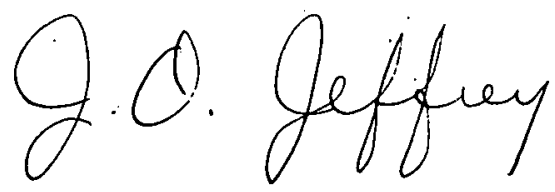

J. 0. Jeffrey 


\section{Tensile Fatigue Tests}

This report covers the results of tensile fatigue tests made at the request of $\mathrm{Mr}$. Robert Mark of ARDE Associates on nine specimens submitted by Mr. Frank V. Naugle of the Bettis Atomic Power Division of the Westinghouse Electric Corporation.

The specimen shape, dimensions, and weld penetration measurements have been submitted by Mr. Naugle and are therefore not repeated here.

\section{Testing Machine}

The testing machine used was a Universal Fatigue Testing Machine Model SF-I-U made by the Sonntag Sclentific Corporation, Greenwich; Connecticut, and located in the Research and Development Laboratories of the Morse Chain Co. at Ithaca, New York who gave the writer their permission to use the machine for these tests.

The machine produces a completely reversed, sinusoidal vibratory force at a frequency of 1800 cycles per minute superimposed on a static force. These forces are maintained throughout the duration of a fatigue test within limits of plus or minus 20 pounds. The machine has a rated capacity of 2000 pounds, and contains a multiplying fixture which increases Its load capacity by a factor of five. Forces generated by the machine are vertical in direction and are applied by an oscillator through proper fixtures to the specimen, one end of which is attached to a stationary holder

The dynamic or vibratory force, as generated by the oscillator and applied to the specimen, is produced by rotating an unbalanced mass at 1800 RPM. The dymamic load is set by adjusting the amount of unbalance of this mass. The static force is applied to the specimen through springs whose tension can be adjusted to suit the static Iosd requirements. The dynamic 


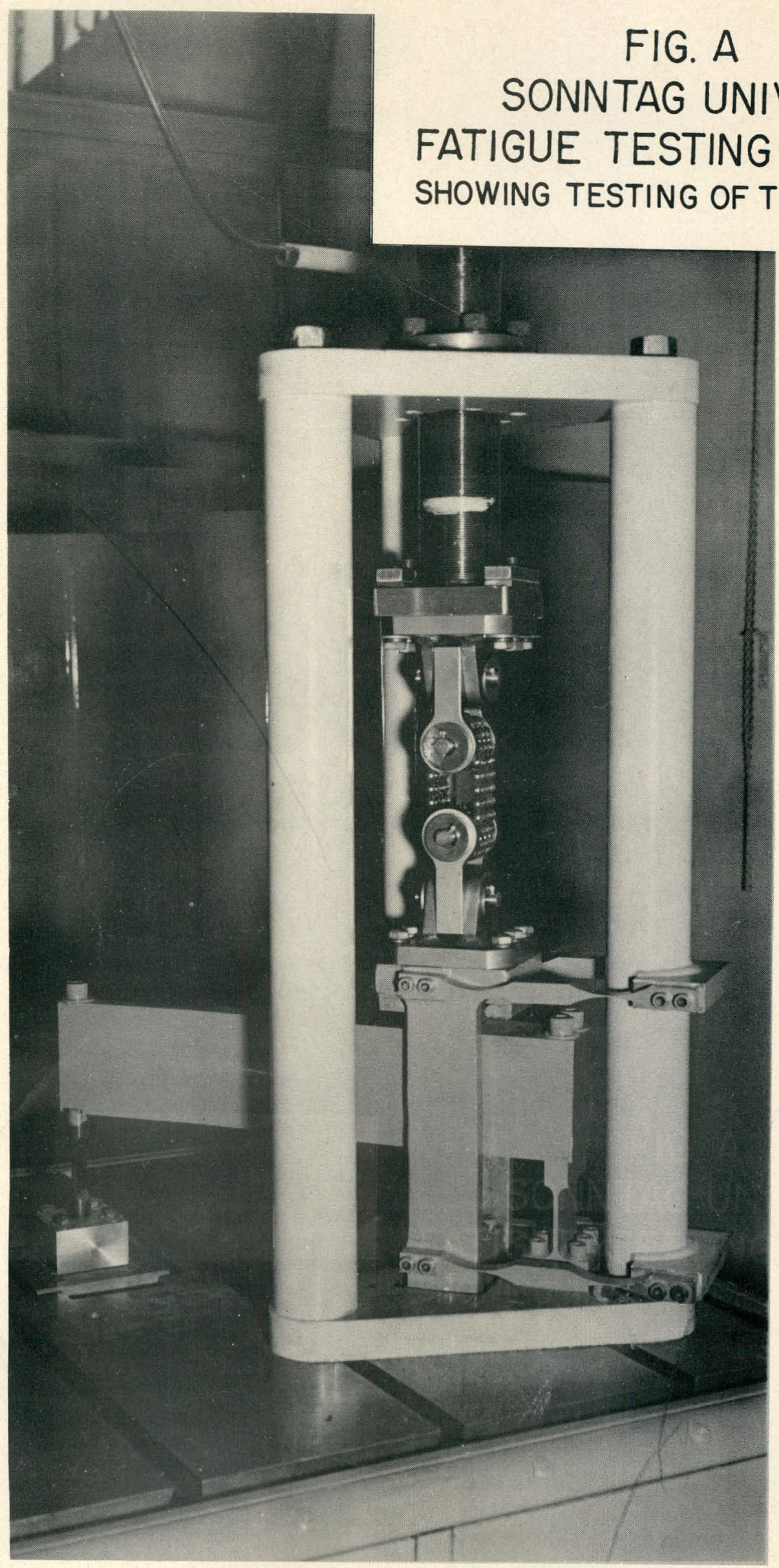




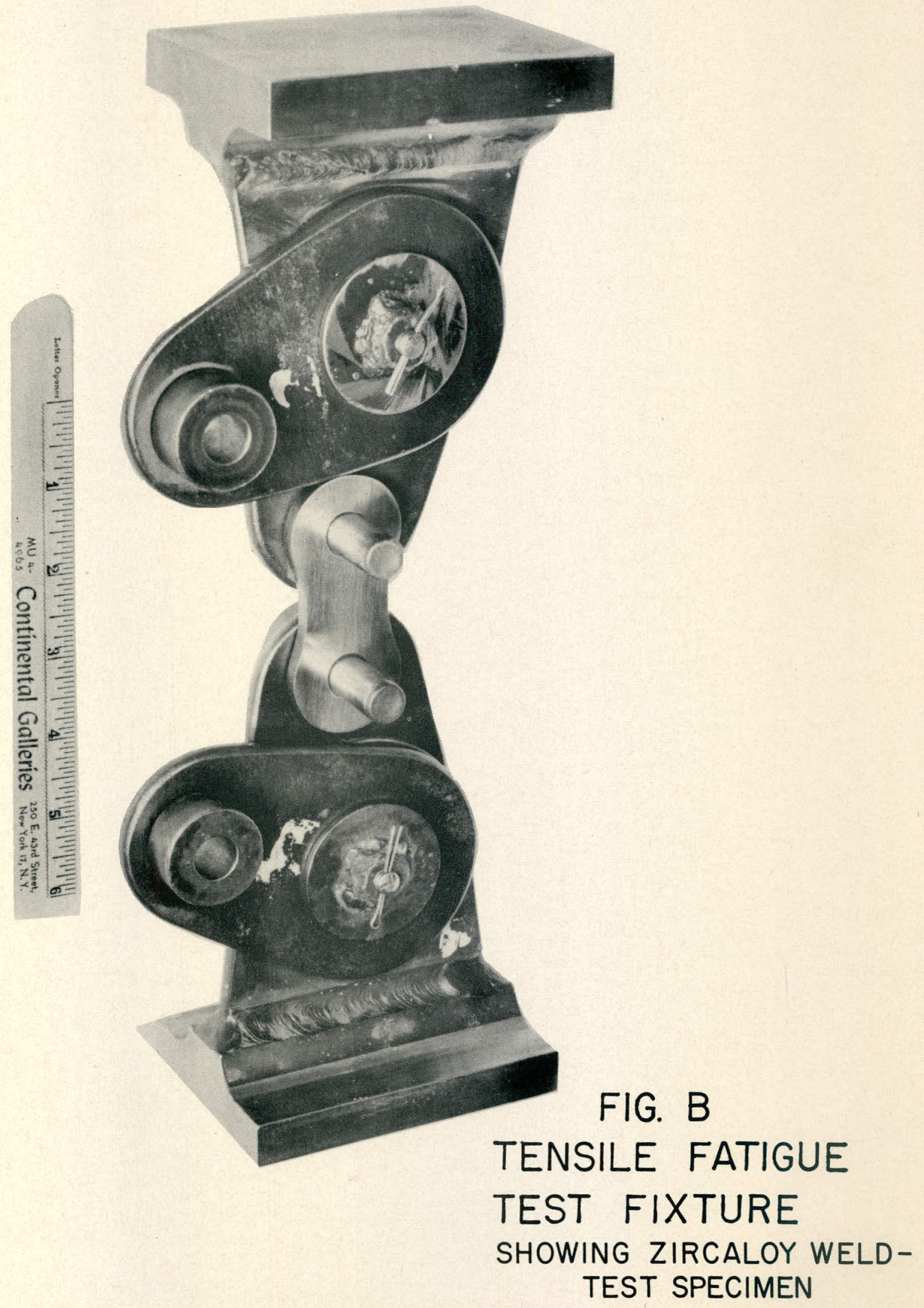


load due to the rotating mass adds to and subtracts from the static spring $10 a d$ with each revolution. The "Upper Load" on the specimen is therefore the sum of the static and dynamic loads, while the "Lower Load" is their difference.

\section{Test Procedure}

As the test specimen was held in the fixtures by pins, it was desirable not to permit the machine to try to exert a compressive force on the specimen. Hence, the lower load was arbitrarily chosen as 100 pounds in a11 cases where the upper $10 a d$ was less than 2000 pounds. For upper $10 a d s$ of 2000 pounds or more, a lower load limit of 200 pounds was selected.

In accordance with your recent verbal instructions to get as much useful fatigue information as possible from the specimens, the testing procedure fortunately did not adhere to the arbitrary "go, no-go" method for 10,000 cycles at a specified upper load which our contract called for.

The first group of samples tested consisted of the five having the lower penetration, and your suggested upper load of 2500 pounds was applied on specimen \#8. It broke as soon as the dynamic load started to rotate. Specimen \#7 was. therefore started with an upper load of 2000 pounds. When the same thing happened to it, the upper 10 ad was reduced to 1500 pounds for specimen $\# 9$. After running 10,000 cycles, the upper $10 a d$ was increased by 200 and 1ater by 300 pound increments for each 10,000 cycles until, after 70,000 cycles when the upper load was raised to 3400 pounds, the specimen broke upon application of the dynamic 1oad.

Specimen \#16 was started at an upper $10 a d$ of 2500 pounds. The $10 a d$ was increased by 300 pounds after 20,000 cycles and after each succeeding 10,000 cycles. At an upper load of 5000 pounds, the specimen broke at the pin aperture after 98,000 cycles. Specimen \#25 was also started at an upper 1oad of 25,000 pounds 
but only survived 200 or 300 cycles. The counter on the machine registers only in 1000 cycle increments and, of course, showed nothing.

Based on experience with the lower penetration group, I started the tests on the higher penetration group more conservatively than the 5000 pound load you suggested. In this classification, specimen \#5 was run first under a 4000 pound upper 10ad. It survived 10,000 cycles, but failed as soon as the dynamic load started to rotate for the 4500 pound level. Specimen \#10 lasted only 4000 cycles at a 4000 pound upper load. Specimen \#lI was started at the same load, but allowed to run to failure at this load. It required 64,000 cycles, and the specimen broke in the test section outside of the weld. The holes in this specimen were very badly out of parallel which must have produced a highly eccentric load. While the holes in the other samples were by no means perfect, none was as bad as this. The final specimen \#18, was run for 15,000 cycles under the 4000 pound load, to 35,000 cycles under 4500 pounds, and broke adjacent to the weld at 39,000 cycles under an upper load of 5000 pounds.

All of the fatigue dats are summarized on a separate sheet attached hereto. The broken specimens are being mailed to you under separate cover for your examination.

I trust that the procedures adopted will meet with your approval, and I hope that the data obtained by this testing will provide the information you expected to get.

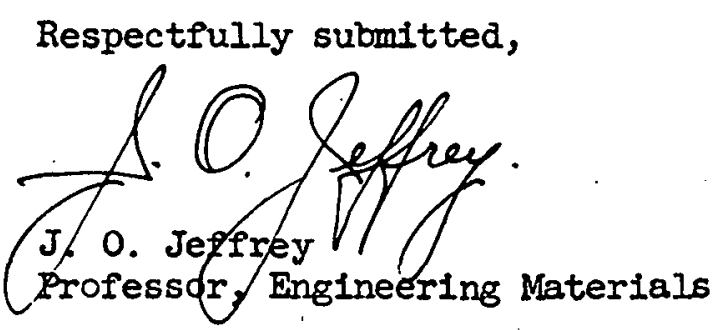


Tensile fatigue oata

\begin{tabular}{|c|c|c|c|c|c|c|}
\hline & \multirow{2}{*}{ 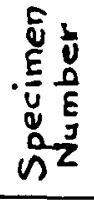 } & \multicolumn{2}{|c|}{$\begin{array}{l}\text { Loads } \\
\text { (pounds) }\end{array}$} & \multicolumn{2}{|c|}{$\begin{array}{l}\text { Cycle Counter } \\
\text { Reapding }\end{array}$} & \multirow{2}{*}{ Remarks. } \\
\hline & & Upper & Lower & Start & Stop & \\
\hline \multirow{5}{*}{ 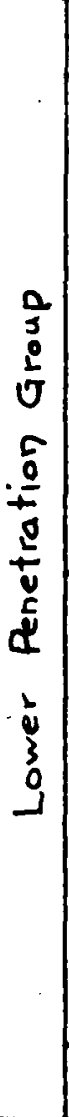 } & 8 & 25,00 & 200 & 0 & 0 & Broke on $1^{\text {st }}$ application of dynamic load. \\
\hline & 7 & 2000 & 200 & $\circ$ & o & Broke on $1^{\text {st }}$ application of dynamic load. \\
\hline & 9 & $\begin{array}{l}1500 \\
1700 \\
1900 \\
2100 \\
2500 \\
2800 \\
3100 \\
3400\end{array}$ & $\begin{array}{l}100 \\
100 \\
100 \\
200 \\
200 \\
200 \\
200 \\
200\end{array}$ & $\begin{array}{c}0 \\
10000 \\
20000 \\
30000 \\
40000 \\
50000 \\
60000 \\
70000\end{array}$ & $\begin{array}{l}10000 \\
20000 \\
30000 \\
40000 \\
50000 \\
60000 \\
70000 \\
11\end{array}$ & Broke on $1^{\text {st }}$ application of this dynamic load. \\
\hline & 16 & $\begin{array}{l}2500 \\
2800 \\
3100 \\
3400 \\
3700 \\
4000 \\
4300 \\
4600 \\
5000\end{array}$ & $\begin{array}{l}200 \\
200 \\
200 \\
200 \\
200 \\
200 \\
200 \\
200 \\
200\end{array}$ & $\begin{array}{c}0 \\
20000 \\
30000 \\
40000 \\
50000 \\
60000 \\
70000 \\
80000 \\
90000\end{array}$ & $\begin{array}{ll}20 & 000 \\
30 & 000 \\
40 & 000 \\
50 & 000 \\
60 & 000 \\
70 & 000 \\
80 & 000 \\
90 & 000 \\
98 & 000\end{array}$ & Broke out metal around pin grip: \\
\hline & 25 & 2500 & 200 & 0 & 0 & Broke after approximately 200 to 300 cycles \\
\hline \multirow{4}{*}{ 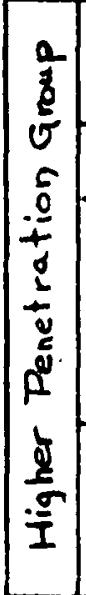 } & 5 & $\begin{array}{l}4000 \\
4500 \\
\end{array}$ & $\begin{array}{l}200 \\
200\end{array}$ & $\begin{array}{c}0 \\
10,000\end{array}$ & $\begin{array}{c}10.000 \\
.\end{array}$ & Broke on I application of this dynamic load \\
\hline & 10 & 4000 & 200 & 0 & 4000 & \\
\hline & 11 & 4000 & 200 & 0 & 64000 & $\begin{array}{l}\text { Broke in test section but outside of weld } \\
\text { (Holes for gripping pins were badly out } \\
\text { of parallel causing severe eceentricity } \\
\text { of loading) }\end{array}$ \\
\hline & 18 & $\begin{array}{l}4000 \\
4500 \\
5000\end{array}$ & $\begin{array}{l}200 \\
200 \\
200\end{array}$ & $\begin{array}{r}0 \\
15000 \\
35000 \\
\end{array}$ & $\begin{array}{l}15000 \\
35000 \\
39000\end{array}$ & Broke in test section but outside of weld. \\
\hline
\end{tabular}

$$
\begin{aligned}
& \text { J.o. Jeffrey } \\
& \text { Aug. 6. } 1957 .
\end{aligned}
$$


This report covers the results of bending fatigue tests made at the request of Mr. Robert Mark of ARDE Associates on twelve specimens submitted by Mr. Frank V. Naugle of the Bettis Atomic Power Division of the Westinghouse Electric Corporation.

The specimen shape, dimensions, and weld penetration measurements have been submitted by Mr. Naugle and are therefore not repeated here.

\section{Testing Machine}

The testing machine used was an Upton-Lewis transverse-loading fatigue testing machine built by the Tinius Olsen Company, and located in the Materials Testing Laboratory in Thurston Hall of Cornell University, Ithaca, N.Y. who gave the writer pemission to use the machine for these tests. The accompanying photograph shows the machine, and the dimensions of its principal elements are given on the diagram which follows. Reference to the latter will be helpful in understanding the description of the machine and Its operation.

The specimen is rectangular in section, $1 / 8 \times 1$ inch and about 7 inches long, and is securely clamped in the two jaws. The upper jaw pivots on a fixed hinge pin directly above the test piece. The lower jaw is fastened to the upper member while the machine is runing only through the test piece. A stop and guide limit the iall or the lower jaw when the specimen breaks. The free length of the test specimen between the jaws is designated by $I$ on the diagram and in the data. For all of the tests, the weld was located $1-3 / 8$ inches above the lower jaw.

The arm extending below the lower jaw is an integral part of the jaw and Is attached to the connecting rod through a pin. The throw of the connecting rod is adjustable at the crank-wheel to which it is attached. This eccentricity is designated as $E$ on the diagram and in the data, and is always adjusted to produce the desired bending moment at any section in the free length of the test specimen. It is apparent that the bending moment is substantially constant, however, along the entire free length of the specimen. The upper jaw carries a horizontal arm, held at its right end between a pair of stiff springs, set under sufficient initial compression so that the maximum throw of the arm will not remove it from contact with either spring.

The total motion of the springs is measured by a pair of micrometer screws, the "wheels" of which are graduated in tenths of thousandths of an Inch. The brackets containing these micrometer screws are electrically insullated from the rest of the testing machine so that a dry cell and an ear phone grounded on the machine and connected to the brackets gives a precise indication of coniact of the screw with the arm. Settings of these micrometer screws are reproducible to within one twentleth of a thousandth of an inch. Sucin precision is essential, as the maximum deflection, $\delta$, of the arm measured at 15 Inches from its fixed hinge was only 12 thousandths of an inch. Thus it is apparent that the upper clamped end of the test specimen is substantially fixed while the relatively large movement of its 


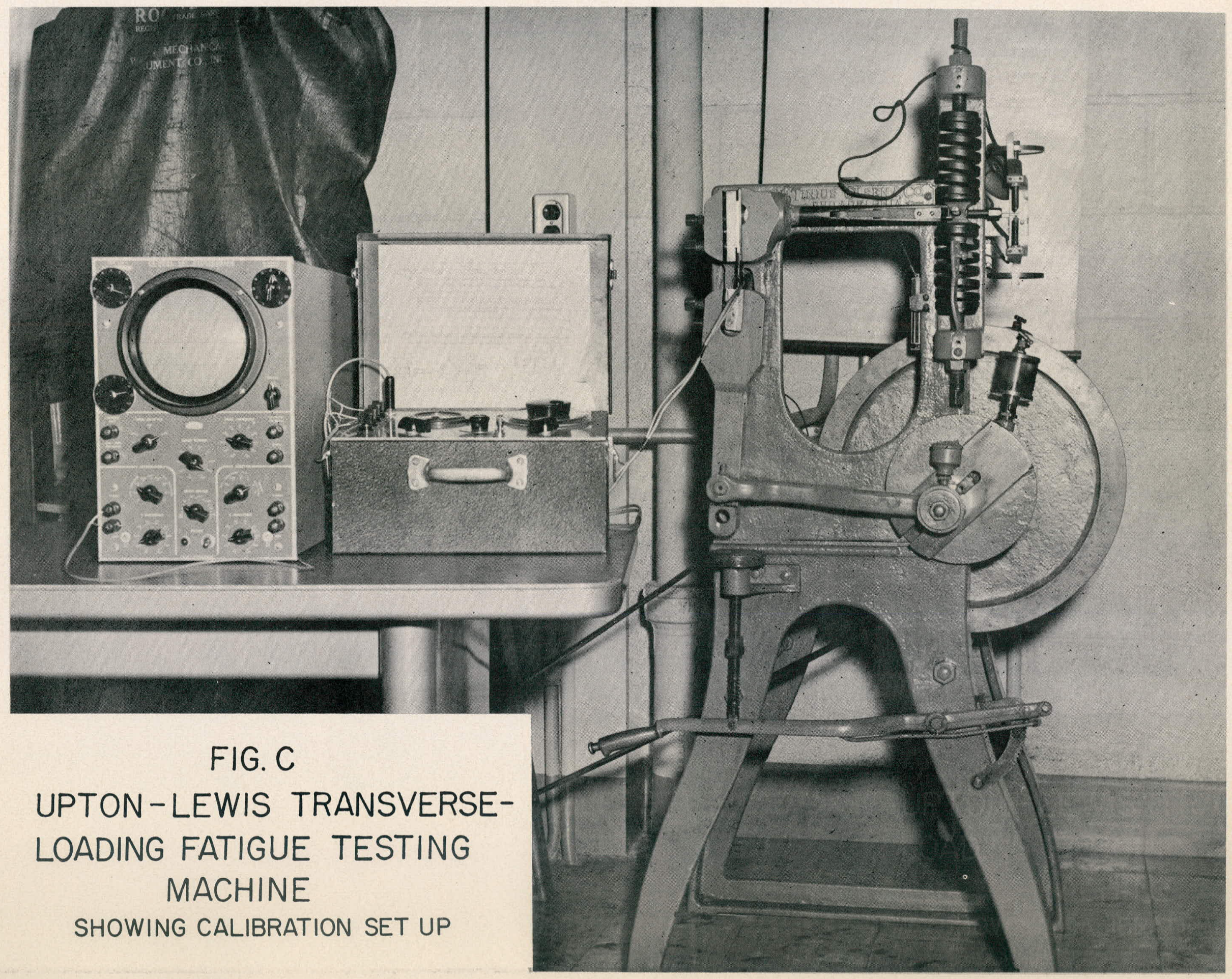


lower end is governed by the eccentricity, $E$, and the dimensions and elastic modulus of the test specimen.

\section{Calibration}

The springs were carefully calibrated on a 20,000 pound 0lsen Universal Testing Machine. The load was applied mechanically through screws and weighed through a level system by manually balancing the beam with its rider. A recent calibration of the testing machine indicated that it was accurate to \pm 10 pounds in this load range. The spring deflection was measured by a dial indicator placed between the heads of the machine as the spring was being compressed. Approximately ten readings were taken on each spring, loading and unloading, over its entire range. The slopes of the resulting load-deflection curves gave spring constants of 1085 and 1097 pounds per inch or a total machine spring constant of 2182 pounds per inch. This value was checked by calibrating both springs together in the testing machine, and found to be in precise agreement with that obtained by individual calibration.

A further check of the calibration and of the dymamic characterlstics of the bending fatigue machine was carried out by means of "dumm" specimens of the same material, size, and shape, as the test specimens but without any weld. Baldwin SR4 electric strain gages, type A7, were cemented to both sides of these specimens at the section where the weld was located on the other test pieces. Similar gages were also cemented to two steel pieces having this size and shape. The latter were used to check the strain indicator, testing machine and testing technique. The gages were wired up as a four arm bridge circuit using a Young Strain Indicator as the strain measuring device and the 20,000 pound Olsen Universal testing machine for loading. The gages on the piece to be loaded were placed in opposite arms of the bridge, while gages on the unloaded specimen in the other two arms compensated for temperature. This arrangement affords maximum sensitivity and also eliminates errors due to any bending that might be present. After several loading and unloading cycles, data were taken for loading and unloading between 8,000 and 48,000 psi. The accompanying graph shows the excellent agreement obtained for the elastic portion of the stress-strain curve whose slope measured 31,600,000 psi which is an acceptable value for this steel. Following the same procedure for the dummy alloy specimens, the curve labeled "zircoloy" on the accompanying graph was obtained. The slope indicates that its modulus of elasticity is 14,300,000 psi. All of the test work was done at ordinary temperature, between 70 and 80 degrees Fahrenheit.

The next step involved substituting an oscilloscope for the null indicating meter in the strain indicator. Within the limits of accuracy of reading the grid on the scope, the same stress-strain curve was obtained for the Zircoloy specimen. This indicated that the bridge could be properly balanced to an accuracy of \pm 4 percent statically, and therefore dynamically, by using the oscillograph. Since it would be necessary to know the strain on each side of the specimen independently in the bending tests, a two arm bridge was made before removing the 


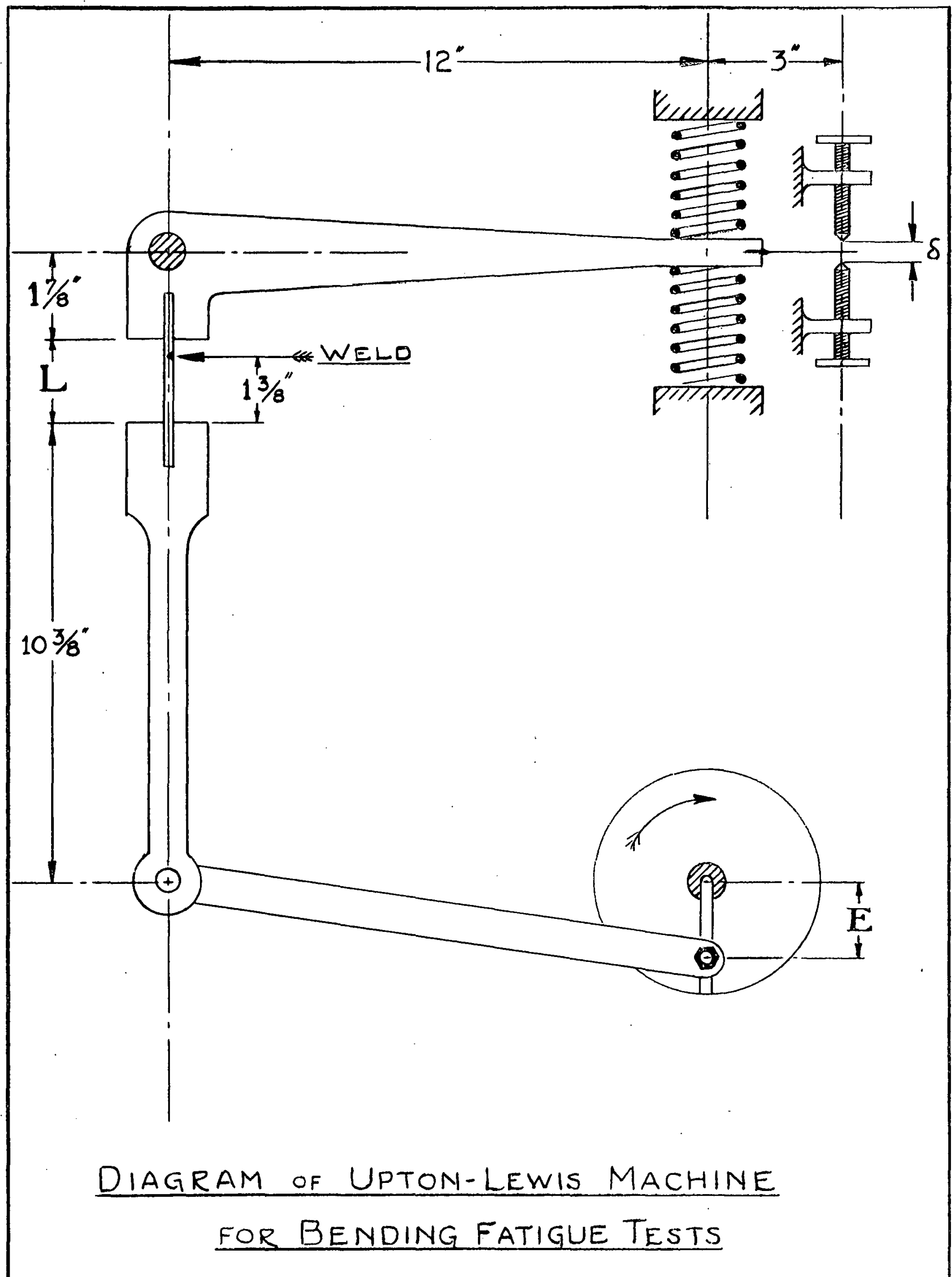

J.0.J.

402 jor 
dumy from the static tensile machine. For loads which produced calculated stresses in excess of about $15,000 \mathrm{psi}$, the resulting stress-strain curve was straight and had the same slope as that given by the Iour arm bridge. Disagreement in the lower stress range simply confirmed that the specimen was initially bent or curved, and until the applied force was large enough to straighten it, an accurate modulus could not be determined experimentally in tension loading from strain readings on only one side of the piece. The wrlter can only attribute the initial curviture of the unwelded dumny specimens to interval stresses set up by grinding. Regardless of tine cause of the distortion, the fact remains that it was sufficient to displace the section at the midale of the piece about one thirty-second of an inch from the end sections. This curviture was noticed before any testing was done, and was one of the reasons for using a four arm bridge to measure Young's modulus. Incidentally, it is perhaps fortunate that this distortion was present in the dummy, as all of the welded specimens were similarly curved to a greater or lesser extent.

The final step involved checking the fatigue machine by clamping the durmy in the grips, and, for each of several eccentricity settings, $E$, reading the maximum deflection, $\delta$, and the strain on each side of the specimen, balancing the strain indicator both with the null meter and with the scope. At each eccentricity setting, after the above data were taken statically, the machine was started and run at its normal operating speed of 500 cycles per minute for several hundred cycles. The trace on the scope showed that the strain under dynamic conditions was identical with that obtained statically. Due to the initial curviture of the specimen, it was necessary to adjust the springs on the testing machine so that the top arm tilted slightly downward toward the right with the concave side of the specimen facing right (see Diagram of machine). It is obvious that this adjustment is essential in order to equalize the stresses on both sides of a curved test piece. It is equally obvious that a different adjustment would be required for each curviture of specimen. For this work, it could only be assumed that the dumy was representative of all the welded pieces, and care was taken to always place the concave side of the specimen on the right.

For the unwelded dumy specimen, the above procedure showed that, in the elastic range, surface stress calculations resulted in identical values, within the limits of accuracy of measurements, when

(I) strain was measured and stress calculated by multiplying this by Young's modulus

(2) spring deflection was measured, and stress calculated by the simple beam formula: $6 \mathrm{M} / \mathrm{wt}^{2}$

where $M=$ bending moment, inch pounds

$W=$ width of cross-section, inches

$t=$ thickness of cross-section, inches

$M$, at the weld, for a machine spring constant of 2182 pounds per inch is given by

$$
M=(2182)(\delta / 2)(12 / 15)(12)\left[11.75 /(12.25+I)^{\top}\right]
$$

(See diagram of machine for symbols and dimensions) 
Using the dumy specimen, a final check was made on the dymamic vs. static characteristics by measuring the maximurn movement of the lower jaw under both conditions. Fo do this, a dial indicator, clamped to the frame of the machine, was adjusted so that its spindle just contacted a sheet of paper interposed between it and the lower jaw. When the paper was removed and the machine started, tine jaw oscillated without iouching the spindle, but interposition of the naper caused the jaw to strike the spindle of the gage. This merely furnished further evidence that the deflection of the test specimen under dymamic loading was identical with that of the static condition.

Test Procedure

The cranls of the machine was turned until the slots in the two jaws were in line, and the specimen was slipped in, care being taken to keep the concave side on the right. A spacing gage or parallel rectangular stock of width equal to the desired free test length $I$ was inserted between the jaws just outside the piece. The lowwer jaw was lifted up against the gage and the specimen tightly clamped in both jaws. The gage was then removed. In this way, dimension $I$, the free length of test piece was precisely lnown, and could be duplicated $\overrightarrow{i 0 r}$ all tests if desired. To keep this distance constant also simplifies calculations as only one constant has to be computed. The flywheel was then slowly rotated manually while the micrometer screws were adjusted to determine the distance $\delta$, after which the maximum stress on the specimen vas calculated. If the stress was not at approximately the desired value, the eccentricity, E, was changed and the micrometer screws readjusted until the required stress was produced. The machine was then started and run continuously for 10,000 cycles or until fracture.

The accompanying data sheet summarizes the test results. For the first group having the lower penetration the eccentricity was set initially to produce an outer fibre stress at the welded section of approximately 25,000 psi. As all of the specimens survived after 10,000 cycles, the eccentricity was Increased to give a stress between 30,000 and 40,000 psi and the pieces were run for an additional 10,000 cycles or unitil fallure. The first specimen tested was $1 / 6$ on which the free length was 2-3/8 inches: the same as that of the dummy. (This was the shortest length that could be used without damaging the SR-4 gages and lead wires)

As this specimen survived at the 30,000 psi stress for more than 10,000 cycles, a third test was made at 37,800 psi which broke the piece at the upper jaw where the clamping stresses and bending stresses would combine to produce the highest stress, neglecting any possible discontinuities due to the weld. For all of the other specimens, the test length was reduced to $1-7 / 8$ inches which is the shortest free length that could be accommodated and still keep the welded section a reasonable distance from the jaws.

As noted on the data sheet, only one test was run on each of the six samples having the higher penetration. The stress in all cases was between 30,000 and $33,000 \mathrm{psi}$. Half of the pieces survived 10,000 cycles, the other three brolke earlier at the welded section. 


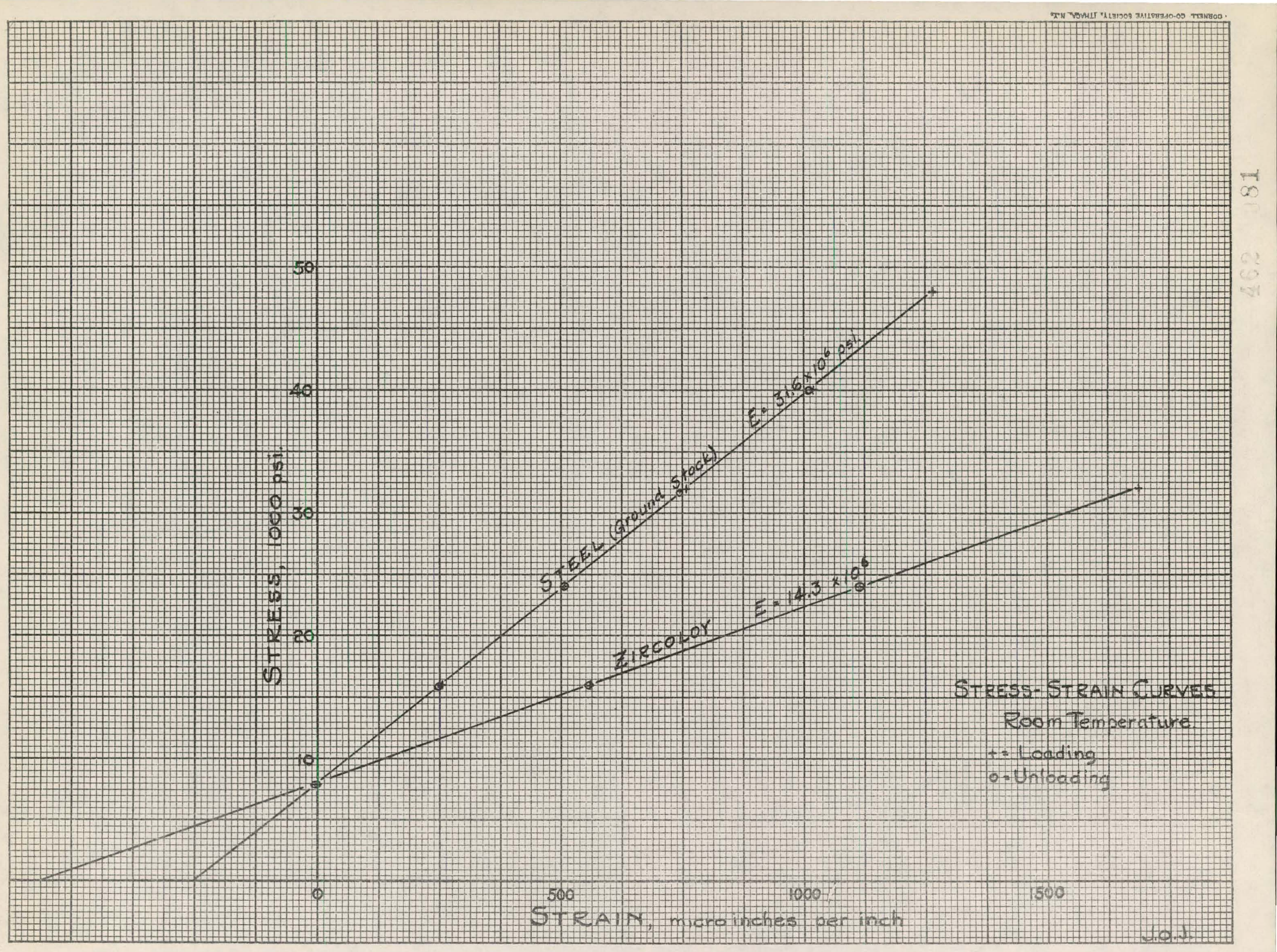


BENDING FATIGUE DATA

\begin{tabular}{|c|c|c|c|c|c|c|c|}
\hline & 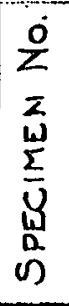 & 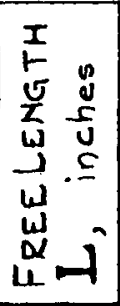 & 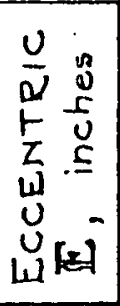 & 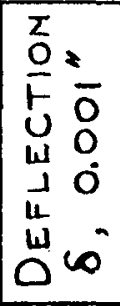 & 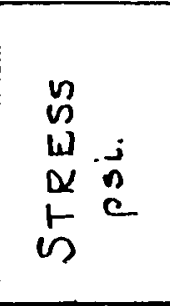 & $\begin{array}{l}n \\
u \\
u \\
u \\
u\end{array}$ & COMMENTS. \\
\hline \multirow{6}{*}{ 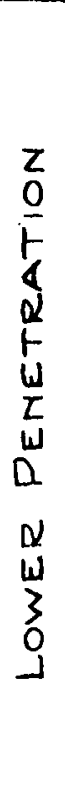 } & 1 & $17 / 8$ & $\begin{array}{l}13 / 16 \\
11 / 8\end{array}$ & $\begin{array}{r}8.40 \\
12.00\end{array}$ & $\begin{array}{l}28,100 \\
40,100\end{array}$ & $\begin{array}{r}10,020 \\
1,080\end{array}$ & Brote in weld. \\
\hline & 2 & $17 / 8$ & $\begin{array}{l}3 / 4 \\
11 / 8\end{array}$ & 17.10 & $\begin{array}{l}23,800 \\
36,800\end{array}$ & $\begin{array}{l}10,730 \\
10,130\end{array}$ & Not broken; possibly cracked?? \\
\hline & 3 & $17 / 8$ & $\begin{array}{l}13 / 16 \\
11 / 8\end{array}$ & $\begin{array}{r}7.85 \\
11.45\end{array}$ & $\begin{array}{l}26,300 \\
38,300\end{array}$ & $\begin{array}{r}10,320 \\
1,440\end{array}$ & Broke in weld. \\
\hline & 4 & $1 / 8$ & $\begin{array}{l}13 / 16 \\
1 / 8\end{array}$ & $\begin{array}{r}7.80 \\
10.05\end{array}$ & $\begin{array}{l}26,100 \\
33,600\end{array}$ & $\begin{array}{l}10,020 \\
10,010\end{array}$ & Not broken. \\
\hline & 5 & $17 / 8$ & $\begin{array}{l}13 / 16 \\
11 / 8\end{array}$ & $\begin{array}{l}7.55 \\
10.50\end{array}$ & $\begin{array}{l}25,300 \\
35,100\end{array}$ & $\begin{array}{r}10,020 \\
9.740\end{array}$ & Broke in weld. \\
\hline & 6 & $23 / 8$ & $\begin{array}{l}11 / 8 \\
11 / 4 \\
13 / 8\end{array}$ & $\begin{array}{r}8.55 \\
9.20 \\
11.70\end{array}$ & $\begin{array}{l}27,600 \\
29,700 \\
37,800\end{array}$ & $\begin{array}{r}10,090 \\
10,050 \\
890\end{array}$ & Broke at grip. (upper grip). \\
\hline \multirow{6}{*}{ 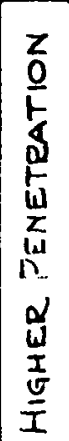 } & 7 & $1 \%$ & 1.03 & 9.80 & 32,800 & 7.580 & Broke in weld. * \\
\hline & 8 & $17 / 8$ & 1.03 & 9.85 & 32,900 & 8,990 & Broke in weld. \\
\hline & 9 & $17 / 8$ & $11 / 8$ & 9.10 & 30,400 & 6.000 & Broke in weld. * \\
\hline & 10 & $17 / 8$ & 1.03 & 9.50 & 31,800 & 10,010 & Not broken. \\
\hline & 11 & $17 / 8$ & 1.03 & 9.00 & 30,100 & 10,010 & Not broken. \\
\hline & 12 & $17 / 8$ & 1.03 & 9.55 & 32,000 & 10,000 & Not broken. * \\
\hline
\end{tabular}

* Crack, about 1/32" deep showed on exposed front side of specimen during initial manual operation of eccentric when deflection $\delta$ was being measured statically.

Frequency, 500 cycles per minute. J.O.J. 
The broken specimens have been returned to you for examination. The techniques and procedure described above are in complete accordance with your instructions and in order that you may obtain as much useful information as possible from the samples submitted, I have provided more data than that wilch our original agreement expected. I hope that you are satisfied with the testing program and pleased with the results.

Respectfully submitted,

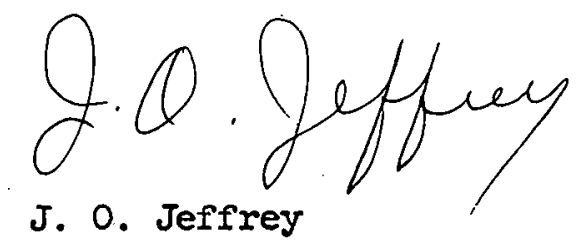




$$
\text { V.10 }
$$

A $\underline{P} \underline{P} \underline{\mathrm{E}} \underline{\mathrm{N}} \underline{\mathrm{D}} \underline{\underline{I}} \underline{\mathrm{X}} \quad \underline{\mathrm{B}}$

WELD AREA CROSS SECTION EVALUATIONS

sis is 


\section{V.11}

Preliminary measurements of the weld penetration were made by examining the edges of the specimens under a microscope. As the veld penetration varies across the width, (See figures A - C), these measurements can only provide an indication of the true penetration (pages V.12-15).

After testing, the broken edges were placed under a tool-maker's microscope. Examination of the surface reveals the presence of high spots on the unpenetrated side (Figures A - C show typical tensile failures). In the 1ight of the test results, one must conclude that these represent areas of fusion. It is not possible to make a quantitative study of these areas. He have considered only the solid penetrated area as a parameter.

The general method of evaluating this cross sectional area is illustrated by Figure (D). It was decided to consider the penetration to end where the surface of the break had a definite failure appearance. The reported weld areas (Table $A$ and $B$ ) are therefore minimal with the actual area of fusion being a good deal greater. 
TENSILE SPECIMENS

$+$

\begin{tabular}{|c|c|c|c|c|c|}
\hline SPEC. & AVG. THICK. & WIDTH & EDGE & NETRATION 1 & CHES) \\
\hline No. & AT KELD & AT WELD & LEFT SIDE & RIGHT SIDE & AVERAGE \\
\hline 13 & 0.125 & .0991 & 0.089 & 0.096 & 0.093 \\
\hline 14 & 0.125 & 1.002 & 0.087 & 0.088 & 0.088 \\
\hline 17 & 0.1 .28 & 0.991 & 0.083 & 0,091 & 0,087 \\
\hline 19 & 0.124 & 1.001 & 0.047 & 0.065 & 0.056 \\
\hline 20 & 0.125 & 0.989 & 0.062 & 0.060 & 0.061 \\
\hline 21 & 0.121 & 0.992 & 0.062 & 0.057 & 0.060 \\
\hline 22 & 0.126 & 1.000 & 0.067 & 0.067 & 0.067 \\
\hline 23 & 0.124 & 0.991 & 0.052 & 0.052 & 0.055 \\
\hline 24 & 0.123 & 0.992 & 0.065 & 0.058 & 0.062 \\
\hline
\end{tabular}

1 Preliminary Measurements. 


\section{$\mathrm{V} .13$}

MODIFIED TENSILE SPECIMENS

\begin{tabular}{|c|c|c|c|c|c|}
\hline $\begin{array}{l}\text { SPEC. } \\
\text { NO. }\end{array}$ & $\begin{array}{l}\text { AVG. THICK. } \\
\text { AT WELD }\end{array}$ & $\begin{array}{l}\text { KIDTH } \\
\text { AT KELD }\end{array}$ & LEFT $\frac{\text { EDGE }}{\text { SIDE }}$ & $\frac{\text { PENETRATION }^{1}}{\text { RIGHT SIDE }}$ & $\frac{\text { (INCHES) }}{\text { AVERAGE }}$ \\
\hline 7 & 0.123 & 0.995 & 0.043 & 0.046 & 0.045 \\
\hline 8 & 0.124 & 0.994 & 0.044 & 0,056 & 0.050 \\
\hline 9 & 0.1 .23 & 0.996 & 0.049 & 0.047 & 0.048 \\
\hline 16 & 0.118 & 1.000 & 0.068 & 0.062 & 0.065 \\
\hline 25 & 0.119 & 0.984 & 0.063 & 0.059 & 0.061 \\
\hline 5 & 0.124 & 0.996 & 0.083 & 0.085 & 0.084 \\
\hline 10 & 0.124 & 0.994 & 0.085 & 0.086 & 0.086 \\
\hline 11 & 0.122 & 0.994 & 0.082 & 0.088 & 0.085 \\
\hline 18 & 0.123 & 1.002 & 0.086 & 0.094 & 0.090 \\
\hline
\end{tabular}

1 Preliminary Measurements 


\section{V.14}

\section{BENDING SPECTMENS}

\begin{tabular}{|c|c|c|c|c|c|}
\hline SPEC. & AVG . THICK. & KIDTH & EDGE & NETRATION ${ }^{1}$ ( & \\
\hline No. & A'S WELD & AT WELD & LEFT SIDE & RIGHT SIDE & AVERAGE \\
\hline 1 & & & 0.072 & 0.082 & 0.077 \\
\hline 2 & & & 0,059 & 0.049 & 0.054 \\
\hline 3 & & & 0,058 & 0.062 & 0.060 \\
\hline 4 & & & 0.057 & 0.054 & 0.056 \\
\hline 5 & & & 0.060 & 0.074 & 0.067 \\
\hline 6 & & & 0.067 & 0.052 & 0.060 \\
\hline 7 & & & 0.0 .93 & 0.088 & 0.091 \\
\hline 8 & & & 0.101 & 0.111 & 0.106 \\
\hline 9 & & & 0.103 & 0.087 & 0.095 \\
\hline 10 & & & 0.099 & 0.088 & 0.094 \\
\hline 11 & & . & 0.086 & 0.080 & 0.083 \\
\hline 12 & & & 0.077 & 0.096 & 0.087 \\
\hline
\end{tabular}

1 Preliminary Measurements 


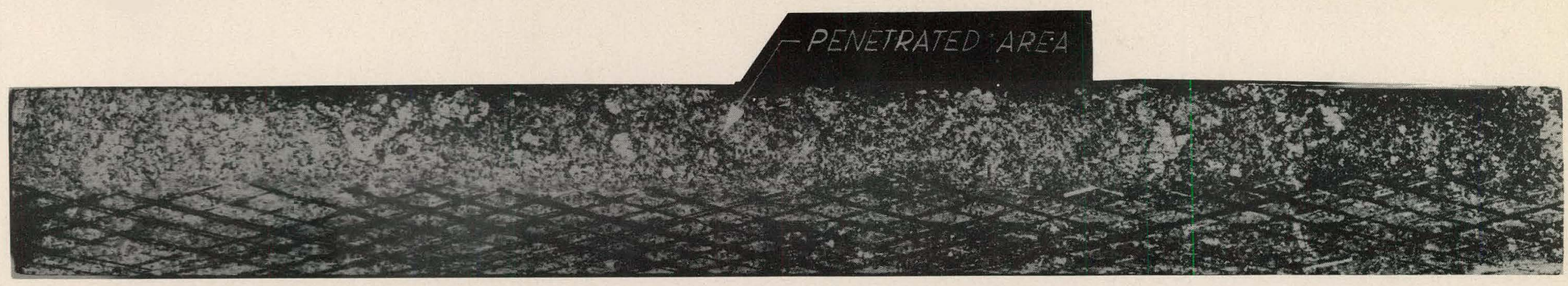

FIG. A

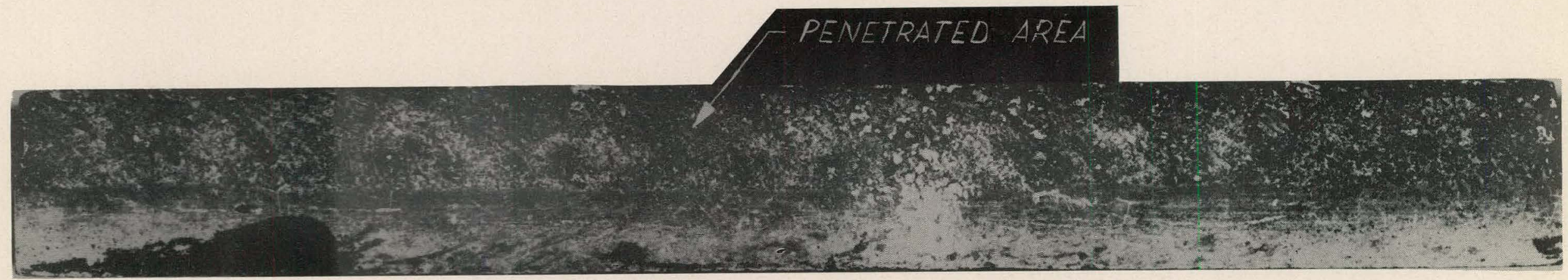

FIG. B

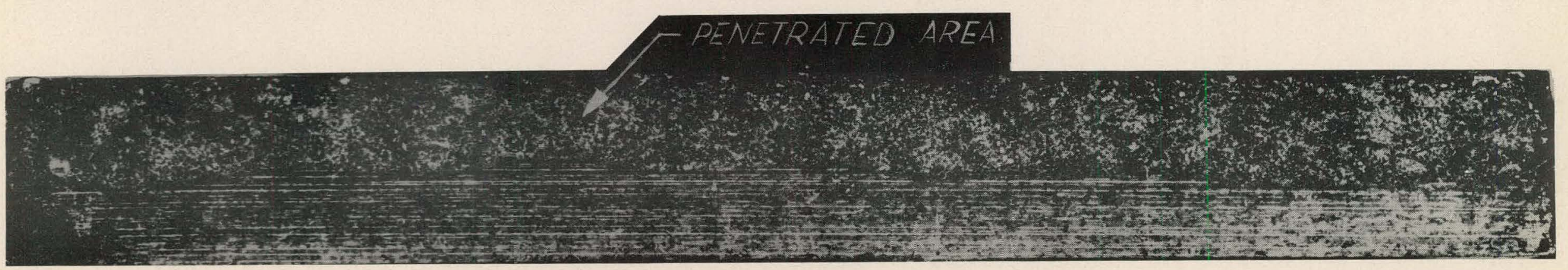

FIG. C 


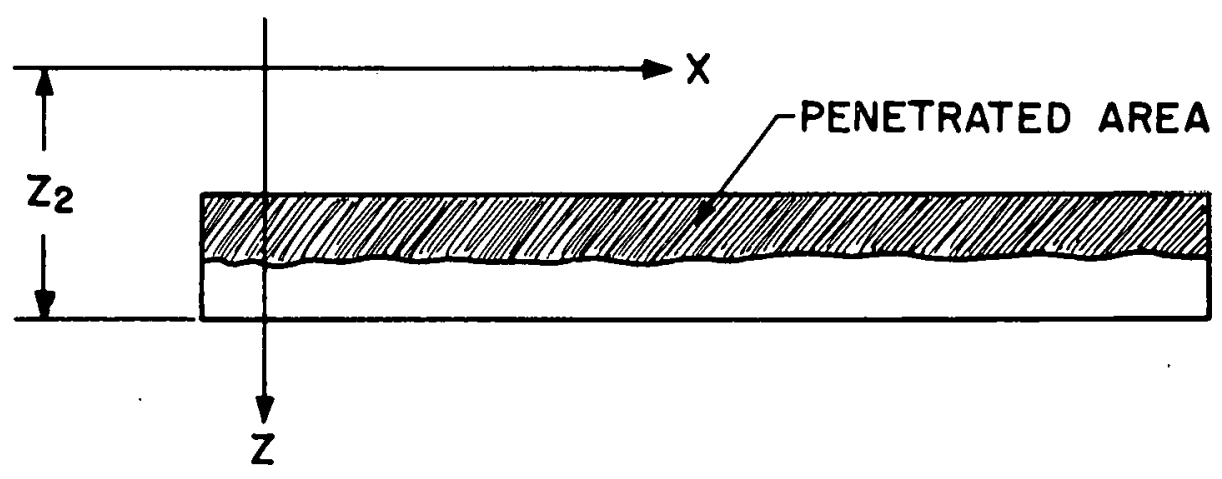

FIG.D

\begin{tabular}{|c|c|c|c|}
\hline$X$ & $Z_{1}$ & $Z_{2}$ & $Z_{1}{ }^{\prime}$ \\
\hline-0.0226 & 0.5236 & 0.5733 & 0.5159 \\
\hline 0.1 & 0.5296 & 0.5719 & 0.5198 \\
\hline 0.2 & 0.5213 & 0.5702 & 0.5124 \\
\hline 0.3 & 0.5183 & 0.5683 & 0.5110 \\
\hline 0.4 & 0.5122 & 0.5667 & 0.5038 \\
\hline 0.5 & 0.5067 & 0.5645 & 0.5016 \\
\hline 0.6 & 0.4962 & 0.5639 & 0.4892 \\
\hline 0.7 & 0.5064 & 0.5662 & 0.5020 \\
\hline 0.8 & 0.5036 & 0.5610 & 0.4969 \\
\hline 0.9 & 0.5110 & 0.5594 & 0.5043 \\
\hline 0.9630 & 0.5021 & 0.5579 & 0.4885 \\
\hline
\end{tabular}

NOTES:

DATA WAS MEASURED WITH A TOOL-MAKERS MICROSCOPE ON THE LEFT SIDE OF SPECIMEN 20.

$Z$, WAS MEASURED TO THE POINT WHERE THE SURFACE BEGAN TO HAVE A CHANGED APPEARANCE.

$Z_{1}^{\prime}$ WAS MEASURED TO THE POINT WHERE THE MATERIAL BEGAN TO HAVE DEFINITE TENSILE FAILURE APPEARANCE.

AN ATTEMPT WAS MADE TO PLACE THE SPECIMEN PARALLEL TO THE X-AXIS, BUT THIS IS ONLY APPROXIMATELY TRUE AS INDICATED BY THE $Z_{2}$ MEASUREMENTS.

AREAS WERE MEASURED WITH PLANIMETER AFTER DRAWING SMOOTH CURVE THROUGH MEASURED POINTS.

PENETRATED AREA BY SUBTRACTIONS $=A_{P}$

$A_{P}\left(\right.$ USING $\left.Z_{1}\right)=0.0704 \mathrm{IN}^{2}$

$A_{p}\left(\right.$ USING $\left.Z_{1}^{\prime}\right)=0.0638 \mathrm{IN}^{2}$ 


\section{TABUL ATED AREAS \\ WELD PENETRATION}

\begin{tabular}{|c|l|c|c|c|}
\multirow{2}{*}{ SPECIMEN } & $\begin{array}{c}\text { CROSS SECTION } \\
\text { AREA( IN }\end{array}$ & LEFT SIDE & RIGHT SIDE & AVERAGE \\
\hline \hline \multirow{2}{*}{5} & WELD & .0907 & .0901 & .0904 \\
\cline { 2 - 5 } & UNWELDED & .0294 & .0307 & .0300 \\
\hline \multirow{2}{*}{7} & WELD & .0485 & .0505 & .0495 \\
\cline { 2 - 5 } & UNWELDED & .0733 & .0695 & .0714 \\
\hline \multirow{2}{*}{8} & WELD & .0462 & .0472 & .0467 \\
\cline { 2 - 5 } & UNWELDED & .0743 & .0734 & .0738 \\
\hline \multirow{2}{*}{9} & WELD & .0489 & .0521 & .0505 \\
\cline { 2 - 5 } & UNWELDED & .0703 & .0690 & .0696 \\
\hline \multirow{2}{*}{10} & WELD & .0820 & .0817 & .0818 \\
\cline { 2 - 5 } & UNWELDED & .0374 & .0389 & .0381 \\
\hline \multirow{2}{*}{20} & WELD & .0704 & & \\
\cline { 2 - 5 } & & & & \\
\hline \multirow{2}{*}{22} & WELD & & .0738 & \\
\cline { 2 - 5 } & & & & \\
\hline \multirow{2}{*}{25} & WELD & .0618 & .0606 & .0612 \\
\cline { 2 - 5 } & UNWELDED & .0532 & .0545 & .0538 \\
\hline
\end{tabular}

NOTE: SPECIMENS 11,16 \& 18 FAILED OUTSIDE WELD AREA. 
BENDING TESTS

TABLE B

\section{TABULATED AREAS WELD PENETRATION}

\begin{tabular}{|c|c|c|c|c|}
\hline SPECIMEN & $\begin{array}{l}\text { CROSS SECTION } \\
\text { AREA }\left(\mathbb{N N}^{2}\right)\end{array}$ & LEFT SIDE & RIGHT SIDE & AVERAGE \\
\hline \multirow{2}{*}{1} & WELD & .085 & & \\
\hline & UNWELDED & .0399 & & \\
\hline 2 & & & & \\
\hline \multirow{2}{*}{3} & WELD & & .0585 & \\
\hline & UNWELDED & & .0642 & \\
\hline \multirow{2}{*}{4} & WELD & .0662 & & \\
\hline & UNWELDED & .0558 & & \\
\hline \multirow{2}{*}{5} & WELD & .0608 & & \\
\hline & UNWELDED & .0608 & & \\
\hline \multirow{2}{*}{6} & WELD & .0598 & .0593 & .0595 \\
\hline & UNWELDED & .0607 & .0629 & .0618 \\
\hline \multirow{2}{*}{7} & WELD & .0955 & & \\
\hline & UNWELDED & .0236 & & \\
\hline \multirow{2}{*}{8} & WELD & & .0984 & \\
\hline & UNWELDED & & .0150 & \\
\hline \multirow{2}{*}{9} & WELD & .0935 & & \\
\hline & UNWELDED & .0185 & & \\
\hline \multirow{2}{*}{10} & WELD & .0946 & & \\
\hline & UNWELDED & .0248 & & \\
\hline \multirow{2}{*}{11} & WELD & & .0912 & \\
\hline & UNWELDED & & .0275 & \\
\hline 12 & & & & \\
\hline & & & 463 & \\
\hline
\end{tabular}

